\title{
MECHACHAL:
}

ONLINE DEBATES AND ELECTIONS

IN ETHIOPIA - FROM HATE SPEECH TO

ENGAGEMENT IN SOCIAL MEDIA

\section{ALL FINDINGS}
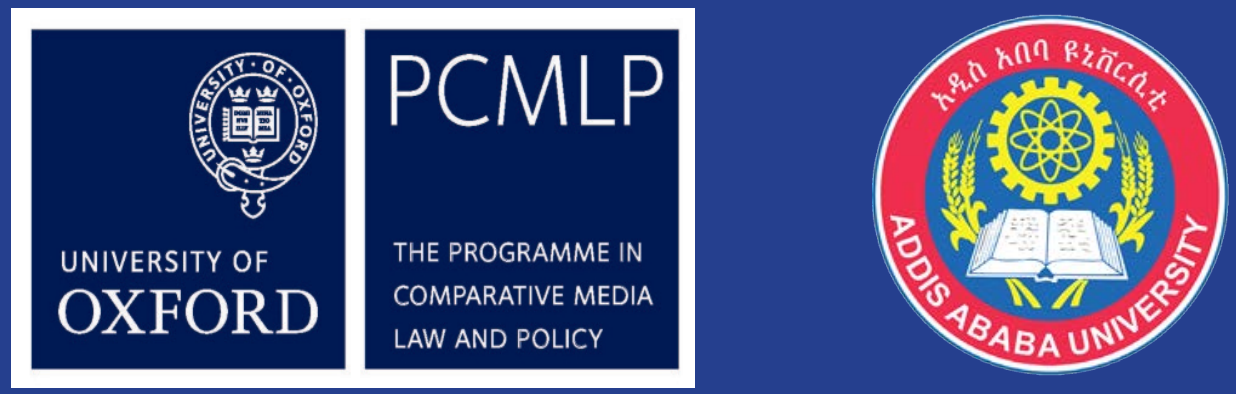
Open Access. Some rights reserved.

We encourage the circulation of this work as widely as possible. Anybody can access the content without charge, and anybody can dowload this work. This is subject to the terms of our Creative Commons license. Its conditions are:

- The author(s) are credited

- The text is not altered and is used in full

- The work is not resold

- A copy of the work or link to its use online is sent to the authors

To find out more go to www.creativecommons.org

\section{Cc) creative}

\section{HOW TO CITE THIS WORK?}

Gagliardone, I. et al. (2016). MECHACHAL: Online debates and elections in Ethiopia. From hate speech to engagement in social media.

This document is published under Creative Commons Attribution-NonCommercial-NoDerivs. For more information or questions about the report, please contact the authors individually.

PICTURE ON PAGE 13: Tristam Sparks (Creative Commons Attribution-NonCommercial-NoDerivs 2.0)

PICTURE ON PAGE 23: Charles Roffy (Creative Commons Attribution-NonCommercial-NoDerivs 2.0)

PICTURE ON PAGE 73: CCTV screenshot, May 24, 2015

PICTURE ON PAGE 97: UNICEF (Creative Commons Attribution-NonCommercial-NoDerivs 2.0) 


\section{TABLE OF CONTENTS}

BACKGROUND AND RESEARCH STRATEGY

$\begin{array}{ll}\text { Researching hate speech online: a cautionary tale } & 13\end{array}$

The Ethiopian media system and political polarisation 14

$\begin{array}{ll}\text { Mechachal's research strategy } & 14\end{array}$

Data sharing and stakeholders engagement $\quad 20$

ANTAGONISM AND ENGAGEMENT IN ETHIOPIA'S SOCIAL MEDIA 22

Going against and going towards $\quad 25$

The Ethiopian online diaspora $\quad 28$

Influence and types of speech 33

Reaction to statements going against and going towards 36

Offensive speech, hate speech and dangerous speech 39

Spaces for engagement $\quad 44$

POWER, ANTAGONISM AND INFLUENCE ON FACEBOOK 47

Online spaces and digital boundaries $\quad 56$

From broadcasting to ... engagement $\quad 61$

Debate and dialogue in popular spaces $\quad 65$

$\begin{array}{ll}\text { Case study: ISIL coverage in popular spaces } & 67\end{array}$

ETHIOPIA'S 2015 ELECTIONS

Online participation in the 2015 elections $\quad 74$

The electoral platforms of Facebook 80

Election-themed speech and online communities $\quad 85$

$\begin{array}{ll}\text { Going against and going towards } & 87\end{array}$

$\begin{array}{ll}\text { CONCLUSION } & 96\end{array}$

$\begin{array}{lr}\text { ENDNOTES } & 99\end{array}$

$\begin{array}{ll}\text { MECHACHAL TEAM } & 101\end{array}$ 
We are grateful to the British Embassy in Addis Ababa for their support in enabling us to envisage and realize this project. The views expressed in this report, however, are those of the authors and should not be attributed to the British Embassy or the British government. 


\section{EXECUTIVE SUMMARY}




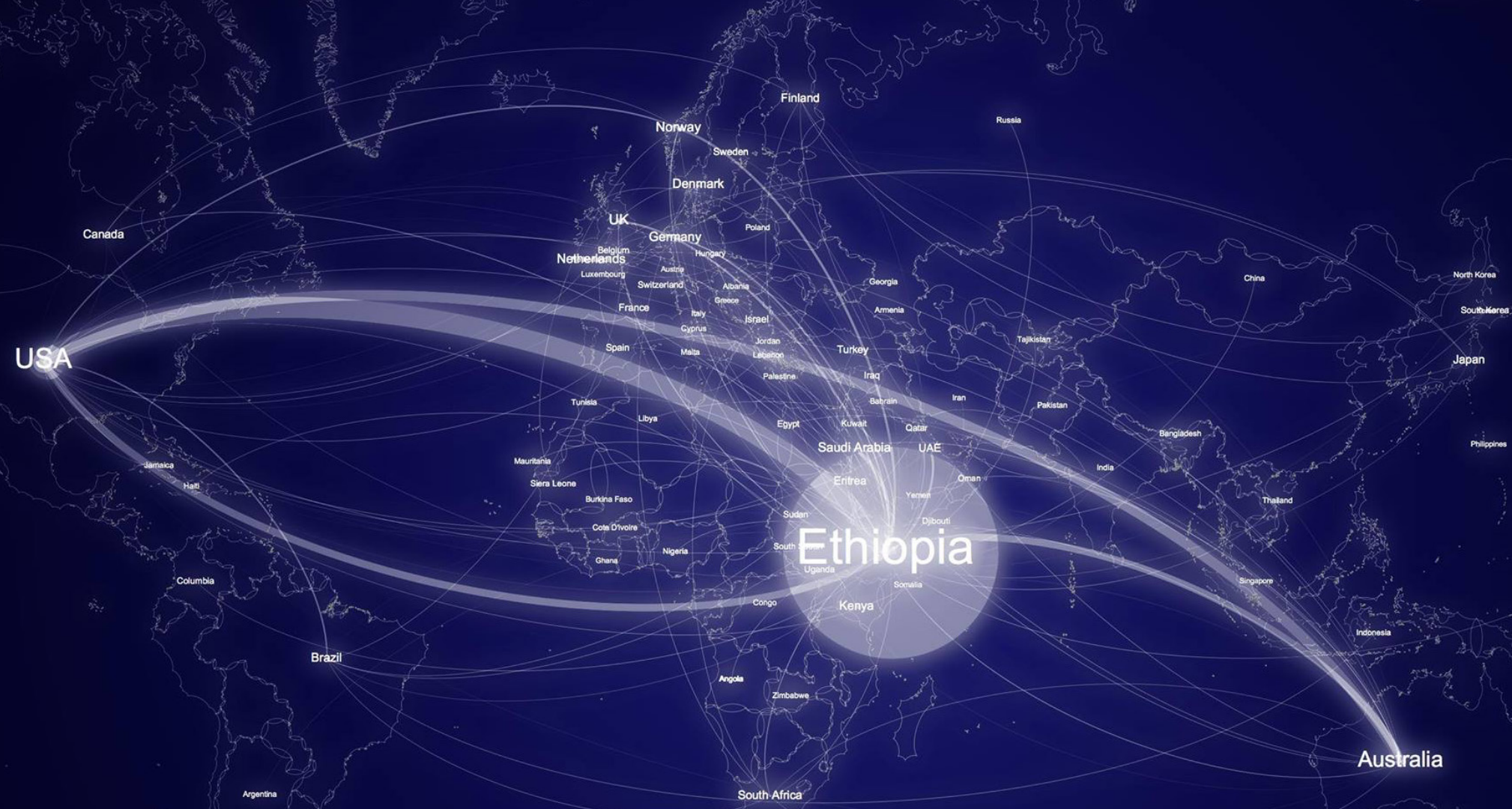

T his report adds a new perspective to the debate on the potential and risks of social media, and addresses growing concerns about their possible use in inciting hatred and violence. Moving beyond the anecdotal evidence that has dominated media debates, we provide a strong empirical base to understand how prevalent the most extreme forms of expression actually are among conversations in social media, how they are received, and what they compare to, in terms of the nature and quality of other types of messages that find space online.

This study is part of a two-year collaborative effort led by the University of Oxford and Addis Ababa University under the name of Mechachal, which can be translated from Amharic as "tolerance". During this period new research methods have been developed and piloted, and results were regularly shared and debated with a broad group of academics, politicians, journalists, bloggers, and representatives of civil society organizations.
Our focus has been on Ethiopia, but the tools we developed and the evidence we collected can contribute to larger debates on the tradeoffs between freedom of expression and security. In Ethiopia, as in many other countries - from the United States to Germany to China - claims that social media can be used to disseminate hate speech and incite violence have been growing. ${ }^{1}$ These claims, however, have largely failed to build on comprehensive and publicly accessible empirical evidence, making it difficult to place the most extreme forms of expression into context, understand how pervasive they are, and find out how they spread, and who is actually behind them.

Mechachal has sought to address these challenges by examining speech that is offensive, hateful, and dangerous together with many other forms of speech that occur in social media, from strong criticism of public figures, to support for a politial party, to engagement across religious or ethnic divides. This complex task has been achieved in three ways. 
First, we concentrated our efforts on one specific social networking platform, Facebook, which has become the most popular space for sharing information and opinions among Ethiopians who access the Internet. ${ }^{2}$ We also took advantage of the distinctiveness of the languages spoken in Ethiopia to develop a comprehensive mapping of Ethiopia's Facebook spaces, ensuring we had access to a realistic sample of the overall online debates focusing on Ethiopia.

Next, we developed a research framework that was capable of analyzing not only statements that go against someone or something, but also statements that go towards. These two terms, which will recur often throughout this report, and are explained in more detail in the next section, are rooted in research on deliberation, political conflict, and political engagement. They are not about agreeing or disagreeing, but about the tendency to take a viewpoint seriously and engage with it, or, on the contrary, to dismiss it and directly attack a person for his/her affiliation with a specific group. They cut the continuum of statements uttered in online debates into two broad categories and represent the beginning of more in-depth analysis of statements. A statement that goes against, for example, can also be offensive, if it is derogatory towards a particular ethnic group; and it can be considered hate speech if, in addition, it incites others to discriminate against members of that particular group.

Building on these premises, we analyzed more than 13,000 statements during the project. This report primarily builds on the statements that were collected between 24 February and 24 June 2015, three months before and one month after the parliamentary elections that took place in Ethiopia on 24 May 2015.

\section{MAJOR FINDINGS}

\section{FINDING 1 - Hate and dangerous speech are marginal forms of speech in social media}

Only $\mathbf{0 . 4 \%}$ of statements in our sample have been classified as hate speech (i.e. speech that incites others to discriminate or act against individuals or groups based on their ethnicity, religion, or gender) and $\mathbf{0 . 3 \%}$ as dangerous speech (i.e. speech that builds the bases for or directly calls for widespread violence against a particular group). In addition, all statements in this latter category were associated with a limited possibility for the speakers (or the groups they appeal to) to actually carry out violence. No statements were found in our general sample to have a high risk that the speakers or the groups they appeal to could carry out violence. These findings are limited to the case of Ethiopia but there are broader implications for researchers studying online hate speech and for policy makers seeking to promote targeted responses to it. To our knowledge this is the first time research focusing on an entire country, and its diasporic community, has been able to quantify the proportion of hate and dangerous speech among the total conversations occurring on a social networking platform. These figures can offer a more solid grounding for shaping the debate on the possibilities and risks of social media in Ethiopia, but also create the foundations for comparative research that can quantify the prevalence and significance of these forms of speech in different national contexts and explore the reasons behind similarities and differences. 
FINDING 2 - The elections on Facebook were a "non-event" - they were broadly discussed, but there was widespread disillusionment

Most Ethiopian Facebook pages discussed the elections, but many statements either directly referred to, or seemed informed by, the perception that the outcome of the elections was already predetermined, with low levels of suspense and low expectations on the part of online users. This contributed to a general perception that the electoral contest was a "non-event". There is little evidence that new social or political tensions emerged, or was heightened, around the elections. No single group was singled out as a target for antagonism. Antagonistic speech was mostly directed against the elections themselves, which were largely dismissed as a futile process. Venting against the electoral process often took the form of sarcastic jokes and remarks, which showed disillusionment and frustration. Because the elections were seen to have a foregone outcome, little political campaigning took place on Facebook, even if opposition parties took greater advantage of the opportunities offered by social media than the incumbent party. Opposition supporters tended to gravitate towards Facebook much more than government supporters, as shown by the higher ratio of positive feedback received by opposition-affiliated pages. Campaigning on Facebook appeared to have the primary objective of reinforcing the sense of identity of the various online communities, and was therefore more an act of community-building than a competitive political effort.

\section{FINDING 3 - Dangerous speech is a distinctive and more deliberate form of attacking other groups or individuals}

When compared to hate speech, as well as to other types of messages, dangerous speech reflects a more deliberate strategy to attack individuals and groups. Almost all dangerous statements in our sample are uttered by individuals seeking to hide their identity (92\%). This proportion is significantly lower for statements classified as hate speech (33\%) and offensive speech (31\%). In addition, while the majority of hateful statements can be found in comments, indicating a tendency for speakers to react angrily to what they read online, there is an equal chance of dangerous statements in posts or comments. Shifting the focus from speakers to targets, dangerous statements appear to focus exclusively on ethnicity. The salience of ethnicity can be found also in other types of messages. $75 \%$ of hate speech and $58 \%$ of offensive speech have ethnic targets, but they also target individuals based on their religion, and, to a much smaller extent, their sexual identity. This finding, more than others, is likely to be specific to the context of Ethiopia, where ethnicity has a central role in national debates, but it also offers new ground to explore some of the distinctive features of dangerous speech as compared to other form of speech.

\section{FINDING 4 - The political, social and cultural views reflected in social media in} Ethiopia are less polarized than might be expected

The relative marginality of hate and dangerous speech is part of a broader trend that involves antagonistic statements more generally (i.e. statements that do not recognize the "other" as a legitimate adversary, but as an enemy). If we zoom out from the sub-categories of offensive, hate, and dangerous speech to the broader category that includes all statements going against, the evidence collected indicates that, in this case too, they represent a minority on Facebook (only $16 \%$ of statements go against). This may not be surprising, especially when we consider that the majority of 
users do not log in to social media simply to attack others, but rather to casually share experiences, interests, and information. It is significant, however, in the context of the political debate in Ethiopia, where media have historically been highly polarized. Later in the report we put forward some explanations as to why social media seem to show less polarization when compared to other media in Ethiopia (e.g. the greater presence of young people with less historical baggage emerging from the struggles that have characterized the contemporary history of Ethiopia).

\section{FINDING 5 - Despite statements going against being few they produce more reactions and travel further than other statements}

Although statements going against are a minority, and are more likely to be uttered by individuals with little influence, they still have the power to shape debates. While statements going towards receive more likes independently from the influence of the speaker, when uttered by speakers that are at least moderately influential, it is statements going against that receive the highest number of comments. This suggests that once a certain threshold of visibility is passed, it is the fact that a statement goes against that produces a significant number of comments, rather than the simple influence of the speaker. The same pattern is found for shares, which can be considered an even stronger form of support, as a shared post appears also in the profile of the user who shares it. Also in this case, once a certain threshold of visibility is passed, it appears that it is the content of the statements that matters, rather than the influence of the speakers. Framed in different terms, it can be argued that while statements going against are less frequent, they are more likely to promote reactions and travel further.

\section{FINDING 6 - Unequal power relationships increase antagonism between speakers and followers}

Users with little or no influence tend to post more statements going against (18\% of the total of statements analyzed) than highly influential speakers (11\%). As we later explain in more detail, the criteria we applied to define influence are limited to online spaces and based on a user's follower base. This decision was made when the team was confronted with the complexities of assessing a user's influence offline, and in order to account for the possibility of a speaker gaining influence through their online presence and activity. Despite this limitation, the possibility of correlating different forms of speech with users' influence revealed some significant aspects of online conversations. For example, if we consider some of most influential pages in Ethiopia's online sphere (e.g. Diretube, Dr. Tedros Adanhom, Semayawi party, Daniel Berhane), a large gap exists between the tone of the posts written by the owners of these pages and the tone of the comments written by their "fans/followers". While posts tend to display a smaller proportion of antagonism, the percentage of comments going against tends to be significantly higher than in the general sample. Taken together, these findings seem to delineate a picture where social media seem to act as a space allowing ordinary citizens to express their anger towards power, rather than as a tool used by influential people to radicalize other individuals. This does not rule out the possibility of social media being used with this particular aim, but it suggests that if we focus on broader trends, these possibilities are fairly limited in scope and scale. 


\section{FINDING 7 - Broadcasting views dominates over dialogue in political communication on Facebook}

The most influential Ethiopian Facebook pages have a distinct identity, in terms of user demographics, topics discussed, and the types of interaction they promote around politics, religion and popular culture. Each page promotes specific modalities of interaction with followers. Most institutional pages, including those of major media outlets such as Diretube.com, tend to adopt a top-down broadcasting communication style, with very little interaction between page owners and page followers, and even less interaction with other Facebook pages, including those belonging to the same political line. This is particularly true for government-affiliated pages, while the opposition, for whom Facebook was an important electoral campaigning tool, has used social media in a more dialogic way. There are, however, exceptions to this general trend, most notably the pages of some influential speakers such as Alula Solomon and Daniel Berhane, two news analysts whose pages have become spaces for audiences of different political affiliations to engage in open discussions. Pages like these have moved from the traditional broadcasting style towards more multidirectional and interlocutory forms of engagement.

\section{FINDING 8 - The Ethiopian Facebook community is characterized by separate and self-contained online communities - but they are not echo-chambers!}

Ethiopian Facebook users tend to coalesce around very few online pages of their choice, whether to express opinions in agreement with the page owner, or, in some cases, to dissent and criticize the page's political line. Few users comment on more than one page, and, in a similar vein, page owners seldom post on other pages. This contributes to giving each page a very distinctive identity, since the page's followers are by and large different from the followers of other pages. Online political communities are not necessarily divided by political affiliation, therefore for the Ethiopian online sphere it would be misleading to talk about "echo-chambers", as spaces that keep bringing back to users ideas they already sympathize with, ultimately reinforcing their belief system. Individuals do not tend to interact with all pages belonging to a certain political line, but to concentrate their time online on a few pages of their choice. Users, in other words, tend to focus their communicative efforts on individual pages, rather than dividing their time between all the pages representing their own political line. The echo-chamber argument is further challenged by the fact that while users may be attracted to specific spaces because of the issues they expect to be discussed, they also seem to steer these discussions into different directions if necessary.

\section{FINDING 9 - Discussions about religion in social media are the least antagonistic}

If we divide the statements we sampled on Facebook into broad categories, such as politics, religion, and ethnicity, some relatively distinct patterns emerge. Discussions on religion, for example, are those displaying the lowest percentage of statements going against, with only $10.5 \%$ falling into this category. This finding is particularly relevant in the context of perceived growing divides among the major faiths in Ethiopia, and of a politicization of religious debates, including the closure of several papers that cater for the Muslim community and the arrest and imprisonment of journalists that work for these outlets. Statements going against that explicitly call upon ethnicity and refer to specific ethnic groups are also relatively marginal (only $14.2 \%)$. Less surprisingly, politics is the area that emerged as the most contentious, but still in a proportion only slightly higher than the average conversations on 
Facebook (21.8\% of statements with a political focus are antagonistic, as compared to the average of $21.4 \%$ ).

\section{FINDING 10 - New opportunities for engagement exist when a more universalistic agenda is embraced}

Over the past twenty years, a high level of polarization has characterized Ethiopia's media. First the press, and then online media, have articulated competing, often irreconcilable, ideas of the Ethiopian nation-state. Conversations on social networking platforms have inherited some of the tones that characterized previous debates; but the strongest forms of antagonism have remained relatively marginal. The greatest opportunities for engagement seem to lie in politics that appeal to universalistic values. For example the campaign for the release of the Zone9 bloggers, despite attracting criticism around the status of freedom of expression in Ethiopia, both at the national and international level, was largely conducted without antagonizing opposing figures. Almost all the selected statements about the Zone9 bloggers were going towards (58 out of the 60 randomly selected statements focusing on the case, or $96.7 \%)$. It seems that a new generation of Ethiopians may be more inclined to adopt less contentious tones and embrace more universalistic forms of politics; while older figures and grievances tend to trigger more polarized debates. However, suggesting a too clear-cut distinction between old and new media, and progressive and conservative politics, would be simplistic and ultimately obfuscate the complexities of political life in Ethiopia. There are issues, such as the proposed "Addis Ababa and its surrounding Oromia Special Zone integrated plan", which cut across entrenched grievances and new debates, and triggered extremely contentious debates online, with corresponding cases of violence on the ground.

Taken together, these findings suggest how social media in Ethiopia are emerging as a space where different forms of tolerance and acceptance are being displayed and new forms of engagement can be experimented with. As it is the case elsewhere in the world, hate speech and dangerous speech do occur on these platforms, but they occupy a marginal proportion of the total online conversations.

In addition, rather than simply fitting into a polarized - but widely popular - debate on social media as either an opportunity or a threat to development and stability, the findings offer some concrete indicators for policy makers about the areas that are the most promising for intervention. For example, the existing and perceived imbalances of power appear to fuel greater antagonism, even among users sharing similar interests.
A greater responsiveness to opinions voiced online may reduce the sense of distance many users experience in their everyday interactions. Furthermore, religion, as discussed in social media among Ethiopians, appears to serve as a unifying, rather than a divisive factor. Especially in tragic circumstances, such as the attacks or killings of Ethiopians abroad, religion has not been used as a pretext to accuse and blame specific individuals or groups, but rather it has served as a base to appeal for unity. A similar argument can be extended to debates and campaigns that reflect on the future of the country, rather than the settling of old scores.

These, and other issues are discussed throughout the report, offering clear indications of the dynamics characterizing antagonism and engagement in social media. 
The next chapter reflects on the methodology that has been developed, tested, and refined throughout the project. Chapter 2 summarizes the findings emerging from our general sample that reflect the nature and quality of debates on Facebook in Ethiopia and among the Ethiopian diaspora as a whole. Chapter 3 explores the dynamics encountered on some of the most popular online spaces in Ethiopia. Chapter 4 summarizes key findings gathered before and after the May 2015 elections. And the Conclusion draws out the major findings reflecting our overall argument that social media represent an opportunity for ordinary citizens, politicians, activists, and media actors to experiment with new forms of engagement online that may also come to influence offline debates. 


\section{BACKGROUND \\ AND RESEARCH STRATEGY}




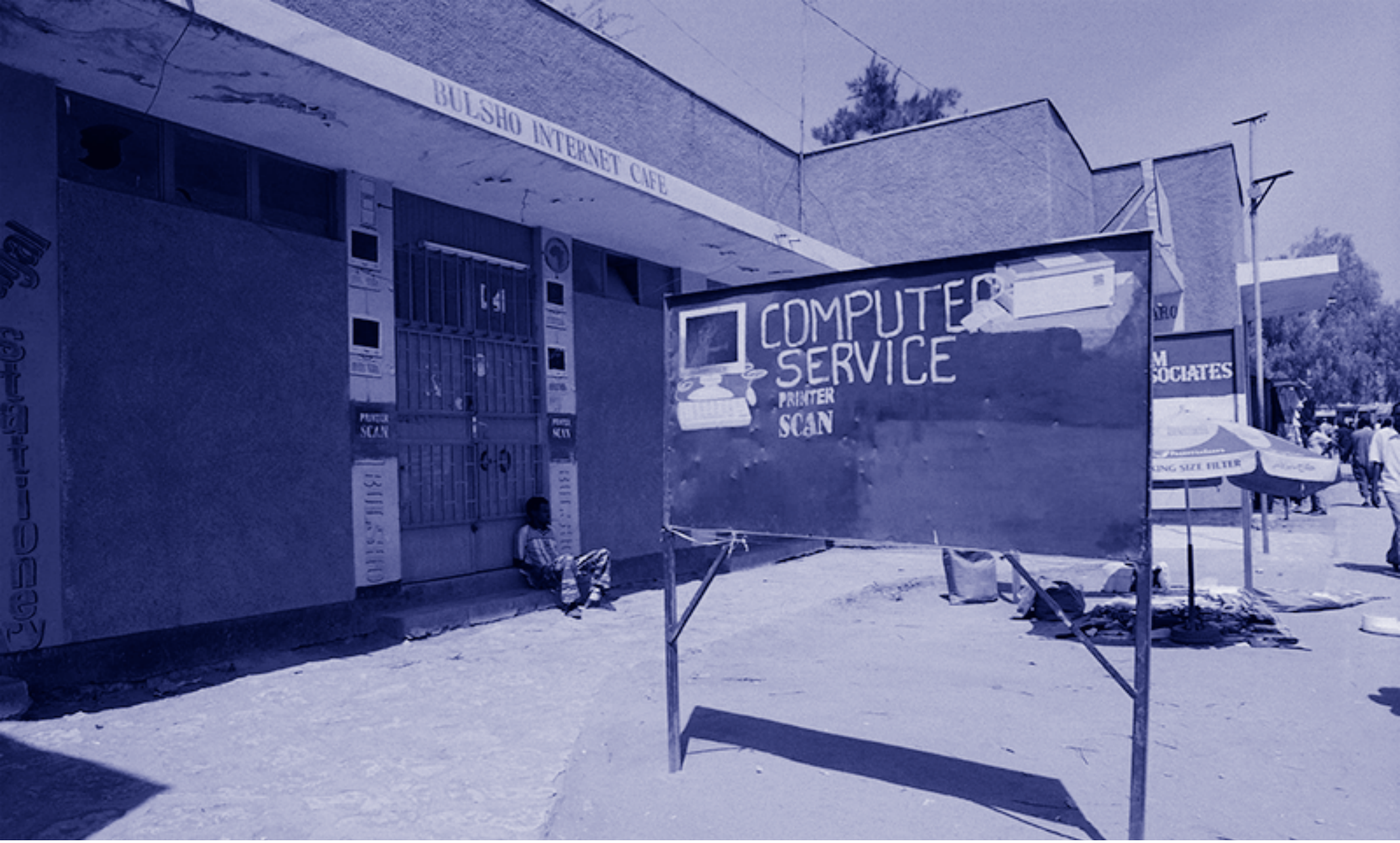

M echachal's research strategy has developed both in response to concerns about uses of social media that can incite hatred and violence, and to the unique conditions that have shaped the relationship between media, politics, and power in Ethiopia.

\section{RESEARCHING HATE SPEECH ONLINE: A CAUTIONARY TALE}

Mechachal began with an interest in identifying and analyzing hate speech, especially messages with the highest likelihood of leading to violence. This spirit informed the project's first pilot study, which was conducted between October 2013 and February 2014. The pilot was limited in scope but it highlighted at least two important challenges for research on hate speech online.

First, the need to understand not just the nature, but also the prevalence of hate speech in the context of broader online debates. The growing concerns about uses of social media that can promote radicalization and incite violent acts has led to increasing demands for research that can detect and monitor these types of online behaviors. As attention towards the "darker" side of the Internet grows, however, in the absence of data that can contextualize how relevant and prevalent extreme speech is in the context of how online media are used more broadly, it may lead to creating an image of online conversations as a whole as potentially harmful. The risk is particularly severe in countries where civil and political liberties are already under threat. This challenge led to developing a sampling strategy, highlighted in the next section, that allows not just detect the most extreme forms of speech (as it has been the case so far for most projects focusing on hate speech online), but also measuring how prevalent they are among conversations in social media.

The second challenge is related to the importance of simultaneously detecting and understanding the functioning of spaces of engagement, where users seek to create communicative relationships across divides, rather than exacerbating existing tensions. These can be spaces where counterspeech emerges as a direct response to hateful messages, but also, more broadly, spaces where users engage in other types 
of exchanges that have the potential to foster more debates. Detecting these types of behaviors can also be important for understanding what resources are already available online that can help counter the most aggressive forms of speech, before resorting to more severe measures such as punishment or censorship.

\section{THE ETHIOPIAN MEDIA SYSTEM AND POLITICAL POLARIZATION}

Researching online media in Ethiopia poses numerous challenges, many of which are related to the high level of polarization that has characterized its political landscape. ${ }^{3}$

In the case of the media, the roots of this polarization can be found in a complex mix of factors that characterized the period following the end of the war against the Derg regime in 1991: the liberalization of the press initiated by the government led by the Ethiopian People Revolutionary Democratic Front (EPRDF) to respond to international pressures, and signal that it was different from its predecessors; the occupation of the newly created spaces for debate by some of the very political forces that had been ousted from power; and the absence of a culture of engagement between political actors belonging to opposing factions. These factors led to what can be considered the 'original $\sin ^{\prime}$ in Ethiopia's contemporary media history: the fact that when the new leaders came to power they opened the space for debate but refused to engage with the very debates they had allowed to bloom. This would have profound repercussions on the nature of the country's media system for many years.

A similar attitude towards dismissing competing points of view seems to have progressively extended to the international domain too. The exhortations of international organizations and NGOs for improving the status of freedom of expression in the country have been insistent, but have received little attention. The Ethiopian government, on its part, has preferred to emphasize the need to ensure media are not used to destabilize the country, often invoking the global antiterrorism agenda to justify its measures.

As in nearby Rwanda, also the scholarship focusing on Ethiopia has supported divergent views on the country's politics and development trajectory. ${ }^{4}$ In contrast to what has been argued for Rwanda, however, a wider middle ground seems to have emerged at the scholarly level, a space where national and international scholars have shown willingness to take into account both the failures and successes of the current policies. Mechachal sought to build on this space and possibly extend it also to research on the media in Ethiopia, where polarization of views has been particularly pronounced.

\section{MECHACHAL'S RESEARCH STRATEGY}

Against the complexities emerging both from conducting research on hate speech online and from the polarized environment that has characterized the media in Ethiopia, Mechachal developed a targeted research strategy built on three main pillars: (1) a sampling strategy that measures the prevalence of hate speech in the total of conversations on social media; (2) a conceptual framework that offers a nuanced understanding of different forms of speech, from dangerous speech, to messages seeking to build bridges across political, ethnic, and religious divides; and (3) the creation of a forum where individuals belonging to organizations at opposite ends of the political spectrum could be offered an equal chance to access data and discuss it collectively. All three pillars are further explained below. 


\section{Sampling strategy}

Conducting research on online spaces in Ethiopia can be challenging, as highlighted above, but it also offers some unique opportunities.

The distinctiveness of the languages spoken in Ethiopia, together with the still limited Internet penetration in the country, made it possible for the team to develop a comprehensive mapping of almost all Facebook spaces of public interest, and derive a realistic sample of the overall debates focusing on Ethiopia. The decision to concentrate our attention on Facebook was motivated by its popularity among Ethiopians online. As in other countries where access is still limited, Facebook has become almost synonymous with the Internet. ${ }^{5}$ In addition, the limited availability of other media sources has turned Facebook into an important platform for politicians, activists, journalists and academics to target a still limited, but increasingly broad, audience, and reach out to younger Ethiopians.

As one of the of social media strategists for the EPRDF commented:

The most important medium that we have used as a party is Facebook. If you say why, it is because Facebook has many users. The majority of Internet users at national level uses social media. Among those who use social media, the majority uses Facebook. Even, those who use Twitter but not Facebook are very few in number. Those who use Twitter also use Facebook. Therefore, working on Facebook means reaching others who use other platforms. Hence, we decided Facebook is the most important. When we set an agenda or assess our work, we mainly focus on Facebook.

The representatives of almost all parties we interviewed stressed in particular the relevance of social media for reaching younger generations. A member of the Semayawi party, for example, responded to a question asking who their main audience is:
The youth! Actually, it is largely the youth that uses Facebook. It is the youth without doubt. The party, not only on Facebook but also generally in its political activity, targets the youth. It is not a class struggle, but the youth can lead, can give sacrifice, have no luggage, not rigid and change resistant in that they entertain different ideas beyond emotion when it comes to ideology.

Members of political parties and traditional media articulated similar positions. As a journalist working for The Reporter, one of Ethiopia's longest running private newspaper, commented:

We give great value to social media. Because it is on social media that we communicate with young audiences. Young people are not in the culture of buying a newspaper and reading long feature stories. Facebook is the main way to reach them. Twitter is not as much. Twitter is limited to 140 characters. That has restrained many things. It is a highly opinionated society.

At the beginning of the project (and with regular updates since), the team embarked on the ambitious effort of mapping any Facebook profiles, pages, and groups fulfilling the following three criteria:

- Have $\mathbf{1 0 0}$ or more followers (for individual profiles)/likes (for pages)/members (for public groups);

- Have at least some content in an Ethiopian language;

\section{- Raise discussion topics on Ethiopia.}

The result was a list of 1055 Facebook spaces covering issues including politics, religion, sport and travel. This offered a sampling frame 
that, as indicated in Figure 1, has enabled the team to regularly select spaces according to three different strategies:

- Spaces selected randomly in order to ensure results could be generalized. This strategy led to the generation of what we refer to in the report as "general sample".

- Popular spaces analyzed every day to map ongoing trends. Statements selected in those spaces built what we call "trends sample".

- Spaces selected purposefully in order to capture a particular event (e.g. a protest, the inauguration of a new project), ongoing issue (e.g. elections), or particular type of speech (e.g. hate speech). We refer to this as "purposeful sample".

In each of these spaces, both posts/status updates and comments were then selected for analysis for a total of $\mathbf{8 0}$ statements per day on average, and approximately 2,000 statements a month.

This strategy has allowed the project team to analyze online debates on a broad variety of issues, and to locate them in their proper context.

\section{Going against / going towards framework of research}

The second pillar of Mechachal's research strategy is a conceptual framework that combines the ability of identifying and classifying different forms of speech that can lead to violence; the possibility of concurrently analyzing messages that are representative of more ordinary uses of social media; and the awareness that in polarized environments it is particularly important to identify spaces for engagement and mutual recognition of political adversaries.

A central element of this framework is the distinction between statements going against and statements going towards.
This classification is rooted in research and theories of deliberation, political conflict, and political engagement, and it has been progressively tailored to apply to Ethiopia's political environment. Going towards and going against are not about agreeing or disagreeing, but more about the tendency to take a viewpoint seriously and engage with it, or, on the contrary, to dismiss it and directly attack a person for his/her affiliation with a specific group.

Statements that go against are statements attacking another speaker or a specific group by belittling, challenging, provoking, teasing them maliciously, or explicitly threatening them. They represent a conflict-producing or a conflict-maintaining behavior. The type of 'name-calling' that has characterized the debates in Ethiopia's traditional and new media, for example, falls in this category. Terms such as 'anti-peace' and 'chauvinist', or puns replacing 'prime minister' with 'crime minister', have been used frequently to dismiss adversaries, removing possibilities of engaging with an issue a priori, because its source made it unworthy of attention.

Statements that go towards, on the contrary, are statements that help initiate, maintain, and/or build a communicative relationship, for example acknowledging another person or group's position, offering additional information about the topic being discussed, joking (in a non-hostile teasing way), and creating engagement and conversation with the other members in the discussion. They include statements that focus on the issues raised rather than attacking the speaker; offer balanced arguments about the positive and negative sides of a conflict; and cite studies and factual sources. Statements going towards can also contain strong criticism, but in the context of a polarized debate, they offer at least a premise for recognizing adversaries as legitimate, rather that simply dismissing them. 
SPACES

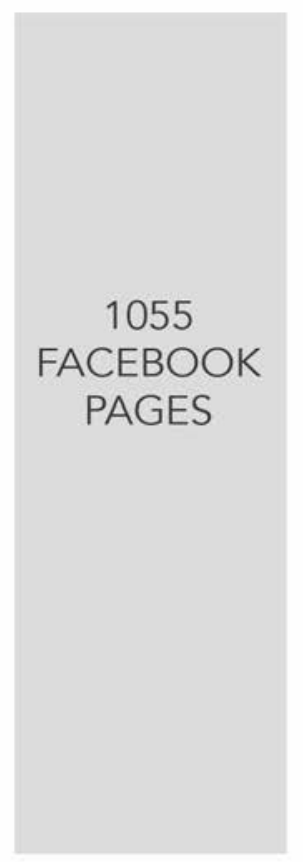

SAMPLING

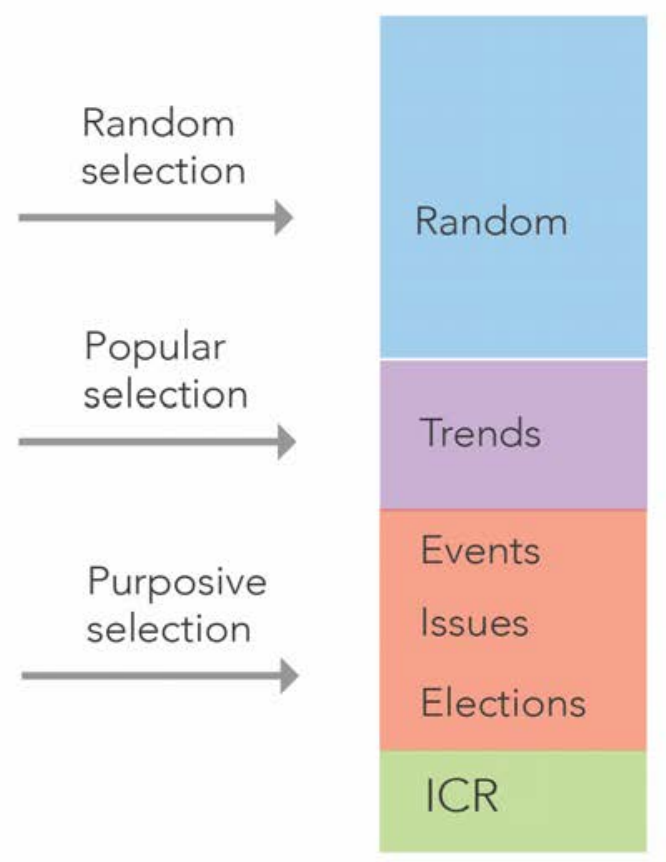

CODING

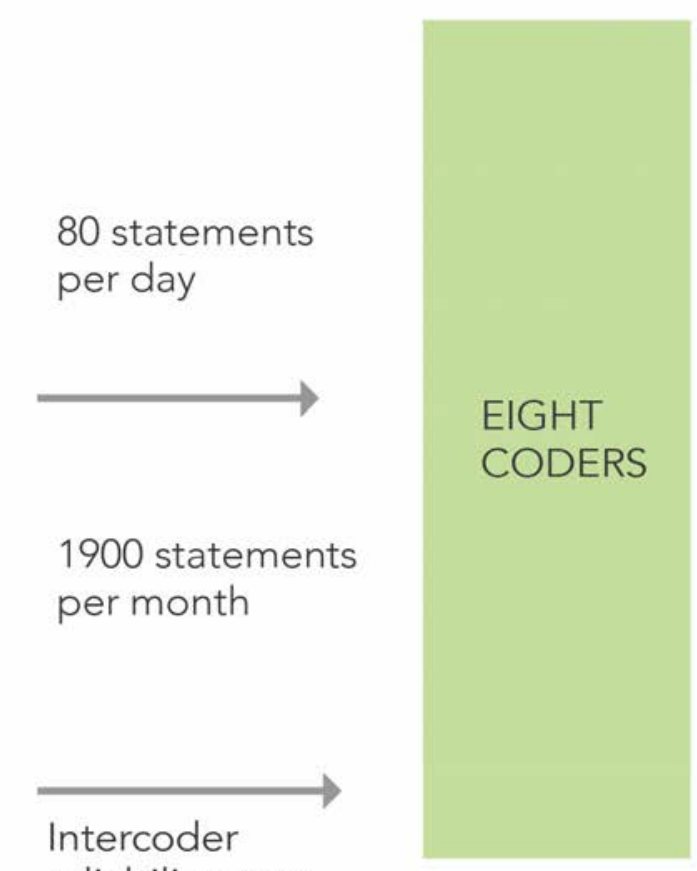




\section{Offensive, hate, and dangerous speech}

The concepts of going against and going towards are aimed at cutting the continuum of statements uttered in online debates into two broad categories and represent the beginning of more in-depth analysis. In the case of statements going against, four subcategories have been created, in such a way that statements could be categorized as: offensive speech; hate speech; dangerous speech with limited possibility for the speakers (or the groups they appeal to) to carry out violence; and dangerous speech with high risk that the speakers (or the groups they appeal to) could carry out violence. The identification of these typologies was based on an equation that factored in different parameters along which each selected statement could be categorized. Figure 2 offers a representation of the different layers of analysis in the form of a decision tree.

A first layer considers the grounds on which an individual or group is being targeted. While statements that go against in general can be antagonistic on any ground, including politics, in the case of these sub-categories, we only considered statements that target people based on their ethnicity, religion, and gender or sexual affiliation. This is to comply with international, regional, and national legal frameworks defining hate speech, which exclude purely political statements from their definitions. In the case of Ethiopia, whose constitution recognizes ethnic federalism as a building block of the Ethiopian nationstate, the distinction between politics and ethnicity proved particularly complex and its operationalization emerged as the result of numerous discussions within the research team and during the stakeholders' meetings in Addis Ababa. Many political parties in Ethiopia are ethnically based, such as the Tigrayan People Liberation Front (TPLF), or the Oromo Peoples' Democratic Organization (OPDO). The team agreed that if a statement targeted a party or one of its members directly, it had to be considered under the label of "politics". However, if in the same statement the speaker attacked, for example, both the OPDO and Oromos in general, the statements had to be flagged under both labels of "politics" and "ethnicity", and this would be computed in the equation.

The second layer focuses on the content of the statement. The analysis at this level is the one that builds most significantly on research on "dangerous speech" and "fear speech". These concepts help in narrowing down the focus to speech that can cause harm and lead to violent outcomes. While hate speech is found, in some shape or form, in almost all societies, including those where the risk of violence is limited, the concept of dangerous speech aims at isolating acts that have a significant probability of "catalyzing or amplifying violence by one group against another." " The concept of "fear speech"7 has been recently advanced to emphasize language that is able to progressively create a siege mentality and ultimately lead to legitimate violent acts as defensive of a group's safety or integrity. Also based on the study of mass atrocities, the idea of fear speech offers a pathway to understanding whether the preconditions for violence may gradually emerge. Based on these premises, we investigated whether or not, for example, a statement uses derogatory terms; contains a rumour based on a particular group's ethnicity, religion, or gender that cannot be easily or factually verified; or suggests that the audience faces a serious threat of violence from another group.

The third layer of analysis asks whether or not a statement encourages the audience to do something specific against an individual or group identified on the basis of ethnicity, religion, or gender. The call to action can refer to psychological forms of violence (e.g. the speaker suggests that immigrants deserve to be treated differently from citizens) or to physical violence (e.g. there is a call to beat, or kill, a specific person or group). The analysis at this level takes into account the arguments put forward by many legal scholars that the content of a speech act alone is not sufficient for considering it to be hate speech. ${ }^{8}$ An exhortation should be present instead towards performing an action that can cause harm to a specific subject. 


\section{GOING AGAINST EQUATION}
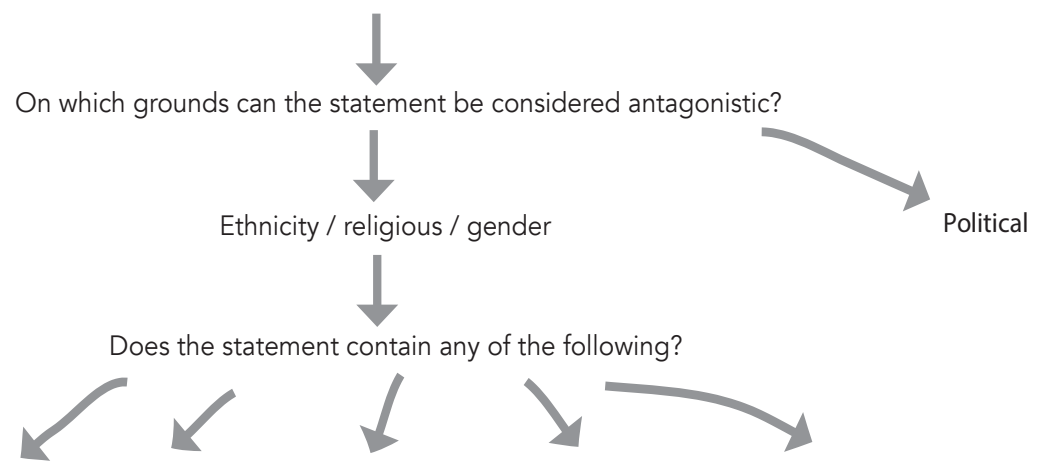

No

Uses derogatory
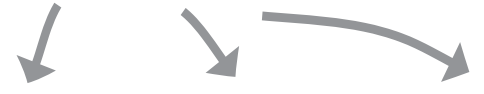

terms

Suggests threat

Contains explicit Spreads a rumour call to action

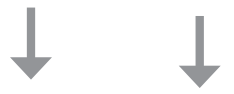

of violence

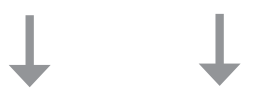

Does the statement encourage the audience to do any of the following actions?

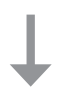

No

Insult or humiliate, Boycott, Discriminate

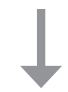

Riot, Loot, Beat, Evict, Kill

It calls for other forms of physical violence
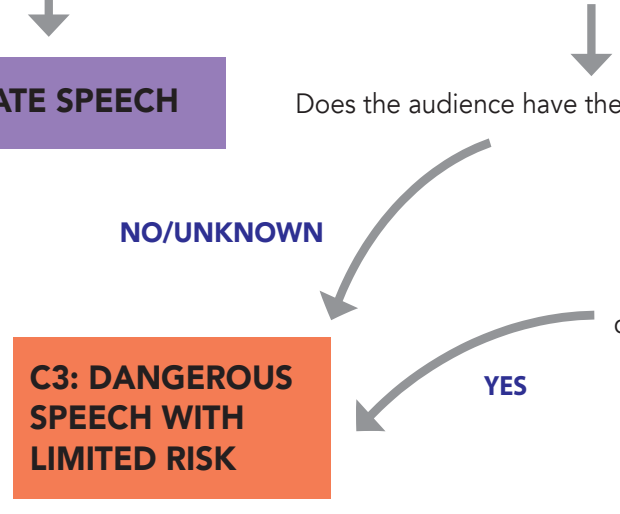

Is the target able to call upon institutions? NO / UNKNOWN WITH RISK OF VIOLENCE 
Finally, a fourth layer of analysis poses questions related to the imbalance of power between the speakers and the target. This layer is important in providing context, as there is significant difference between a statement by a prominent government official or religious leader targeting a group that is already persecuted in their country, and one posted by a loner who uses the Internet as a means of venting his anger against a public figure. This type of analysis, however, poses some particular challenges, as it requires the person coding the statement to make judgments about the world that exists beyond the statements itself. What is being examined in particular is: whether the speakers and/ or those who are likely to support their statements may be able to carry out the actions suggested against the target individual or group; and whether the targeted individual or group is able to call on officially recognized institutions to defend itself against the threat of violence. Given the complexities of making these types of judgments, after having tested different approaches, we settled for a 'conservative' interpretation of this question. This means that if the coder could not clearly assess whether the speaker or the group he appealed to was able to carry out violence, the statement had still to be identified as "dangerous speech, but with limited risk of violence". Similarly, if the coder could assess that the speaker or the group he appealed to was able to carry out violence, but could not clearly assess whether or not the target group could call on officially recognized institutions to defend itself, the statement had to be categorized as "dangerous speech, with high risk of violence".

The combined answers to the questions posed for each of these layers led to classifying statements in one of the four sub-categories. For example, if a statement contained only derogatory terms against followers of a particular religion, it was categorized as offensive; if, in addition to this, it also contained an incitement for other people to discriminate members of that religious group, it was categorized as hate speech. Following a different path, if a statement contained a rumour that members of ethnic group A were going to attack or reclaim land from members of ethnic group B, and called for people of ethnic group $B$ to arm themselves and be ready to act (i.e. what is called accusation in a mirror), it was categorized as dangerous speech.

Despite the discussion among scholars about whether or not dangerous speech has to be considered a subset of hate speech - for example, statements that do not explicitly call for attacking a specific group can still be instrumental in creating a sense of resentment and suspicion that can later lead to violent actions - we considered the four subcategories as part of the same continuum, with an increasing risk of violent outcomes going from the left to the right side of the spectrum.

Our framework is the result of multiple rounds of testing and refinement, but it is not infallible. The connections between speech and violence are complex and, despite regular conversations within our group to analyze how each coder coded specific statements and improvements in our intercoder reliability tests, some messages still posed significant challenges when attempting to clearly categorize them using one of the available options. ${ }^{9}$ Our goal is to contribute to the growing debate on the likelihood of certain types of speech leading to violence, using tools that are able to take this complexity into consideration, and offer rigorously sourced and analysed empirical evidence, rather than being alarmist.

\section{DATA SHARING AND STAKEHOLDERS ENGAGEMENT}

The polarization of the political scene in Ethiopia has negatively affected the possibility of an open and constructive debate on the future of the country's media and has created suspicion towards research seeking to assess the status of freedom of expression in the country. We sought to address this challenge by ensuring the evidence collected in different phases of the project could be shared with a 
broad variety of stakeholders, representing different components of Ethiopian society. Before the publication of each report we presented and debated preliminary results in Addis Ababa with a group that included leading figures from the government of Ethiopia, the major opposition parties (Semayawi, Medrek, EDP), the new and traditional media scene (from The Reporter and Addis Standard, to Horn Affairs and Zone 9), academics, representatives of regional and international organizations (African Union, UNESCO), and members of the national and international civil society (PEN Ethiopia). Between February 2014 and September 2015, four meetings were organized in Addis Ababa. This process offered a unique opportunity to test the convening power of evidence of a kind that is usually scarcely available, but that allows academic insights on hotly debated topics. Individuals sitting at opposite ends of the political spectrum found common ground and agreed on the ability of academically informed research to create a space for individuals and groups holding competing views to engage with one another using evidence as their starting point, rather than personal grievances. ${ }^{10}$ As the following chapter indicates, the possibility of discussing emerging findings with a community of diverse and influential stakeholders had a significant impact on our research framework and interpretation of the evidence. 
2. ANTAGONISM AND

ENGAGEMENT

IN ETHIOPIA'S

SOCIAL MEDIA 
The extensive mapping of online debates also allowed the research to challenge other seemingly entrenched perceptions about online debates in Ethiopia. Contrary to the expectations about the Ethiopian diaspora being more adversarial towards the current regime, Ethiopians posting from outside of the country do not tend to write more antagonistic statements than users living in Ethiopia. Also, against the claim that social media are used by relatively influential figures as a tool for radicalization, most antagonistic messages are actually written by individuals with little or no influence, rather than by speakers with a large follower base seeking to exploit existing divides.

This does not mean that hate and dangerous speech in Ethiopia should be overlooked. As the analyses developed in this chapter indicate, antagonistic statements tend to generate more debate and are shared more widely than other types of statements. Online spaces that regularly host derogatory and offensive statements do exist, even if they are very few, and calls for persecuting individuals based on their political, ethnic, or religious affiliations are common in those spaces. Our findings suggest, however, that spaces inciting hatred and violence in Ethiopia remain marginal, and social media as a whole are more likely to be embraced as spaces to experiment with new forms of communication and engagement rather than as spaces for promoting extremist views.

The next sections expand these arguments in greater detail, examining first the profile of users that engage in different types of speech (e.g. in terms of their location, gender and influence); the reactions to different types of statements; what distinguishes hate and dangerous speech from other types of speech; and, finally, where the greatest opportunities for engagement are likely to exist.

\section{EXAMPLE OF DANGEROUS SPEECH}

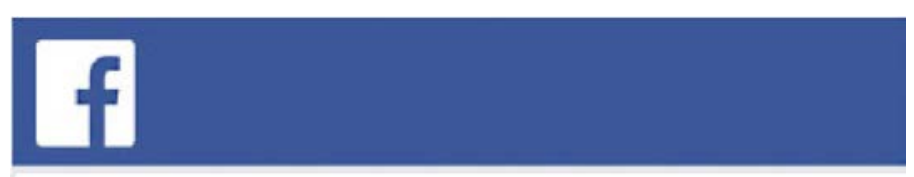

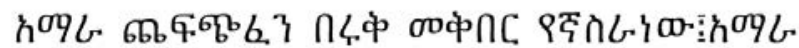

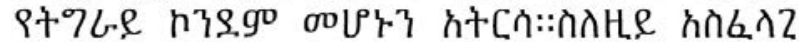

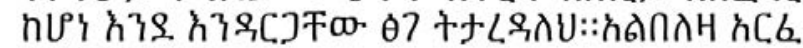
о० 9 C

1. Like Comment $\Rightarrow$ Share

TRANSLATION

'Slaughtering and burying Amhara is our Job. Don't forget that Amhara is the condom of Tigray. So, if need be you will be beheaded, Andargachew Tsige. Otherwise you better behave 


\section{GOING AGAINST AND GOING TOWARDS}

The vast majority of statements posted on Facebook are statements that go towards. They may show support for an individual, group, or ideas; simply offer information or opinions; or jokingly address an issue or problem. They may also contain criticism, which may be strongly worded, but they either address a general audience, without targeting a specific individual or group, or, if they do target a specific group or individual they do so with a recognition of the others as legitimate counterparts, rather than being dismissive, derogatory, or calling for actions against them. As Figure 3 suggests, 59\% of statements go towards, while only $16 \%$ go against. $25 \%$ of statements fall in the "Other" category. The latter are statements that have little or no relevance to debates on politics, ethnicity, religion or gender (for example a comment on a photo capturing a personal moment, or a post related to a sporting event) or that are too unclear to be coded. If we remove "Other", the percentages of statements going towards and going against become $78.6 \%$ and $21.4 \%$ respectively.

These findings are based on a sample of 4028 statements that have been randomly selected from our sampling frame and can be generalized to describe the broader debates occurring on Facebook and focusing on Ethiopia in the period covered by the research.

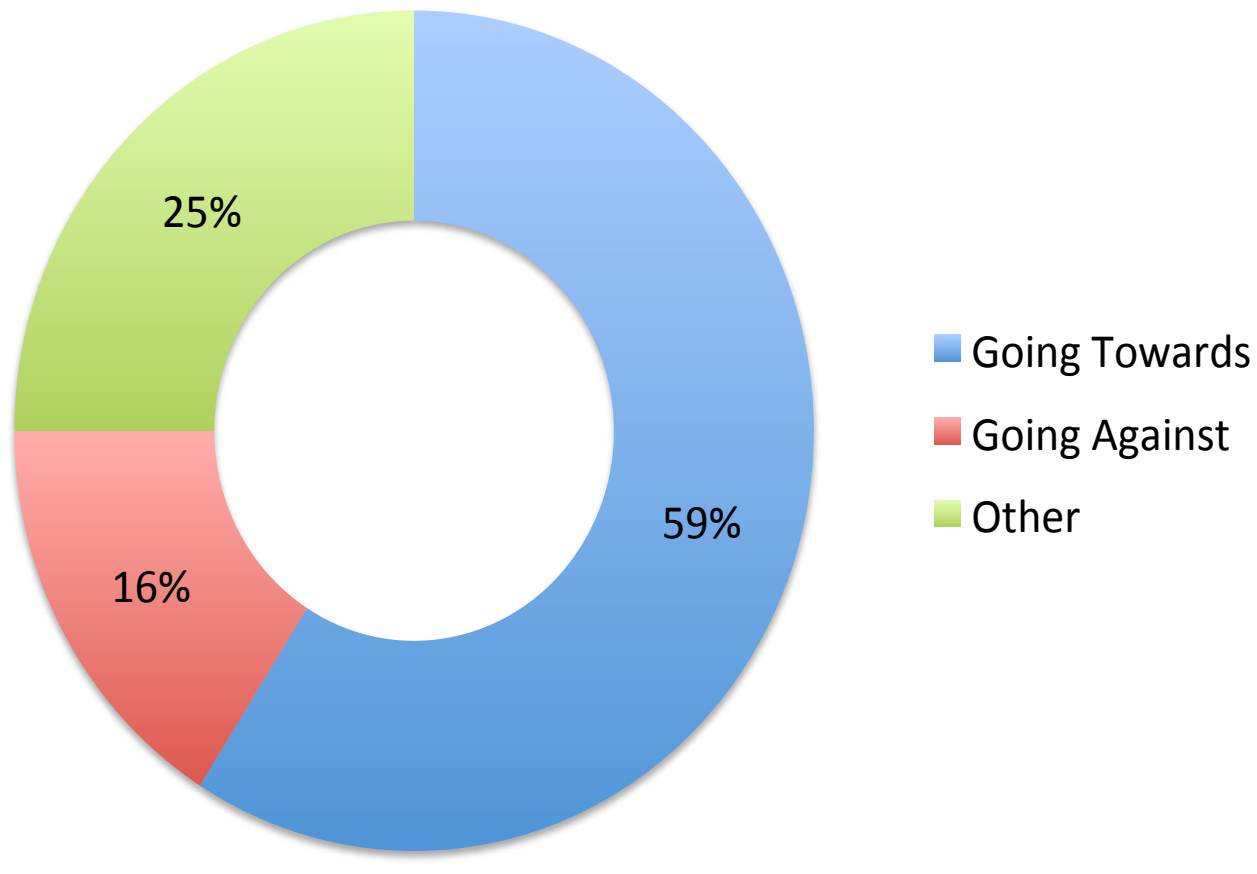


For those who are familiar with Ethiopian politics, these results may appear surprising at first, given the polarization that has characterized debates in the media. We sought explanations from different perspectives: from more qualitative examinations of online interactions; to comparatively examining existing research on interactions on social media; to extensive discussions of preliminary findings during the meetings in Addis Ababa that gathered representatives of the government of Ethiopia and of the major opposition parties, prominent bloggers and journalists, and leading academics from Addis Ababa University and other research centers in Ethiopia (See Chapter 1 for more details). Three explanations stand out:

- The project adopted an extensive definition of going towards. This included strong criticism, but of a kind that still recognizes the adversary as legitimate and offers the conditions for a communicative relationship to exist. The framework we developed sought to avoid risks of 'criminalizing' the vigorous contestation of ideas that is constitutive of a vibrant political debate, with the pretext of combating hate speech.

- In the absence of available and reliable statistics on the prevalence of different types of speech, it is the most sensational messages that, both in a positive and in a negative sense, shape people's perceptions and are often used to describe an entire space. This became particularly clear through our meetings that brought together both government and prominent social media personalities. During one of the workshops, a member of one of the opposition parties discussed some of the images on Facebook that he found "disturbing" and "deeply discriminatory". During our research we identified numerous instances of statements that can fall into this category (for example, one statement used a picture of an Ethiopian about to be beheaded to claim that Ethiopians belonging to a particular ethnic group deserve to die). However, as the findings presented in this report, and in our previous reports illustrate, while these types of messages do exist and need to be examined for their potential to exacerbate tensions and conflicts, they nonetheless represent a very small proportion of the exchanges occurring in social media.

- A third explanation as to why only a limited number of statements go against emerged from an in-depth investigation of users' demographics and from a comparative examination of existing research on social media. As elsewhere in the world, the "Ethiopian Facebook" has attracted a younger generation of users who appear to be less interested in old grievances. According to Facebook's own statistics, an estimated $83 \%$ of users are between 13 and 34 years of age. ${ }^{11}$ While these users may still be advocating change and be critical of their leaders, they seem less inclined to refer to historical disputes, and see current problems, or positive changes, as a reflection of present policies and leadership.

The prevalence of statements going towards, however, is not the only finding that challenges existing perceptions of Ethiopia's online sphere. The following two sections offer a detailed analysis of Ethiopia's online diaspora and of how influential speakers make use of social media. 


\section{EXAMPLES OF STATEMENTS GOING TOWARDS}

\section{f}

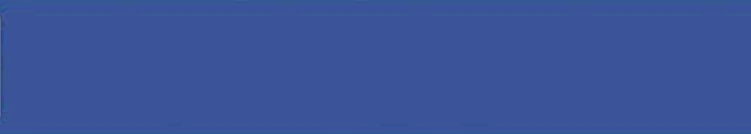

\#Ethiopia: Notes on the election:-

I am surprised that almost all individuals and media are editorializing rather than reporting.

Even with my meager resources, I was able to gather a couple of still opposition hopeful and/or potentially disputable areas. (If my info is good, some areas were/will be swung by university students' votes).

Moreover, we shan't forget State Council seats are as valuable as the Federal Parliament's.

Those on the ground should be encouraged to exhaust the counting process - from recount to court - rather than being discouraged half-way. Regardless who wins, the counting has both symbolic value for the voter and is critical input for the future.

Farsighted activists would take the lead in this regard.

it Like Comment $\Rightarrow$ Share

Honestly, I am not convinced EPRDF got all the seats. But I don't have the resource to go and check. And I can't gather info via facebook for legal reasons.

Like - Reply - 13 4 May 25 at 10:40pm

$\rightarrow$

replied 3 Replies

As is the election, the parliament is ceremonial so is the executive and judiciary so to say. Just keep calm and report as a domestic election reporter.

Like - Reply · $32 \cdot$ May 25 at 10:43pm

$$
\text { QA\&...!! }
$$

Like - Reply $\cdot 31 \cdot$ May 25 at 10:45pm

Are you disputing www. aigaforum.com report that EPRDF has made clean $100 \%$ sweep of all the electorate except Amhara region where they said a few wins by the opposition is possible? Whose source is more credible? yours or aigaforum's?

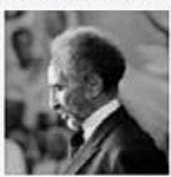

Aiga Forum, an Ethiopian forum for news and views that promotes Ethiopia's...

Like - Reply - May 25 at 10:53pm

I don't wish to debate their report. They may have better sources and resources than me.

However, they posted that statement at 1:15PST that is midnight in Ethiopia Just 5 or 6 hours after the closing of the polling stations. ... See More Like - Reply $132 \cdot$ May 25 at 11:12pm - Edited

$$
\text { why you talk alot while no body ask }
$$
you. Keep calm. The struggle is in the making. No body believe it was a fare election. It was an important process to pass through so that the people would be ready for the next phase. I think Semayawi has achieve its goail in showing what they want, and the real struggle just started. So, relax......EPRDF won $100 \%$ and you shouldn't have a problem Like - Reply - B 3. May 25 at 11:13pm

replied 1 Reply

(Heated but reasonable engagement between users from different political background in the comment section - strong and firm criticism that nonetheless recognizes the other as a legitimate adversary)

\section{f}

My anxiety is not being a fan of opposition parties or EPRDF. believe that every government done privileged and unprivileged things to their own people.EPRDF has brought lots of changes since 1997(E.C).Because of the opposition(Kinejet)!!!People are more advanced than Gov.My friend if every one of us gets a chance to go out of our mother land believe me only $z$ advantageous will remain here.we never know when we $r$ going to die. as long as we $r$ living we should get the basic necessary things + to that human right is the necessity. The most important thing is Love.God create us with freedom. I don't know how come most EPRDF officials forget where they come from? I don't know when my ppl will eat at least twice aday?get right to speak, write free from Gail,.........? May God bless Ethiopia Like · Reply · May 20 at 9:47pm

View more comments

(Strong and firm criticism that nonetheless recognizes the other as a legitimate adversary) 


\section{THE ETHIOPIAN ONLINE DIASPORA}

The Ethiopian diaspora has been instrumental in creating the first online spaces dedicated to discussing Ethiopian politics. In the late 1990s and early 2000s, before the diffusion of social networking platforms, the most popular websites - The Ethiopian Review, Nazret, and Ethiomedia - were all launched by Ethiopians living in North America. Largely representative of the views of professionals and intellectuals who had escaped political persecution during the Derg regime, but were also hostile to the EPRDF, these spaces adopted adversarial tones similar to those that had characterized the private press in Ethiopia in the 1990s. Moderate online spaces did emerge in following years, with bloggers such as Enset posting from the diaspora, and others like
Ethio-Zagol beginning to contribute from Ethiopia. But it was the earliest experiences that created a perception of a diasporadominated online sphere, offering a platform for strongly oppositional voices to pursue their agenda.

The comparison of messages from within and outside Ethiopia, however, reveals a different picture for debates taking place on Facebook. Messages posted from Ethiopians based abroad do not tend to be more antagonistic than those posted from within Ethiopia. The balance between statements going against and towards is practically identical $(21.6 \%$ of statements posted outside Ethiopia go against vs. $21.4 \%$ in the general sample).

\section{FIGURE 5: DISTRIBUTION OF SPEAKERS IN THE DIASPORA BY COUNTRY (TOP 10)}

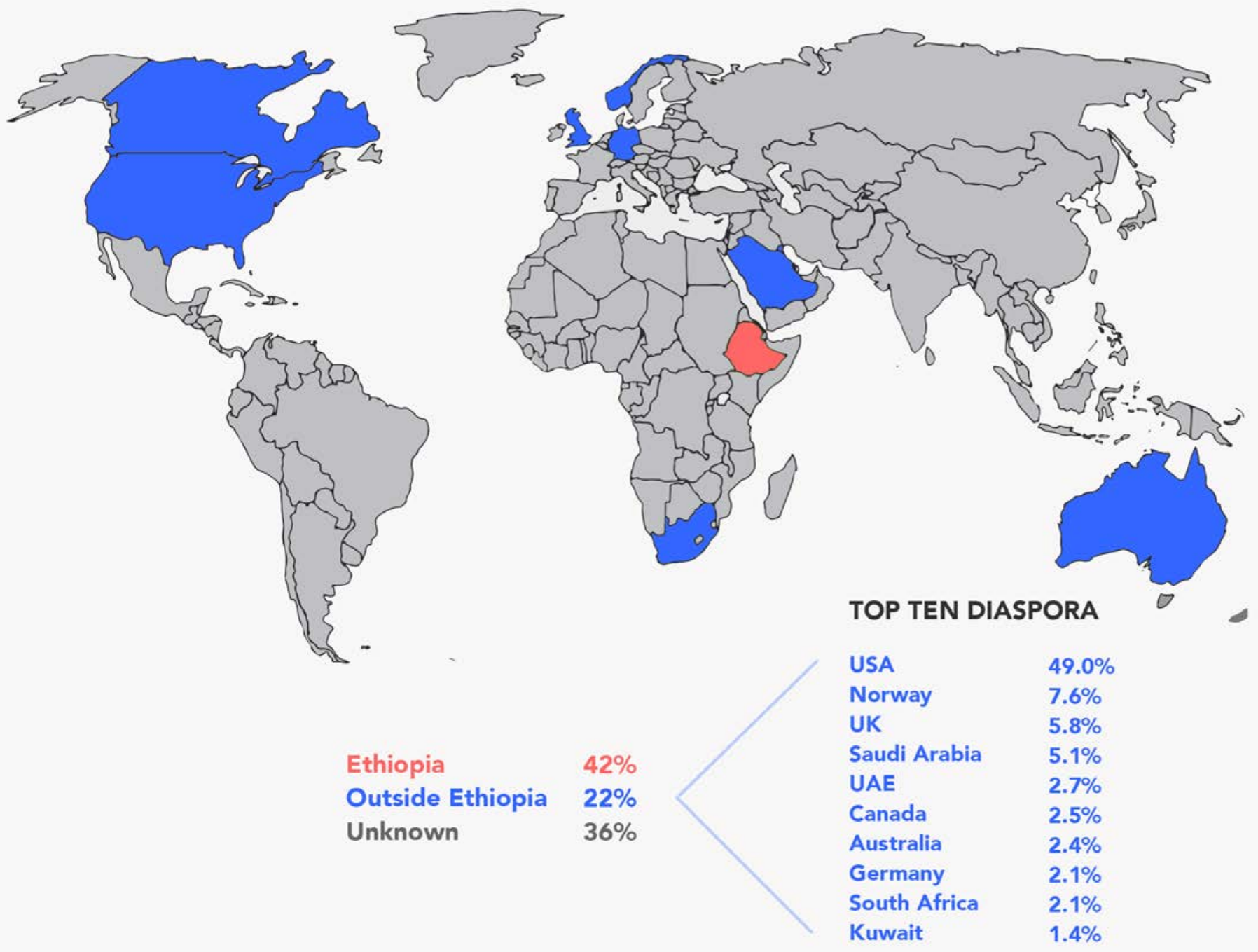


TABLE 1: DISTRIBUTION OF SPEAKERS IN THE DIASPORA BY COUNTRY (TOP 30)

\begin{tabular}{|c|c|c|}
\hline No. & Country & Percent Share \\
\hline 1 & USA & 49.0 \\
\hline 2 & Norway & 7.6 \\
\hline 3 & UK & 5.8 \\
\hline 4 & Saudi Arabia & 5.1 \\
\hline 5 & UAE & 2.7 \\
\hline 6 & Canada & 2.5 \\
\hline 7 & Australia & 2.4 \\
\hline 8 & Germany & 2.1 \\
\hline 9 & South Africa & 2.1 \\
\hline 10 & Kuwait & 1.4 \\
\hline 11 & Denmark & 1.3 \\
\hline 12 & Kenya & 1.3 \\
\hline 13 & The Netherlands & 1.3 \\
\hline 14 & Sudan & 1.3 \\
\hline 15 & Eritrea & 2.1 \\
\hline 16 & Uganda & 1.1 \\
\hline 17 & Brazil & 0.9 \\
\hline 18 & Djibouti & 0.8 \\
\hline 19 & Finland & 0.8 \\
\hline 20 & Argentina & 0.7 \\
\hline 21 & North Korea & 0.7 \\
\hline 22 & Qatar & 0.5 \\
\hline 23 & South Sudan & 0.5 \\
\hline 24 & Turkey & 0.5 \\
\hline 25 & Burkina Faso & 0.4 \\
\hline 26 & Egypt & 0.4 \\
\hline 27 & Israel & 0.4 \\
\hline 28 & Japan & 0.4 \\
\hline 29 & Singapore & 0,4 \\
\hline 30 & Belgium & 0.4 \\
\hline
\end{tabular}


When we further disaggregate findings according to the specific countries from which users post, the results also indicate how despite the Ethiopian diaspora often referred to as a unitary entity - different diasporic communities exist, each characterized by a relatively different composition (e.g. varying gender balance and influence of speakers) and a distinctive approach to going towards or going against.The tables below offer a breakdown in terms of influence, gender, and type of speech for the five countries contributing the most statements, plus South
Africa, which is the most active country in Africa in terms of participation in debates focusing on Ethiopia.

When it comes to users' comparative influence, those from the USA are more likely to have a larger follower base, while speakers based in Saudi-Arabia - another country with a significant community of Facebook users contributing to online debates on Ethiopia tend to have a small or moderate influence (See Figure 6).

\section{FIGURE 6: DISTRIBUTION OF SPEAKERS IN THE DIASPORA BY INFLUENCE}

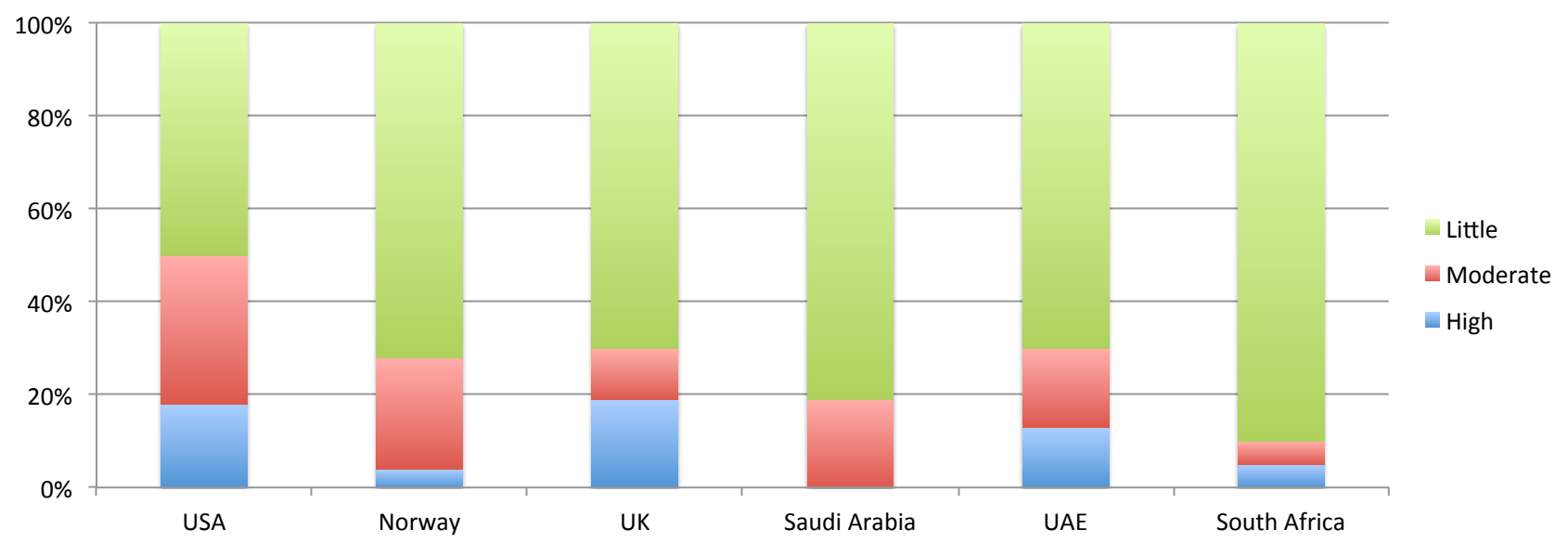

Differences in the gender balance among various diasporic communities are also striking, going from male dominated discussions coming from South Africa, to the significant participation of women in the Gulf.

\section{FIGURE 7: DISTRIBUTION OF SPEAKERS IN THE DIASPORA BY GENDER}

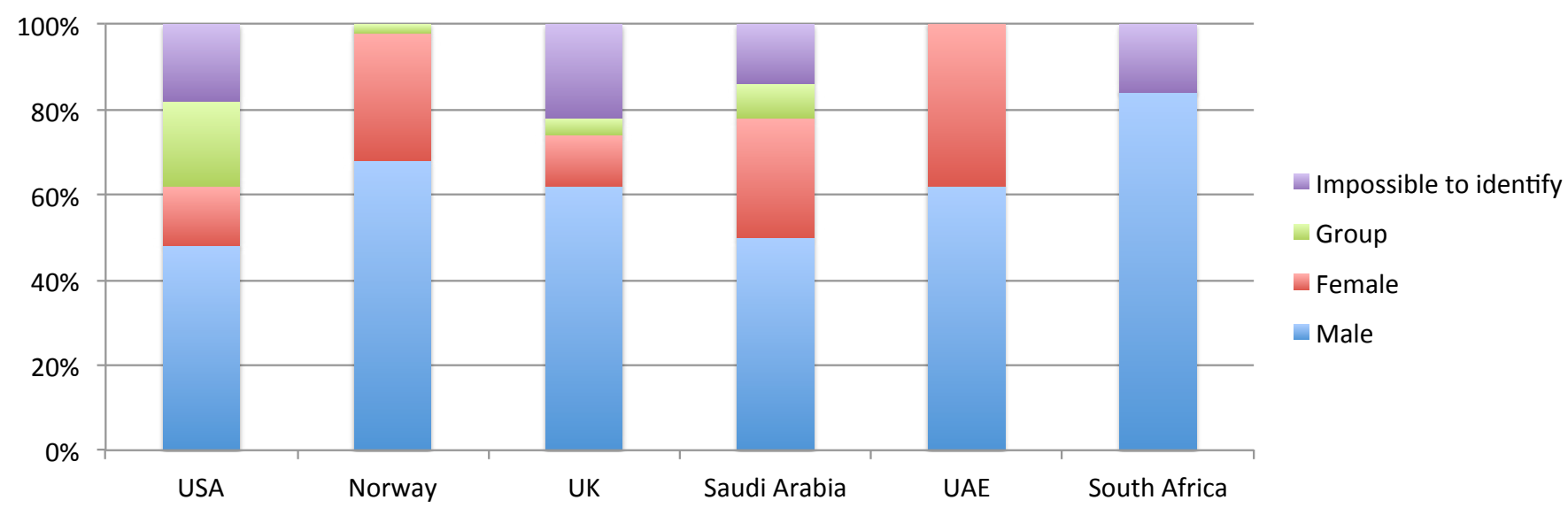


These findings, which reflect other research on the composition and demographics of different Ethiopian diasporic communities, offer a unique insight into how migratory flows are reflected in online conversations (e.g. prevalence of female domestic laborers in the Arab Peninsula vs. males pursuing business and trade in South Africa). ${ }^{12}$

When it comes to the tone of the statements, however, some relatively unexpected results emerged from the analysis of diasporic communities. Among the five countries displaying the highest level of participation in conversations on Facebook, the USA and the UK exhibit patterns that are not too dissimilar from the average - with a slightly greater prevalence of statements going towards. Norway, in contrast, shows a significantly higher share of antagonism, followed by Saudi Arabia.

FIGURE 8: DISTRIBUTION OF SPEAKERS IN THE DIASPORA BY TYPES OF STATEMENT

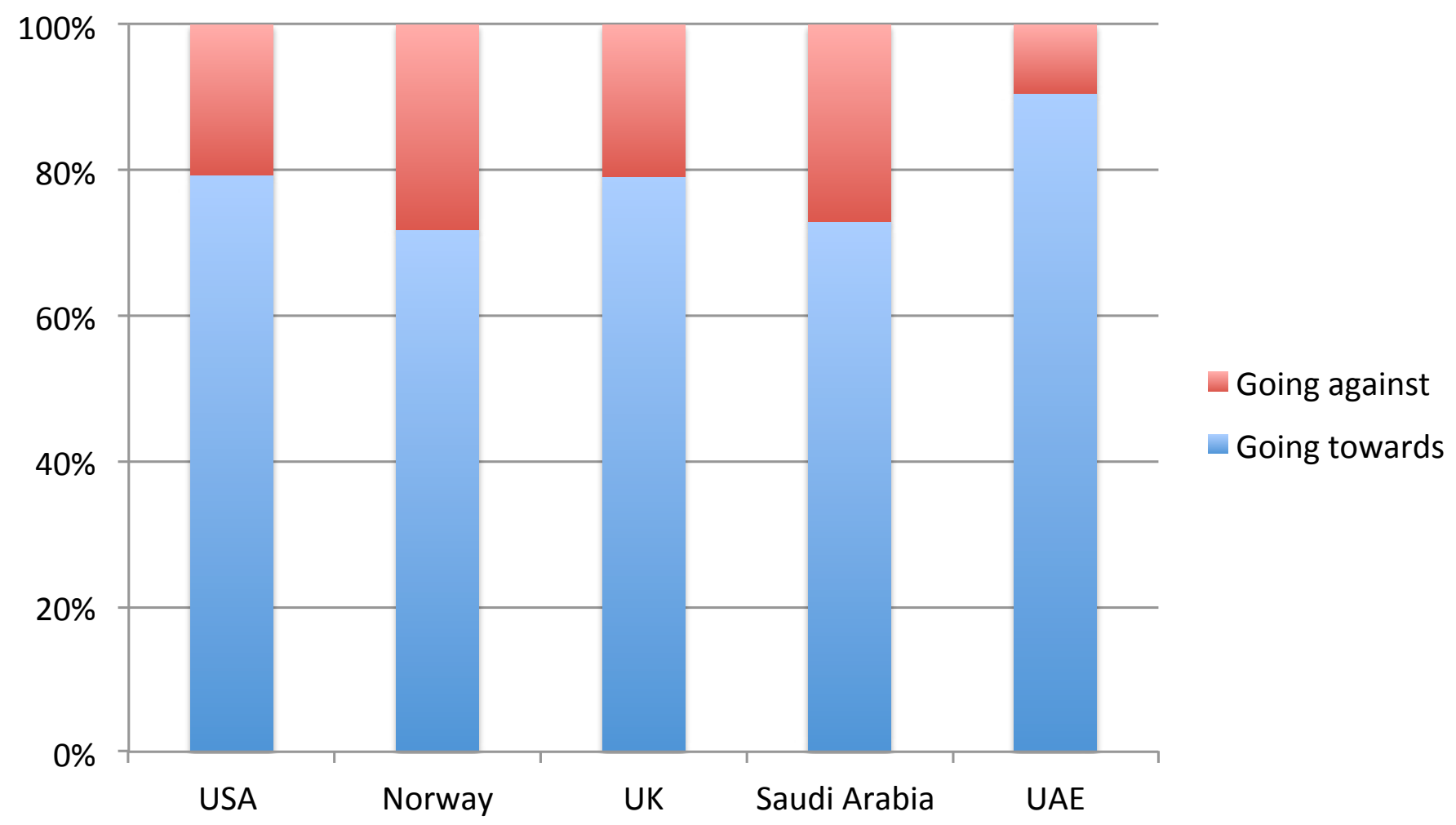

When we aggregate the findings on a continental basis, it is also possible to find some distinctive patterns, with users posting from African diasporic communities being the most antagonistic, and those from North America being the least. 

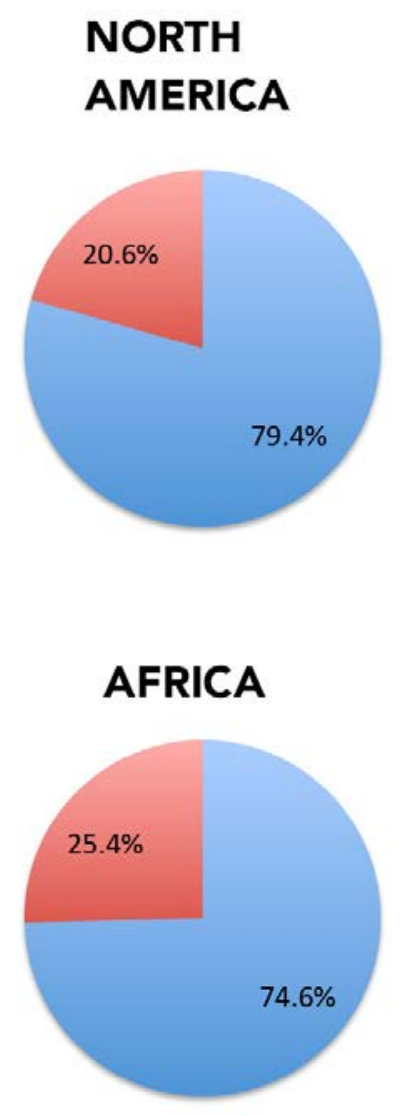

\section{EUROPE}

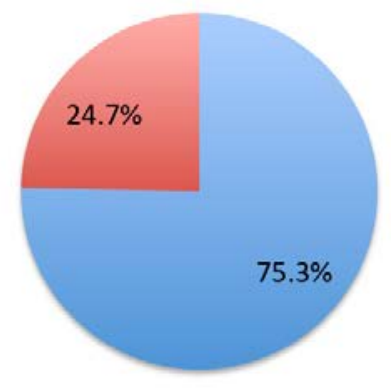

ARABIAN PENINSULA

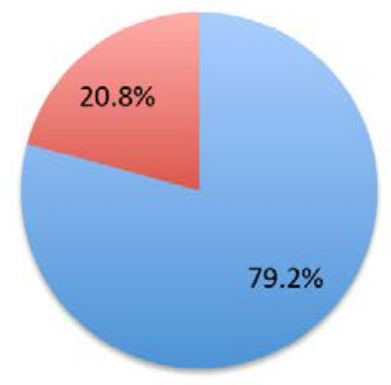

These findings require further investigation, particularly to identify the reasons why users posting from different countries display such a remarkable variety of attitudes online. For example, what is the influence of the more media-rich environment encountered in the USA or in Northern Europe on the forms of online participation? Or, vice-versa, to what extent does the relatively low level of education of migrants seeking employment as domestic labor in the Arab Peninsula prevent them from becoming influential figures in online debates? What the findings do suggest is that the recurrent reference in public debate to the Ethiopian diaspora online as a unitary entity is inaccurate. Variations clearly exist in the motivations leading individuals to choose a specific country; in the experiences they are likely to have in each of them; and in the repercussions of displayed attitudes online. 


\section{INLUENCE AND TYPES OF SPEECH}

If we examine the correlation between different types of statements and the influence of speakers, it is evident that the most influential users are the least likely to make statements going against. (The criteria and thresholds we have used to assess users' influence are listed on the following page). Users with little or no influence are the most inclined to post statements going against (uttering $18 \%$ of them, as compared to only $11 \%$ by users with high influence). When we consider that most people on Facebook have a very small follower base, this tendency also means that the vast majority of statements going against are uttered by people with little or no influence (72\%).

FIGURE 10: DISTRIBUTION OF STATEMENT TYPE BY INFLUENCE

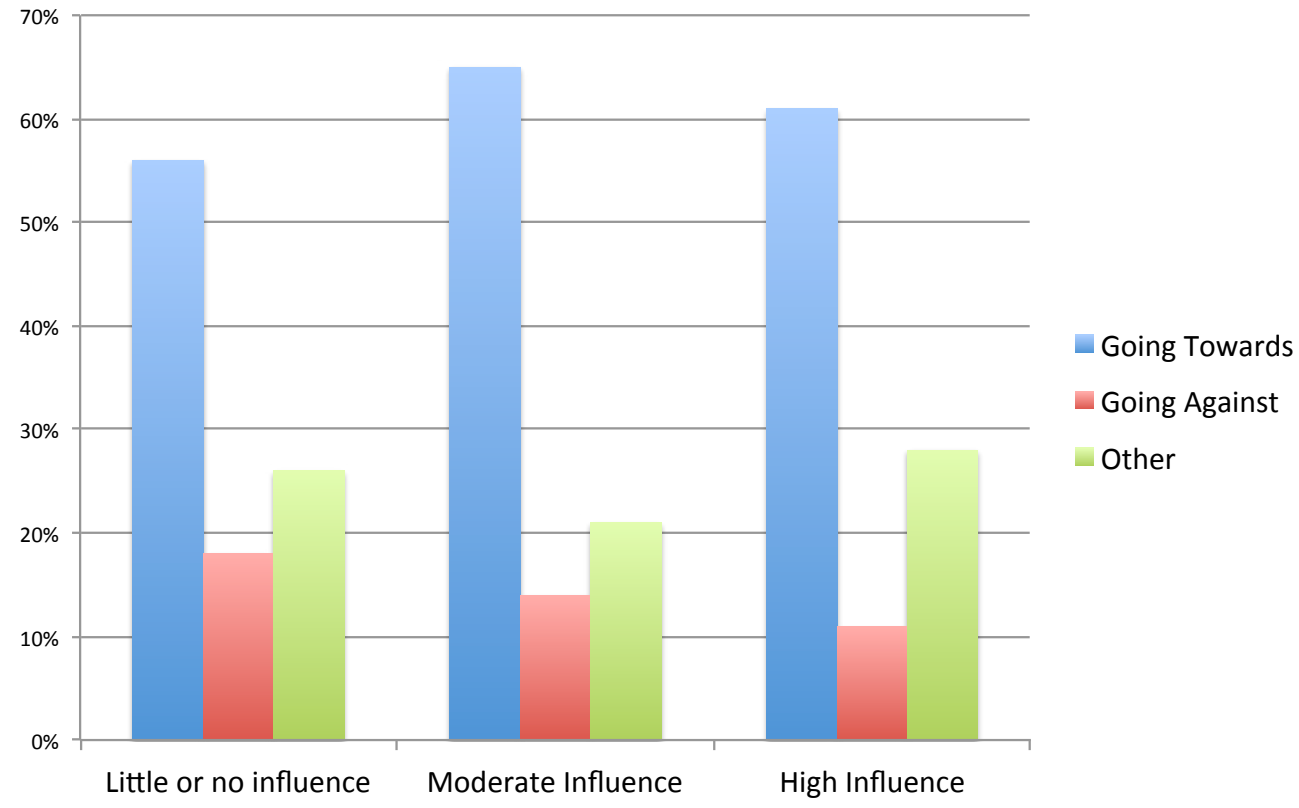

FIGURE 11: DISTRIBUTION OF INFLUENCE BY STATEMENT TYPE

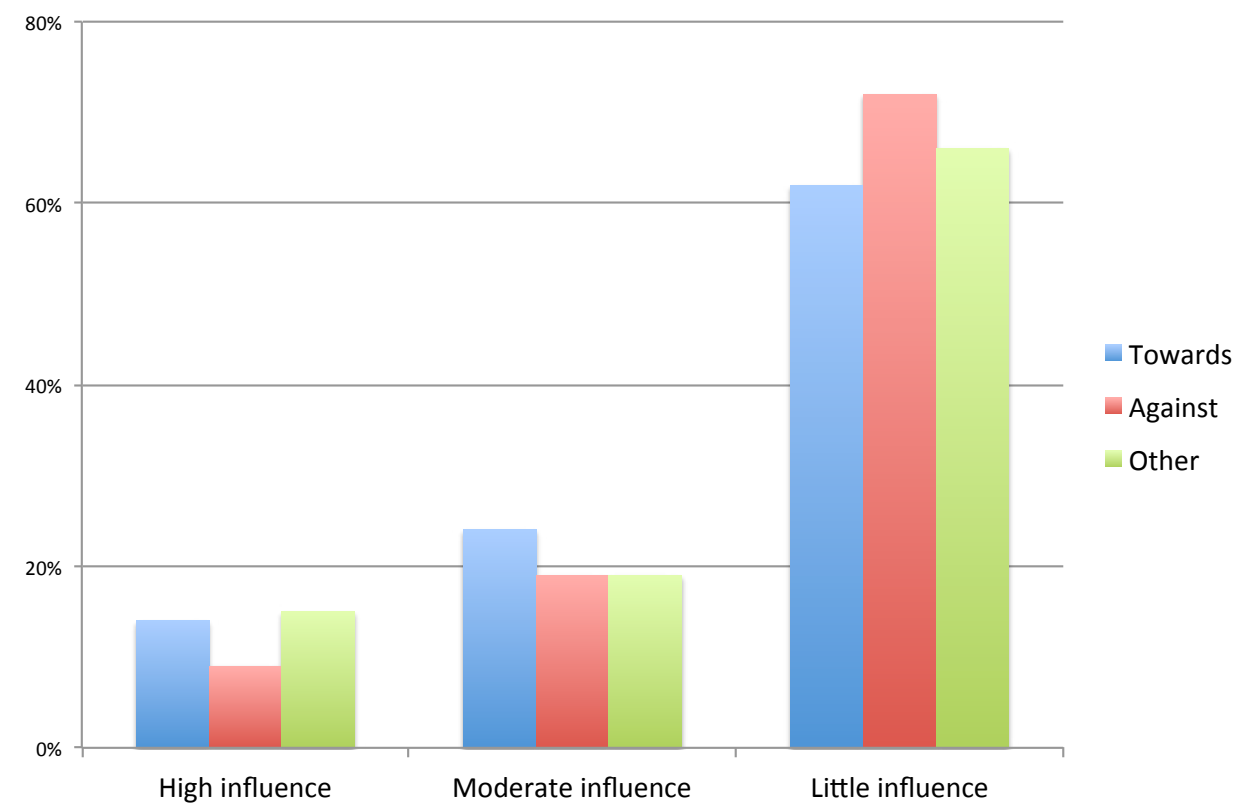


Statements going against are also slightly more likely to appear as comments rather than as posts or status updates. As discussed in Chapter 3, this proportion is even higher in the most popular online spaces.

\section{FIGURE 12: DISTRIBUTION OF INFLUENCE BY STATEMENT TYPE}

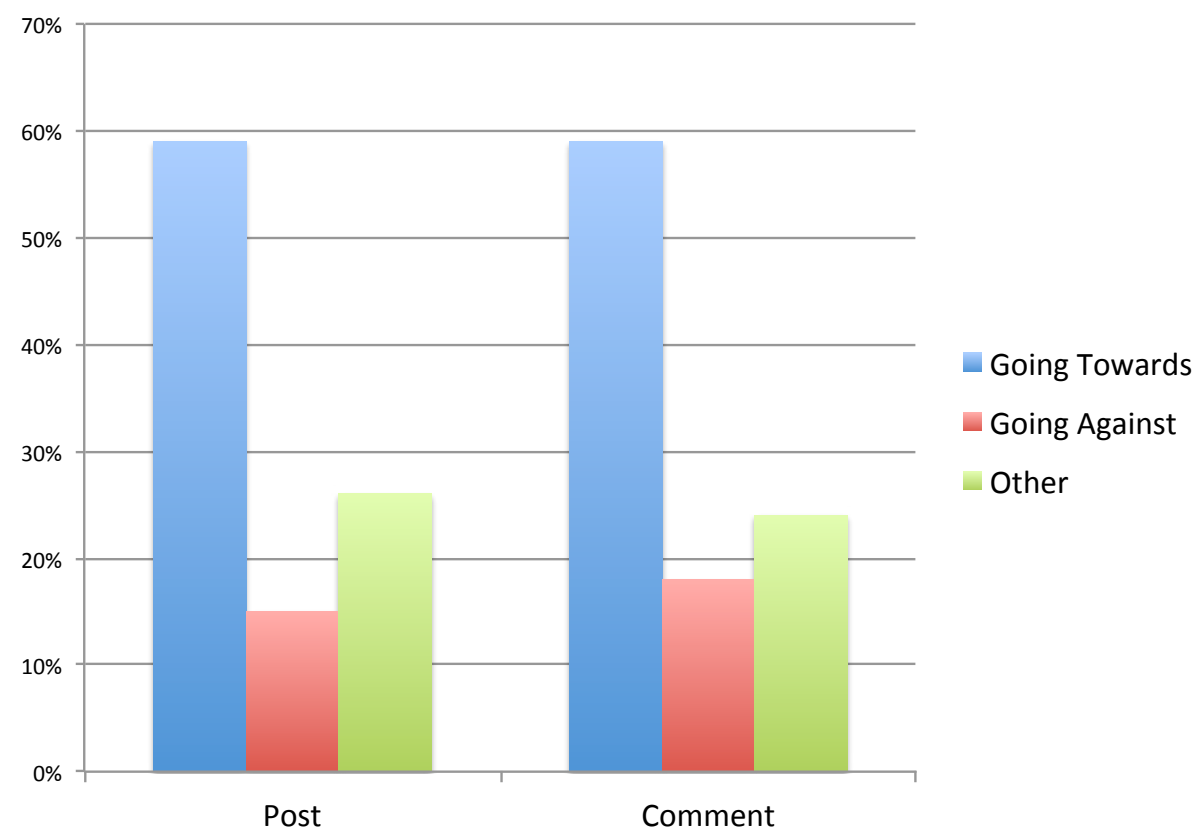

\section{OUR CRITERIA FOR MEASURING INFLUENCE}

- LiTTLE OR NO INFLUENCE: less than 500 followers (for an individual profile) or less than 4,000 likes (for a page); speaker posts only occasionally (around twice per month) or irregularly (periods of activity followed by long periods of inactivity); speaker's posts only occasionally generate significant amounts of comments/shares/likes; speaker's posts receive an average of less than 30 comments/shares/likes all together

- AVERAGE INFLUENCE: between 500 and 5,000 followers (if individual profile), between 4,000 and 20,000 likes (if page); speaker posts rather regularly (there may be periods of inactivity, but short ones) but not too frequently (around once per week); speaker's posts often get a good response but sometimes pass unnoticed; speaker's posts receive an average of between 30 and 100 comments/ shares/likes all together

- HIGH INFLUENCE: more than 5,000 followers (for an individual profile), more than 20,000 likes (for a page); speaker posts regularly (no periods of inactivity) and frequently (at least 2-3 times a week); speaker's posts almost always get a significant response; speaker's posts receive an average of more than 100 comments/shares/likes taken all together. 
Contrary to claims that social media are used by influential figures to stir divisiveness and hatred, our data suggests that when statements are dismissive or derogatory, these come from individuals with a very limited follower base. These reactions may be the result of a feeling of disempowerment or an opportunity to vent. As further illustrated in the next chapter, most of these statements are made towards individuals and institutions in positions of power, rather than towards disenfranchised groups.

\section{EXAMPLE OF A DISEMPOWERED STATEMENT}

\section{$f$}

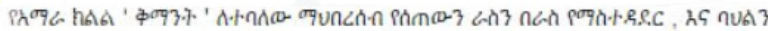

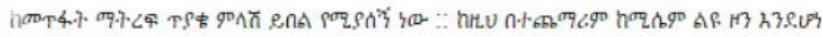
ejog $A$ :

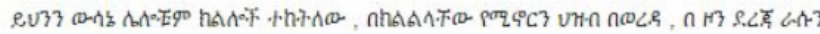

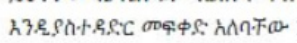

nitne

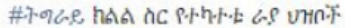

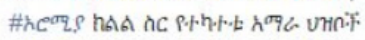

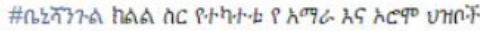

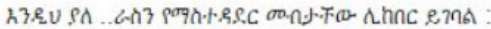

त्व

Down to hegemony of any kind !

Cc : Tigrai Regional State

Oromia Regional State

Benishangul-Gumuz Regional State

See Translation

Itr Like Comment $\Rightarrow$ Share
and 56 others like this.
invaders are not entitled to such rights !!!
Like $-B 2$

\section{TRANSLATION}

The Amhara region's answer to the quest of the Qimant people's self-determination and preservation of culture is commendable. It is to be recalled the Kemisse special zone got the same recognition.

Following this decision, other regions are also expected to recognize the minority people to administer themselves at the Woreda and zone level. Specially:

The Raya people in Tigray region

The Amhara people in Oromia region

The Amhara and Oromo people in Benishangul Gumuz region

Reply: Invaders are not entitled to such rights!!! 


\section{REACTIONS TO STATEMENTS GOING AGAINST AND GOING TOWARDS}

The fact that statements going against are a minority, and are more likely to be uttered by individuals with little influence, does not mean that they lack the power to shape debates. When we analyze the reactions to different types of statements - measured in the number of likes, comments and shares $-a$ complex picture emerges.

In the case of the number of likes, the findings are relatively straightforward and are consistent with the aforementioned findings. Statements going towards receive more likes than statements going against. There is also a close relationship between influence and level of response. The more influential the speaker, the more likes their statement (either towards or against) is likely to receive. This does, however, change when we examine the number of comments and shares different types of statements receive.

In the case of statements going towards, likes and comments follow a similar pattern (the more influential a speaker is, the greater likelihood of their statement receiving comments and shares). In the case of statements going against, however, a different dynamic seems to guide users' responses. When uttered by speakers that are at least moderately influential, it is statements going against that receive the highest number of comments, and this does not change significantly if the popularity of the speaker increases. This seems to indicate that once a certain threshold of visibility is passed, it is the fact that a statement goes against that produces a significant number of comments, rather than the simple influence of the speaker.

\section{EXAMPLE OF A HATE SPEECH WITH MANY COMMENTS}

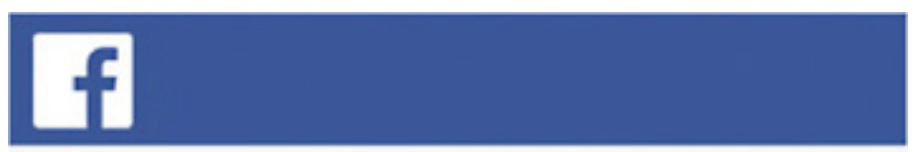

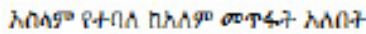

Like -Comment-Share - February 18 near Washington, District of Columbia, DC United States

B 7.976 people like this.

$\Rightarrow 645$ shares

$\square$ View previous comments

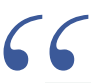

TRANSLATION:

Islam has to be eradicated from the world.

(Note: The 57,310 comments the post has attracted) 


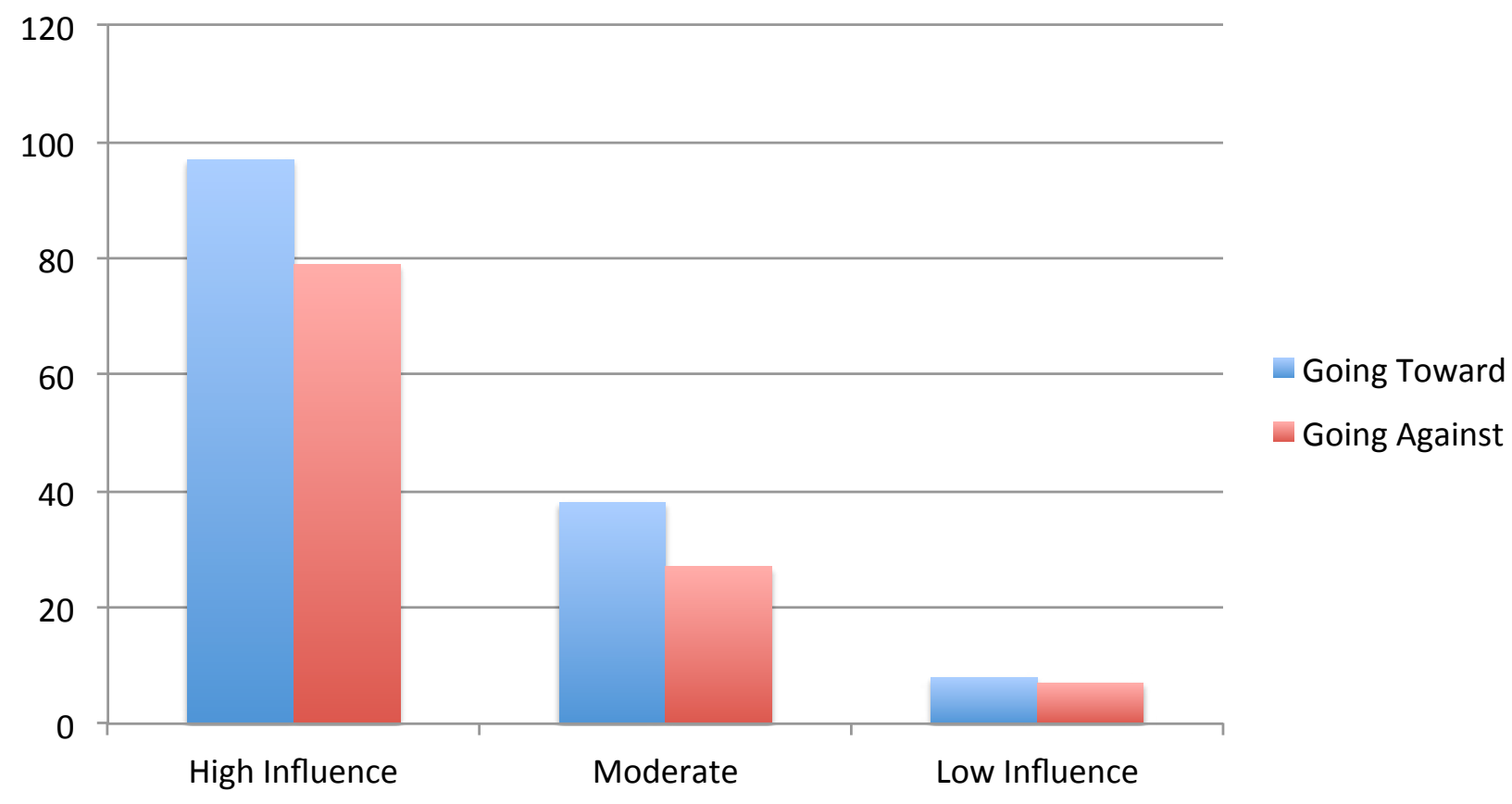

FIGURE 14: NUMBER OF COMMENTS BY INFLUENCE AND TYPE OF STATEMENT (GENERAL SAMPLE)

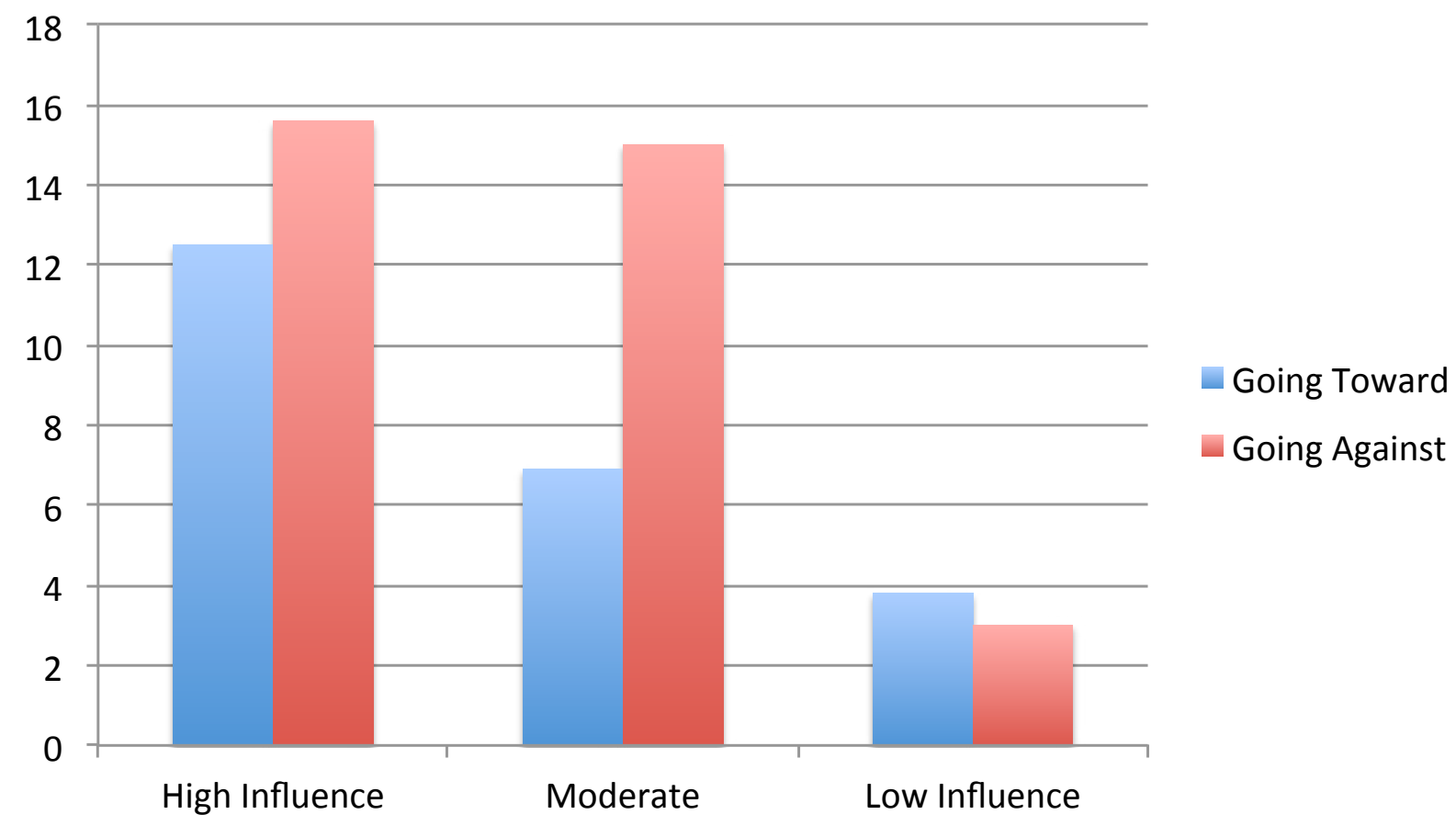


The same pattern is found for shares, which can be considered an even stronger form of support, as a shared post appears also in the profile of the user who shares it. In this case, once a certain threshold of visibility is passed, it seems that it is the content of the statements that matters, rather than the influence of the speakers. Framed in different terms, it can be argued that while statements going against are less frequent, they are likely to travel further.

\section{FIGURE 15: NUMBER OF SHARES BY INFLUENCE AND TYPE OF STATEMENT (GENERAL SAMPLE)}

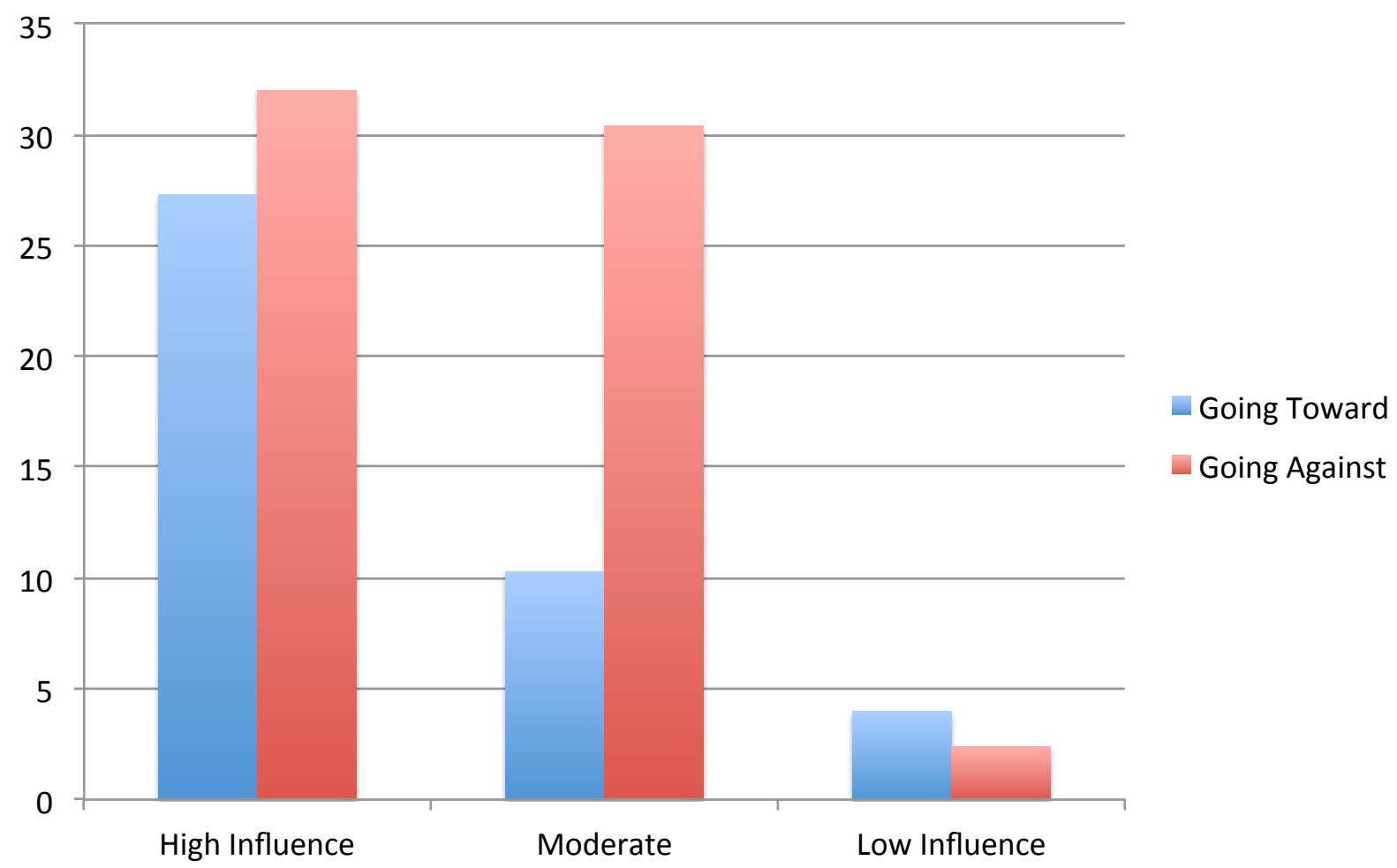

The different dynamics observed in the responses to statements going towards and going against further underlines the analytical potential of this distinction - the fact that it does not only allow mapping statements informed by a different tone, but also uncovers underlying dynamics in the ways people behave when they encounter a specific type of message. This potential becomes even more pronounced in the case of the subcategories of statements going against: offensive, hate, and dangerous speech 


\section{OFFENSIVE SPEECH, HATE SPEECH AND DANGEROUS SPEECH}

As Figure 16 shows, only $1.5 \%$ of the statements in our sample have been classified as offensive, $0.4 \%$ as hate speech, and $0.3 \%$ as dangerous speech. These findings have important implications both for researchers studying online hate speech and policy makers seeking to promote targeted answers to it. To our knowledge this is the first time research focusing on an entire country (and its diasporic community) has been able to quantify the proportion of hate messages among the total of the conversations occurring on a social networking platform.

As highlighted in Chapter 1, the unique conditions encountered in Ethiopia e.g. the distinctiveness of the languages spoken, the limited Internet penetration made this possible. The findings, however, also have significance beyond Ethiopia. Growing concerns about the power of the Internet to incite violence have created new premises that can lead to criminalizing online communication. In the absence of rigorous evidence, messages that are derogatory, hateful, or contain calls to violence, can be (and have been) easily generalized and attributed to the online community as a whole or employed to justify repressive measures. The findings we offer here can help place messages in their proper context.

Despite the significance of the findings, an important clarification is required. When we developed a framework to identify statements that are offensive, hateful or dangerous, political speech was excluded, in resonance with international standards (e.g. ICCPR) and academic literature on hate speech. ${ }^{13}$ On the contrary, as discussed during our workshops, and highlighted by other projects that have analyzed online hate speech in divided societies (UMATI), the common perception of hate speech tends to include attacks on people based on their political affiliation. In our case statements that can be considered derogatory or hateful on purely political grounds have not been included.

\section{FIGURE 16: PROPORTION OF STATEMENTS THAT ARE OFFENSIVE, HATE SPEECH OR DANGEROUS SPEECH}

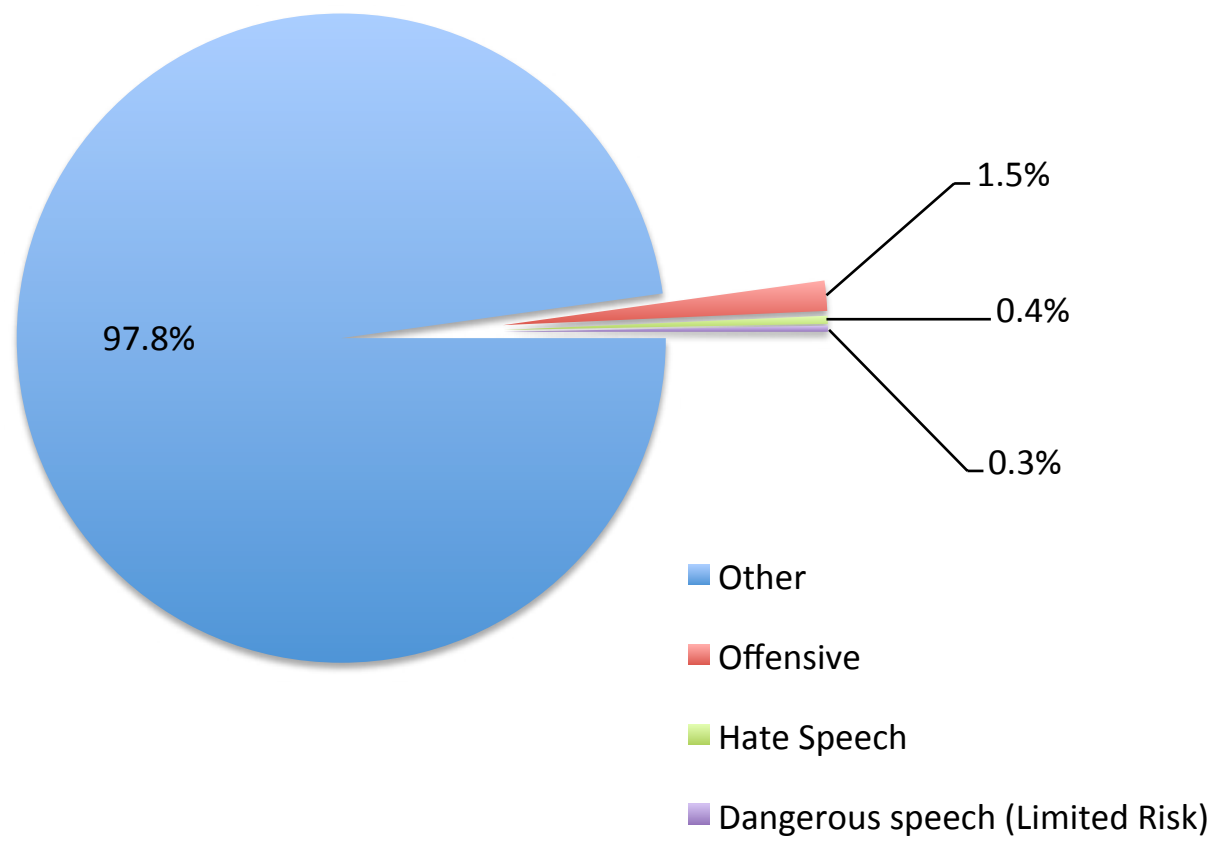




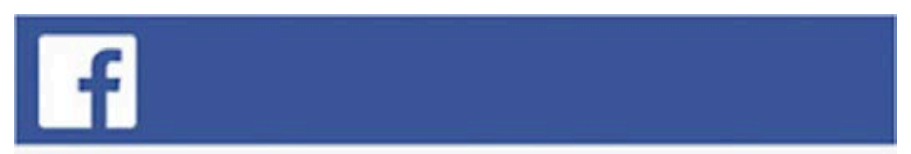

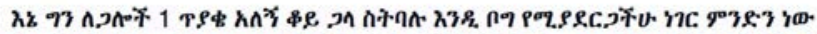

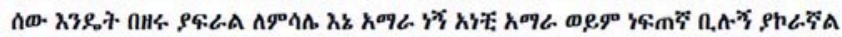

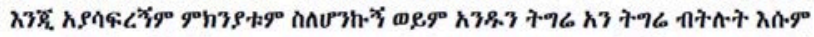

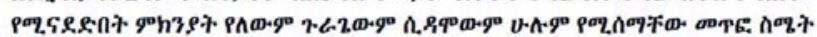

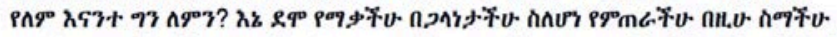

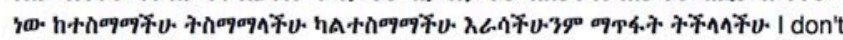
care about gala !!!

See Translation

$$
\text { In Like } \Rightarrow \text { Share }
$$

18 people like this.

\section{EXAMPLE OF HATE SPEECH}

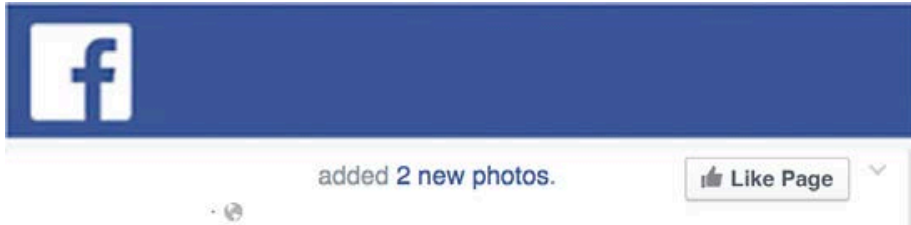

It is safe to say,at least in these videos on facebook, the people we have to watch out for is Radical Oromo Muslim extremists. It has been known that the Tigray government arms, trains, and brainwashes them to target Amharas.

I recollect an interview the dead Tigray parasitic leader Melese gave when being asked about Christian Amharas being targeted. His answer was along the lines of, it happens and we cannot do anything about it. But that bastard went into Somalia to stop the ICU, Al-Shabab and what not.

To Amharas, if you think these Muslim Oromo radicals are your number one enemy then you are confused. These are only brainwashed zombies that have been automatically brainwashed and linked in targeting Amharas. They are only a part of the end game prepared for the final extermination of Amharas.

The Tigrays, and when I mean Tigrays both Hamasien and Tigrays in the North, are the architect of such anti-AMhara design, and for that all you have to do is read the manifesto below.

\section{TRANSLATION:}

I don't care about galla !!!"

"I have 1 question for gallas. What is the reason you are angry when you are called galla? How come a man is ashamed of his race? For example, I am an Amhara. If somebody had called me "You Amhara or Neftegna", I would have been proud rather than being ashamed". There is no reason for a Tigre to be mad if he is called Tigre either. The same goes for Guraghes, Sidamas and others, no one feels bad except you. Why? Since I know you as a galla I will continue to call you so. If you are comfortable with this name welcome, otherwise you can kill yourself. I don't care about gala!!!

\section{EXAMPLE OF DANGEROUS SPEECH}

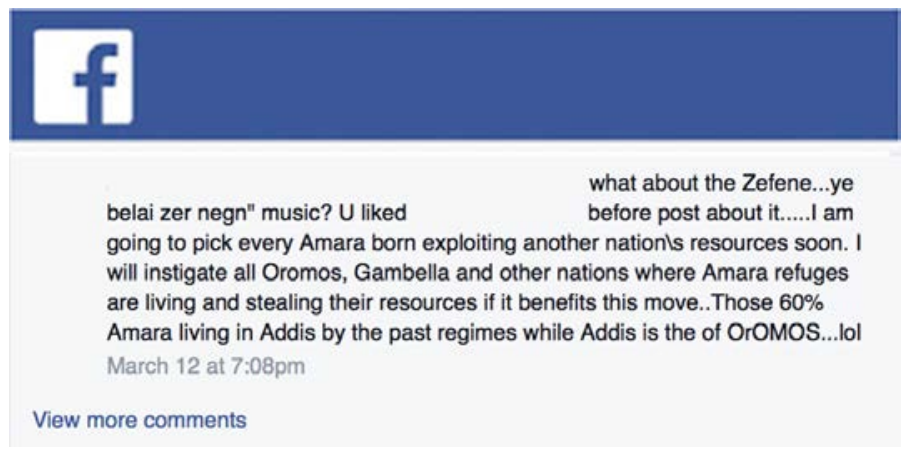


A further analysis of 'offensive', 'hate' and 'dangerous' statements offers insights into what distinguishes different types of speech.

While some elements that characterize statements going against can also be found in these subsets of statements - for example, as Figure 17 illustrates, statements that are offensive are the least likely to be posted by people in the diaspora - others seem to be distinctive to these more hostile types of messages. This is particularly the case for dangerous statements.

\section{FIGURE 17: TYPE OF SPEECH BY LOCATION OF SPEAKERS}

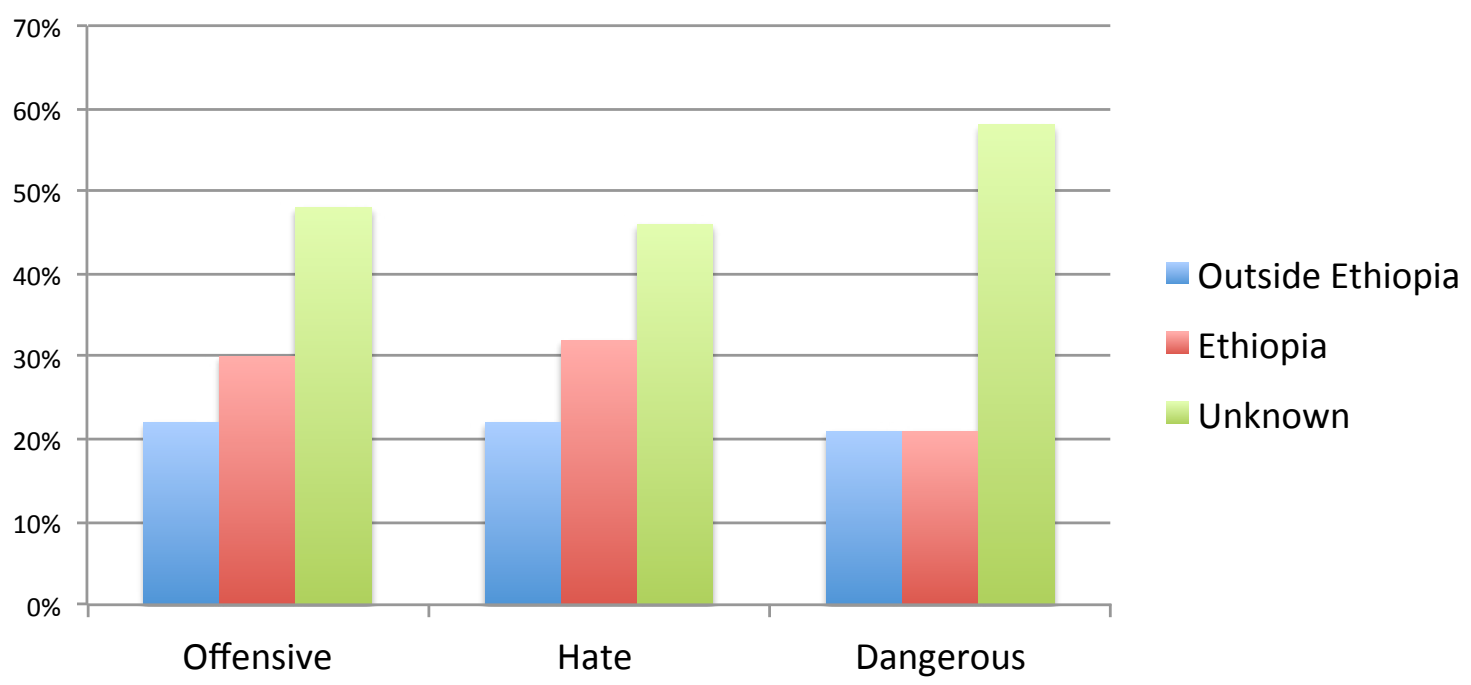

Users posting dangerous statements appear to adopt a more deliberate strategy, rather than simply reacting angrily to what they read online - the large majority of dangerous statements are uttered by users trying to hide their real identity. This emerges in sharp contrast with the other two categories of statements (and our larger sample), where individuals using their own names predominate.

\section{FIGURE 18: TYPE OF SPEECH BY SPEAKER}

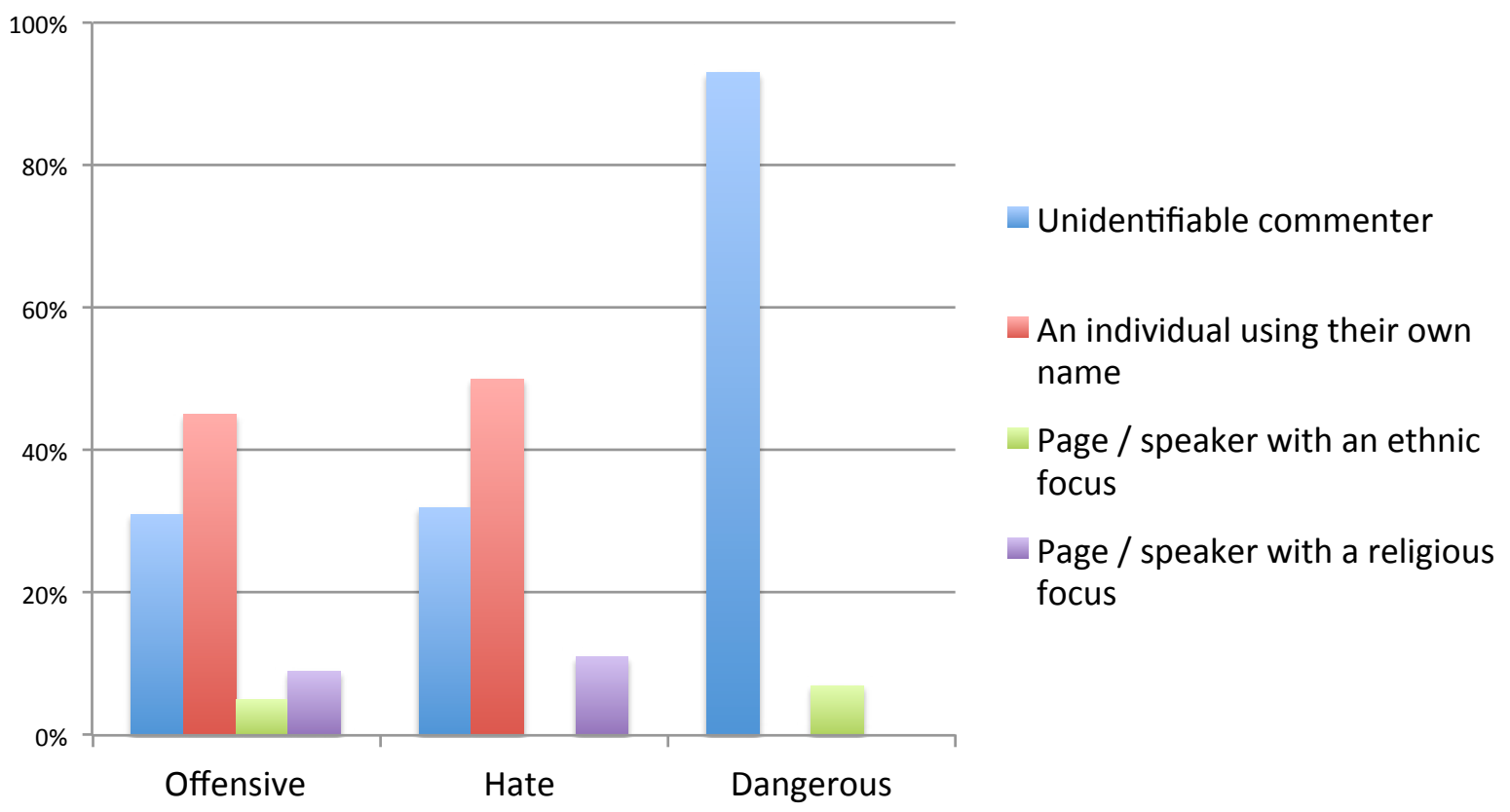


This tendency is further corroborated by Figures 19 and 20. The first offers a breakdown by gender of speaker: the category "impossible to identify" progressively grows as we move from offensive to hate to dangerous speech.

FIGURE 19: GENDER OF SPEAKERS

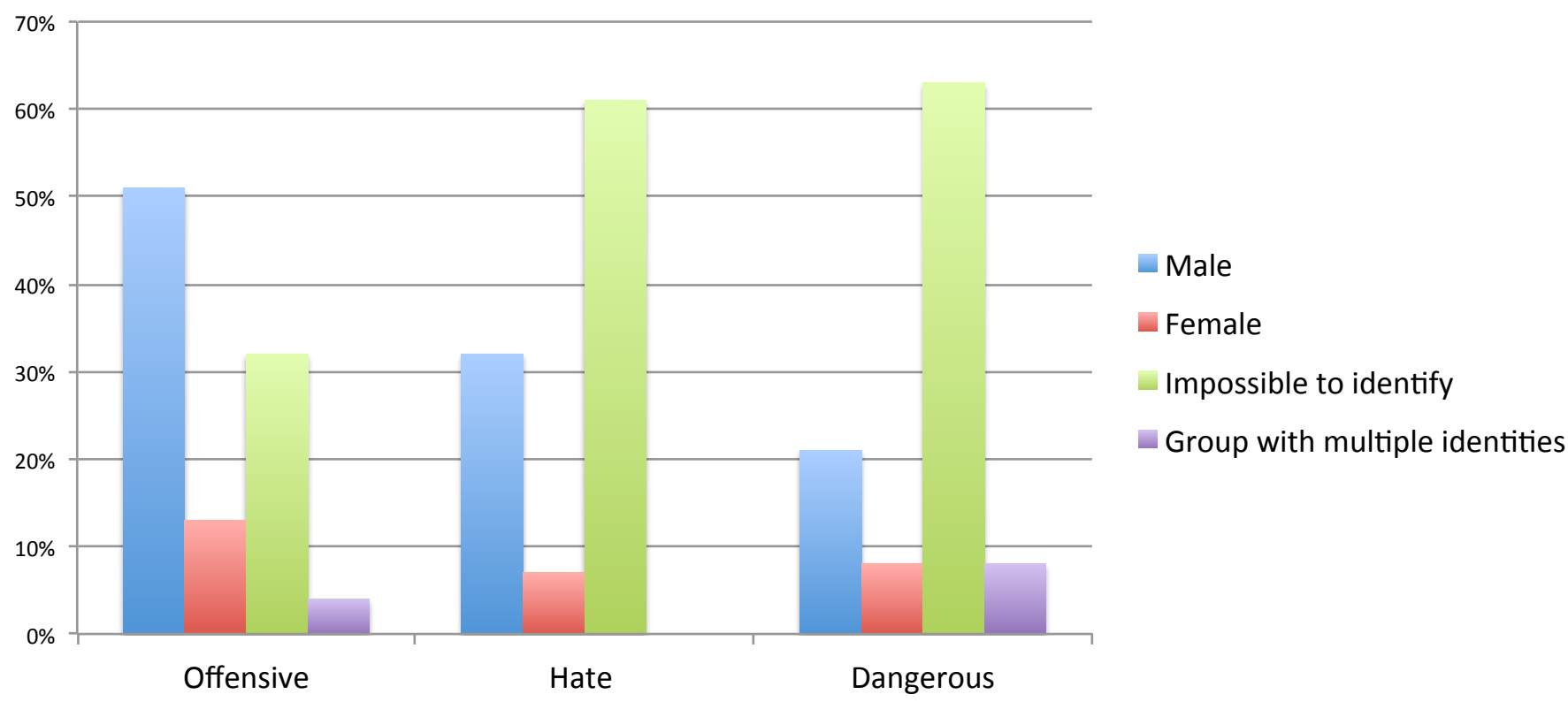

Figure 20 suggests that, as opposed to offensive and hateful statements, which are slightly more likely to appear in comments, dangerous statements are equally likely to appear in comments or posts.

FIGURE 20: RELATIVE SHARE OF POSTS AND COMMENTS IN OFFENSIVE, HATE AND DANGEROUS SPEECH CATEGORIES

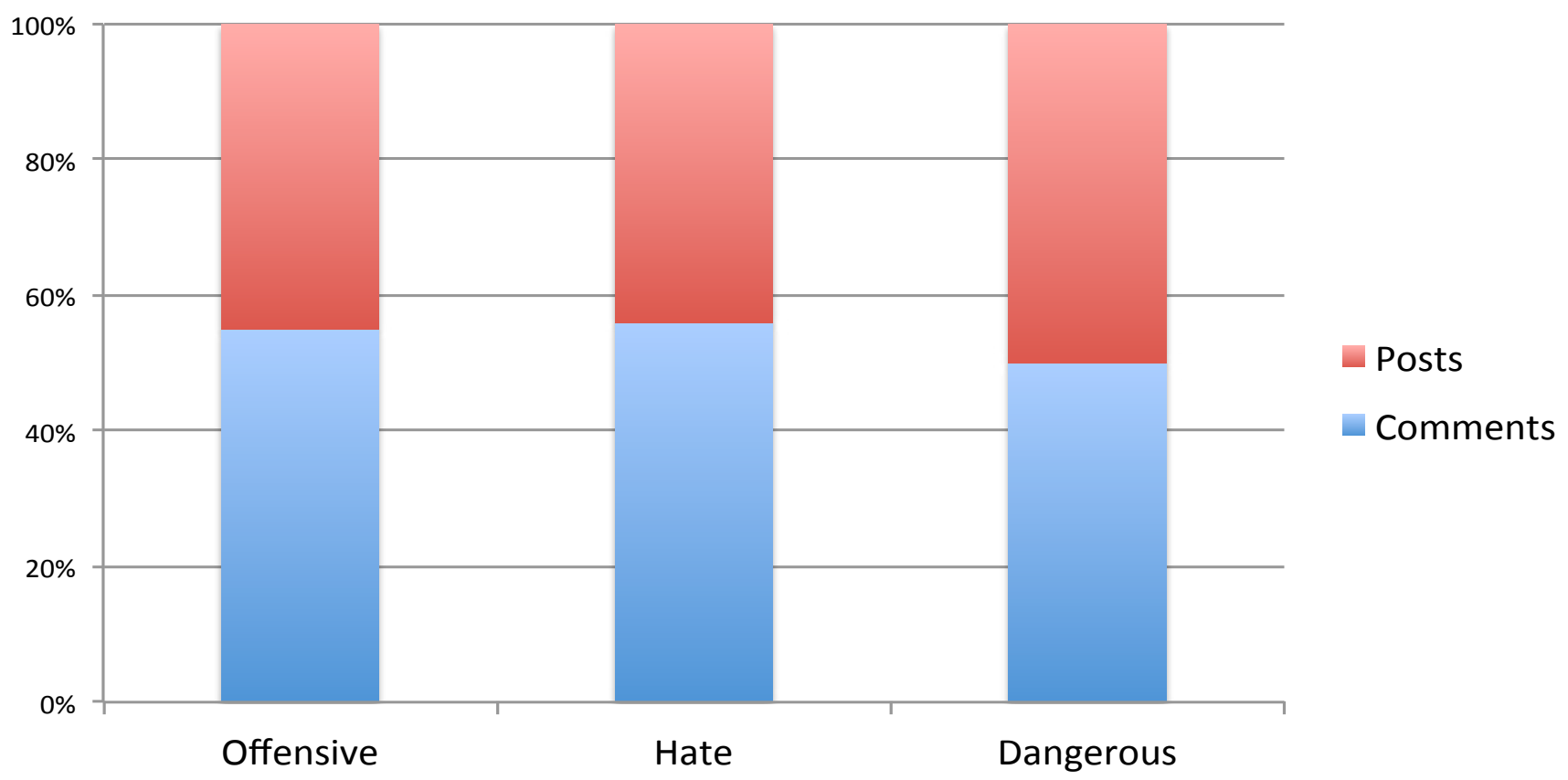


It is important to stress that dangerous statements in the general sample are very limited in number, and more research is needed to corroborate our findings; but it is worth highlighting how these types of statements seem to display characteristics that set them apart from other types of speech acts. They appear as more deliberate attempts to attack a specific group, even when compared with statements that can be categorized as offensive or as hate speech.

Shifting the focus from speakers to targets, ethnicity largely emerged as the most common topic for uttering offensive, hateful, or dangerous statements. 58\% of offensive, and nearly $75 \%$ of hate speech was directed at ethnic groups. The salience of ethnicity becomes even clearer when we consider the dangerous statement category where all the statements were uttered on the basis of ethnicity.

Religion did not feature among the dangerous statements, though it was significantly visible among offensive speech. Forty percent of all offensive statements targeted groups because of their religious affiliations, with Protestant Christians being most targeted. This is different from the pattern for hate speech in which the three major religions were evenly targeted, or from the pattern for dangerous speech where religion was conspicuously absent.

FIGURE 21: TYPE OF SPEECH BY TARGETS OF SPEECH

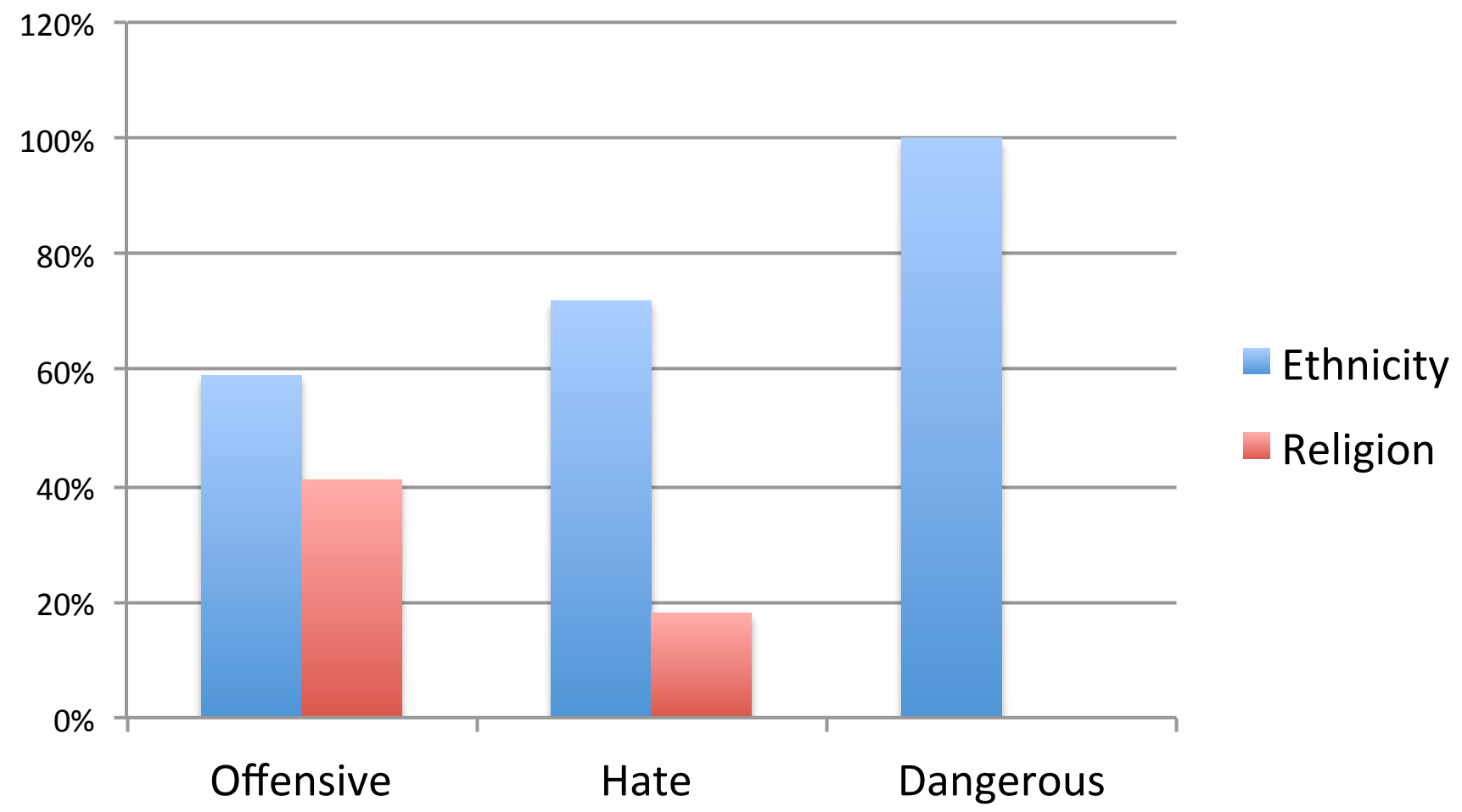




\section{SPACES FOR ENGAGEMENT}

Over the past twenty years, a high level of polarization has characterized Ethiopia's media. First the press, and then online media, have articulated competing, often irreconcilable ideas of the Ethiopian nationstate. Conversations on social networking platforms have inherited some of the tone that characterized previous debates; but, as our research shows, the strongest forms of antagonism have remained relatively marginal. Earlier in this chapter we attempted to explain why this might be the case, reflecting on our own framework; on the prevalence of a new generation of users that has been able to experiment with new languages; and on the distorted perception of online debates that has prevailed in the absence of empirical evidence. In this final section, drawing on our data, we identify where the greatest opportunities for engagement appear to be, in comparison with the topics that trigger the most heated debates.

If we divide the statements we sampled on Facebook into broad categories, such as politics, religion, and ethnicity, some relatively distinct patterns emerge. Discussions on religion, for example, are those displaying the lowest percentage of statements going against, with only $10.5 \%$ falling into this category. This finding is particularly relevant in the context of perceived growing divides among the major faiths in Ethiopia, and of a politicization of religious debates. Statements going against that explicitly call upon ethnicity and refer to specific ethnic groups are also relatively marginal (only $14.2 \%)$. Less surprisingly, politics is the area that emerged as the most contentious, but still in a proportion only slightly higher than the average conversations on Facebook (21.8\% of statements with a political focus are antagonistic, as compared to the average of $21.4 \%)$.

Discussions within each of these categories, however, exhibit a significant level of variation, and additional lessons can be learned by further analyzing issues or events that have catalyzed people's attention in the period covered by the research.
One example is the detention and trial of six members of the Zone 9 collective, together with three journalists. Originally arrested on 24 April 2014 and charged with accusations ranging from working with foreign organizations and using basic online encryption tools, to terrorism, the bloggers were eventually released after more than a year in prison. ${ }^{14}$ Despite the case attracting criticism around the status of freedom of expression in Ethiopia, both at national and international level, almost all the selected statements about the Zone 9 bloggers were going towards (48 out of the 60 randomly selected statements focusing on the case, or $96.7 \%)$.

The example below is indicative of the types of messages that were most prevalent across Facebook.

\section{EXAMPLE OF TYPICAL STATEMENT ABOUT THE ZONE 9 BLOGGERS}

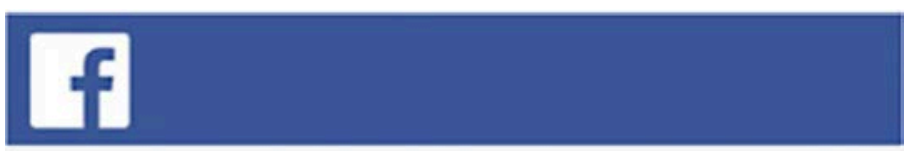

"April 25th, 9 weeks from now, marks exactly one year since Zone 9 Bloggers and Journalists got imprisoned. We are obligated to remember that saddened day by celebrating their courage, resilience and commitment they had and still have even in this tough times. Hence it is with a heavy heart but yet with great pleasure that we introduce the launching of the "The 9 Week Campaign". This campaign will run for the next 9 weeks dedicating each week for one of the bloggers or journalists. We are going to celebrate Zone 9 bloggers and journalists by: 1. Changing our profile pictures with the individual being celebrated in that week. 2. Share their articles, photos and other works of theirs. 3. Write our heartfelt appreciations. 4. Tweet using the hashtag \#FreeZone9bloggers and name initials hashtag of the person being celebrated in that week. 5. And on April 25 th we will remember the day. This campaign is the longest we will have in Social Media is not meant to disrupt everyones usual activity so we would like everyone to feel at ease and take part in their best convenience. Additional campaign materials will be made available every Sunday. Below is the timetable showing the week dedicated to each of them and the name initials hashtag to be used. Come lets show our appreciation!!!" 
The case of the Zone9 bloggers was instructive not just for the tone of discussion, but also for the type of individuals that engaged with the issue, many of whom were activists or journalists, or were individuals that did not hide behind anonymity. Perhaps the most interesting finding relating to individuals expressing opinions on the Zone9 bloggers is how this case was able to attract the attention of different types of speakers, almost irrespective of their degree of influence.

\section{EXAMPLE OF TYPES OF DISCUSSION ABOUT THE ARREST OF ZONE 9 BLOGGERS}

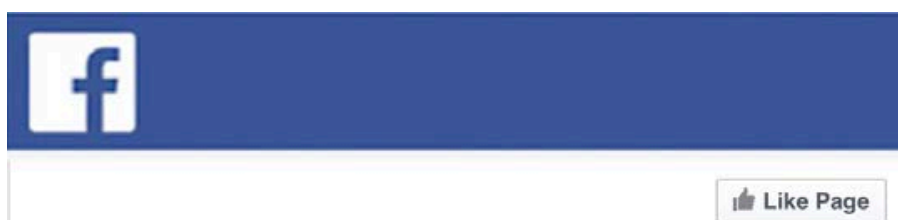

\#FreeZone9FridayMessage--Day 273!!

\#9MONTHS

Writing a status update on Facebook Criticizing a government is Terrorism Publicly expressing care and concern about the sociopolitical issues of Ethiopia is conspiring outrage against the government. Organizing online campaigns, writing articles, sharing thoughts and opinions and using Hashtag on social media platforms are inciting violence and terrorizing the public. And yet, the ever mystic irony is the same government that uses Zone9bloggers to silence dissent and pave the road to Election2015, pledges to commit itself for a free and fair election that will ensure the transfer of power by ballots. (:)

\#FreeZone9Bloggers

\#FreeDissidentJournalists

\#FreeAllPoliticalPrisoners

\#FreeAllPrisonersOfConscience

\#BlogginglsNotACrime

\#JournalismlsNotTerrorism

\#Ethiopia

Like Comment $\Rightarrow$ Share

Almost at the opposite extreme, in terms of the level of political antagonism that they triggered, were debates bringing back tensions between the current government and long-standing political opponents. The case of Berhanu Nega, for example, attracted much attention and encouraged a heated debate on Facebook. Berhanu Nega's involvement in politics dates back to the 1970s, but it was in 2005 that he rose to prominence. As one of the leaders of the largest opposition party, he won the election for the Mayor of Addis Ababa, and was later arrested in the aftermath of the violence that followed the elections. After his release, he returned to the USA where he founded Ginbot 7, a party that embraced different forms of contestation, including the armed struggle, as a means to promote political change in Ethiopia. ${ }^{15}$ In July 2015, he resigned from his university post in the USA to join other fighters in Eritrea. ${ }^{16}$ This decision was particularly divisive among Ethiopians. More than $40 \%$ of statements referring to the issue were categorized as going against. As an indication of how polarizing this issue was, and how it did not simply lead to focusing on a particular target, antagonistic statements were equally distributed between those attacking the government and those attacking Ginbot 7. 


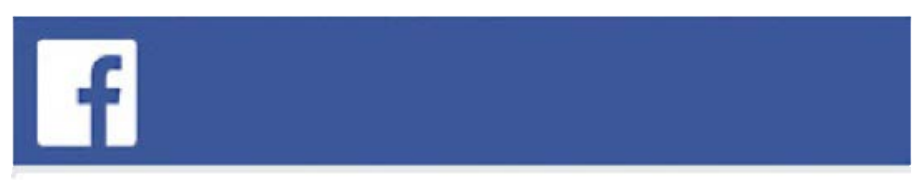

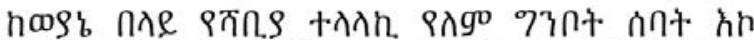

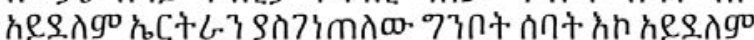

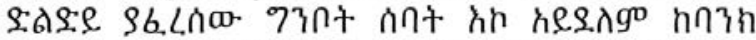

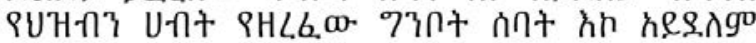

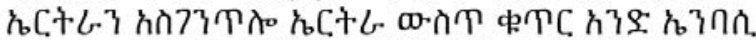

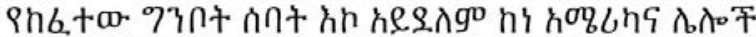
U7C

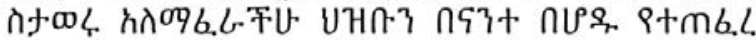

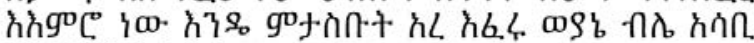
$\left\{\wedge g^{0} h\right\} S_{0} S_{0} S_{0} S_{0}$ ??????"

These two cases suggest how a younger generation of Ethiopians may be more inclined to adopt less contentious tones and embrace more universalistic forms of politics, while older figures and grievances tend to trigger more polarized debates. However, suggesting a clear-cut distinction between old and new media, and progressive and conservative politics, would be simplistic and ultimately obfuscate the complexities of political life in Ethiopia. There are issues, such as the proposed "Addis Ababa and its surrounding Oromia Special Zone integrated plan", which cut across entrenched grievances and new debates, and triggered extremely contentious

\section{6}

\section{TRANSLATION}

There is no better puppet for Shabya than Woyane. It is not Ginbot 7 that led to the separation of Eritrea. It is not Ginbot 7 that demolished bridges. It is not Ginbot 7 who robbed people's money from the bank. How come there is no shame when you were the first to open an embassy and recognize Eritrea ahead of US and other countries after letting it secede. Do you presume the people think with their stomach like you do? There is no such thing called Woyane and thinker. Hmmm ... have little shame.

debates online, with corresponding cases of violence on the ground. ${ }^{17}$

What these cases, and the findings emerging from the investigation of online debates on Ethiopia in general, suggest, is how important it is to distinguish between different actors and issues that are often bundled together in the broad label of 'opposition politics'. Social media in Ethiopia are emerging as a terrain where different forms of tolerance and acceptance are being displayed and new forms of engagement can be experimented with. 


\section{POWER, ANTAGONISM AND INFLUENCE ON FACEBOOK}


TABLE 2: POPULAR SPACES ANALYSED BY THE RESEARCH

\begin{tabular}{|l|l|l|l|l|l|l|}
\hline Name & Location & Created & $\begin{array}{l}\text { Linked to other online } \\
\text { space }\end{array}$ & $\begin{array}{l}\text { Avg. like } \\
\text { per post }\end{array}$ & $\begin{array}{l}\text { Avg. } \\
\text { comment } \\
\text { per post }\end{array}$ & $\begin{array}{l}\text { Avg. } \\
\text { share per } \\
\text { post }\end{array}$ \\
\hline $\begin{array}{l}\text { Dr. Tedros } \\
\text { Adhanom } \\
\text { Ghebreyesus }\end{array}$ & Ethiopia & $\begin{array}{l}24 \text { Nov } \\
2013\end{array}$ & $\begin{array}{l}\text { The Ministry of } \\
\text { Foreign Affairs of } \\
\text { Ethiopia }\end{array}$ & 1772 & 211 & 145 \\
\hline $\begin{array}{l}\text { Daniel } \\
\text { Berhane }\end{array}$ & Ethiopia & $\begin{array}{l}16 \text { Nov } \\
2009\end{array}$ & hornaffairs.com & 89 & 33 & 2 \\
\hline $\begin{array}{l}\text { Dimtsachin } \\
\text { Yisema }\end{array}$ & $\begin{array}{l}\text { Impossible } \\
\text { to identify }\end{array}$ & $\begin{array}{l}3 \text { Feb } \\
2012\end{array}$ & $\begin{array}{l}\text { dimtsachinyisema. } \\
\text { wordpress.com }\end{array}$ & 112 & 15 & 66 \\
\hline $\begin{array}{l}\text { Semayawi } \\
\text { Party }\end{array}$ & Ethiopia & $\begin{array}{l}15 \text { Feb } \\
2012\end{array}$ & semayawiparty.org & 91 & 25 & 33 \\
\hline $\begin{array}{l}\text { Jawar } \\
\text { Mohammed }\end{array}$ & USA & $\begin{array}{l}1 \text { Dec } \\
2008\end{array}$ & oromiamedia.org & 265 & 37 & 21 \\
\hline DireTube & Ethiopia & $\begin{array}{l}28 \text { Oct } \\
2008\end{array}$ & diretube.com & 253 & 64 & 38 \\
\hline
\end{tabular}




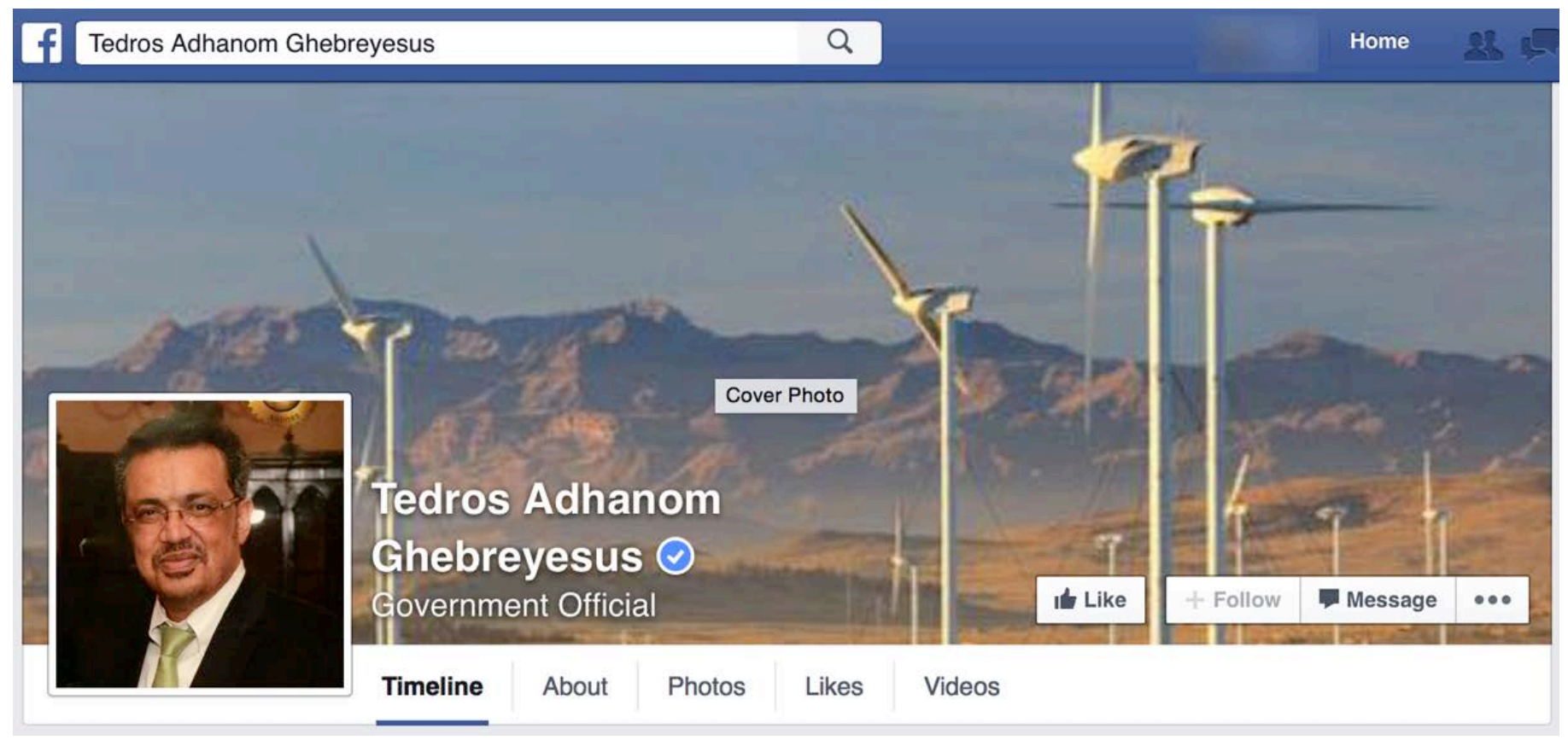

\section{DR. TEDROS ADHANOM GHEBREYESUS}

Dr. Tedros Adhanom Ghebreyesus has been the Minister of Foreign Affairs since November 2012. He has developed the most active social media presence among all government officials and his posts/status updates usually cover different aspects of government policy and contemporary events. On his page Dr.
Tedros usually shares photos of Ethiopia's infrastructure projects and development successes. He also reports on his meetings with the foreign ministers of other countries and posts interview video links. These statements often encourage conversation about government policies and events, which can be seen by the 217 comments and 123 shares that each of his statements receives on average.

FIGURE 22. TYPES OF STATEMENTS (DR. TEDROS ADHANOM GEBREYESUS)

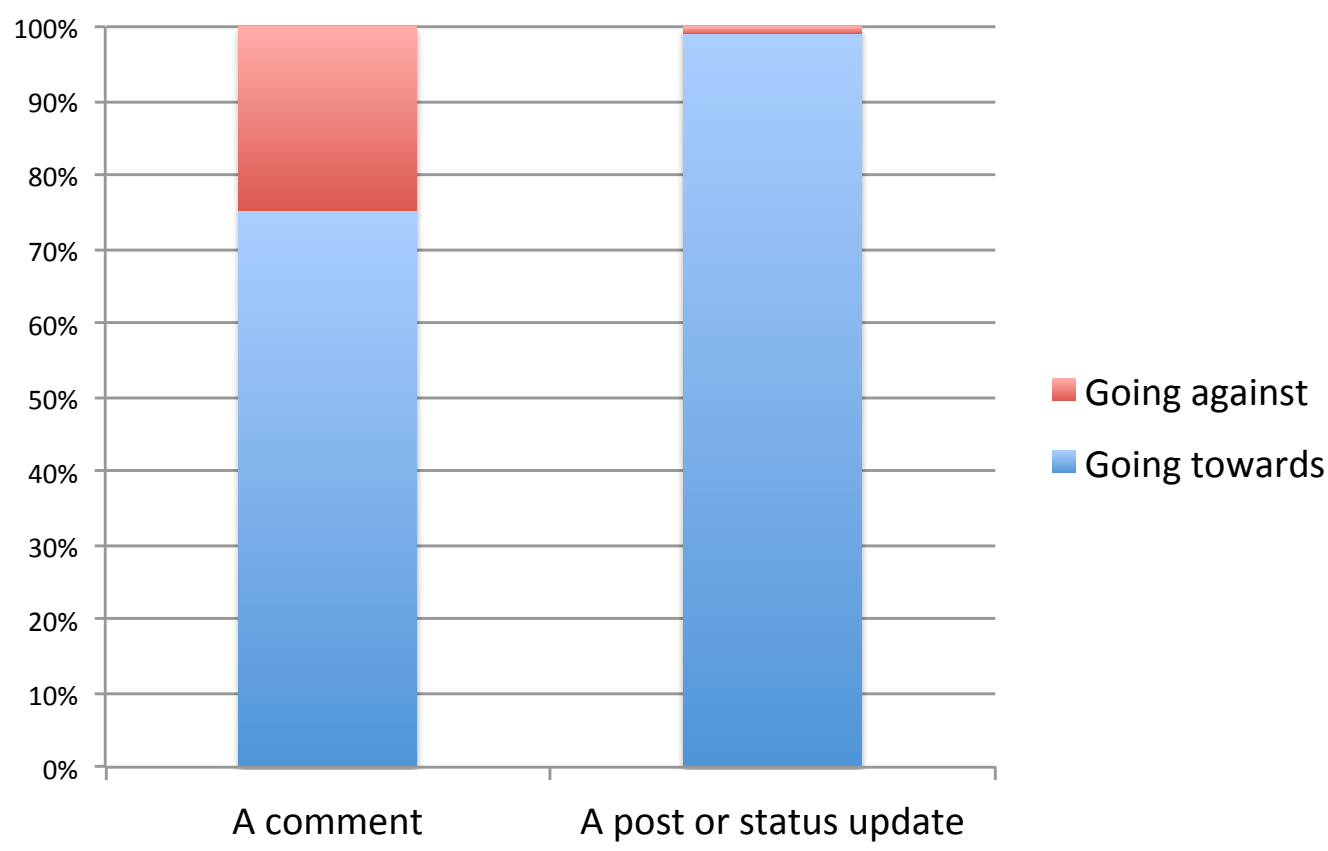




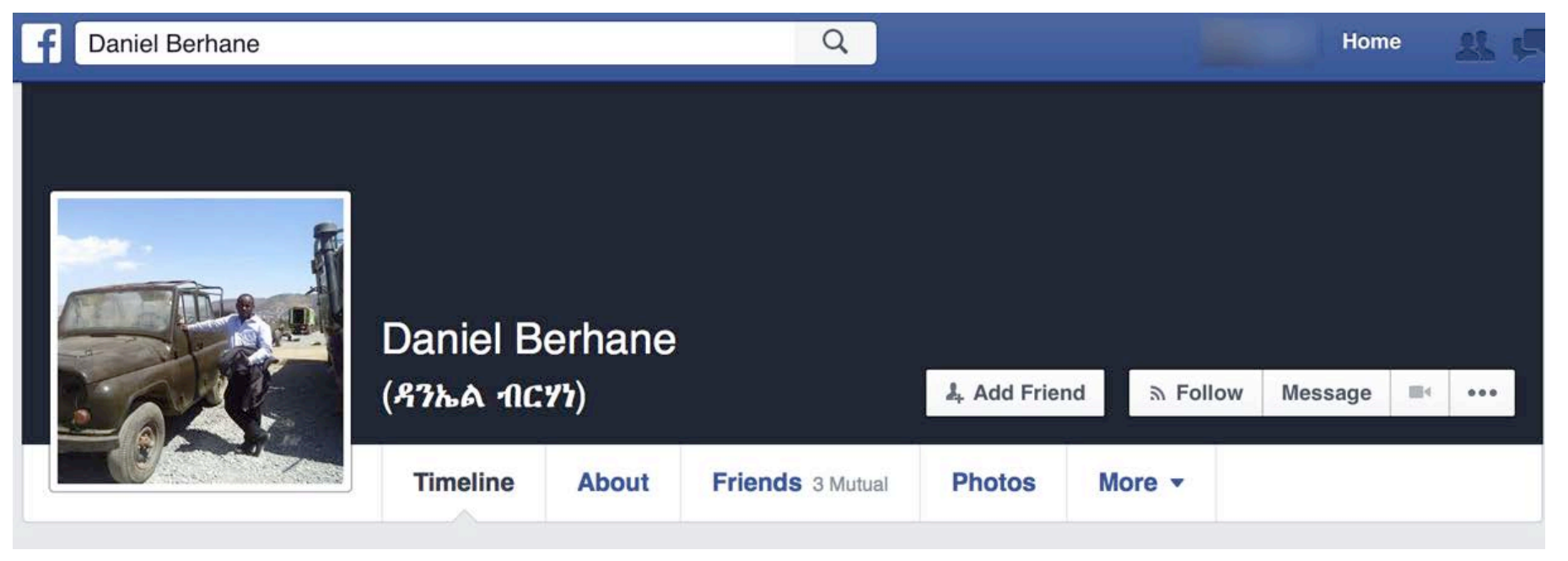

\section{DANIEL BERHANE}

Daniel Berhane is one of the most prominent Ethiopian online commentators and bloggers. His Facebook page discusses Ethiopian political issues and reposts links to articles from his online website hornaffairs.com. In Ethiopia's polarized political environment, Daniel is often known for critically challenging the claims of opposition politicians and international organizations, as well as for his criticism of the bureaucratic failures of the government. He has been an influential figure since 2010 and his own blog now attracts other contributors, transforming it into a collaborative media portal for discussing politics related to the Horn of Africa.

\section{FIGURE 23. TYPES OF STATEMENTS (DANIEL BERHANE)}

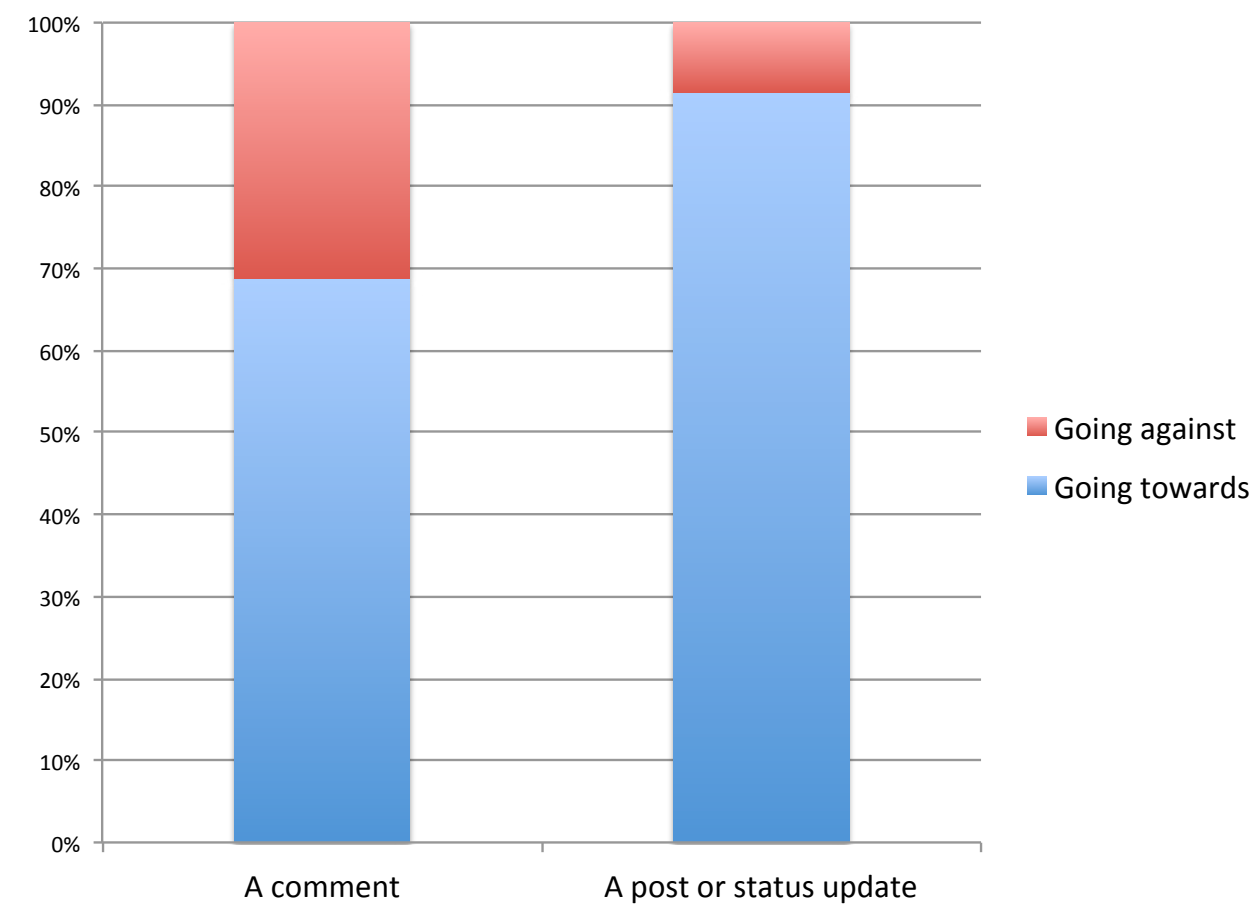




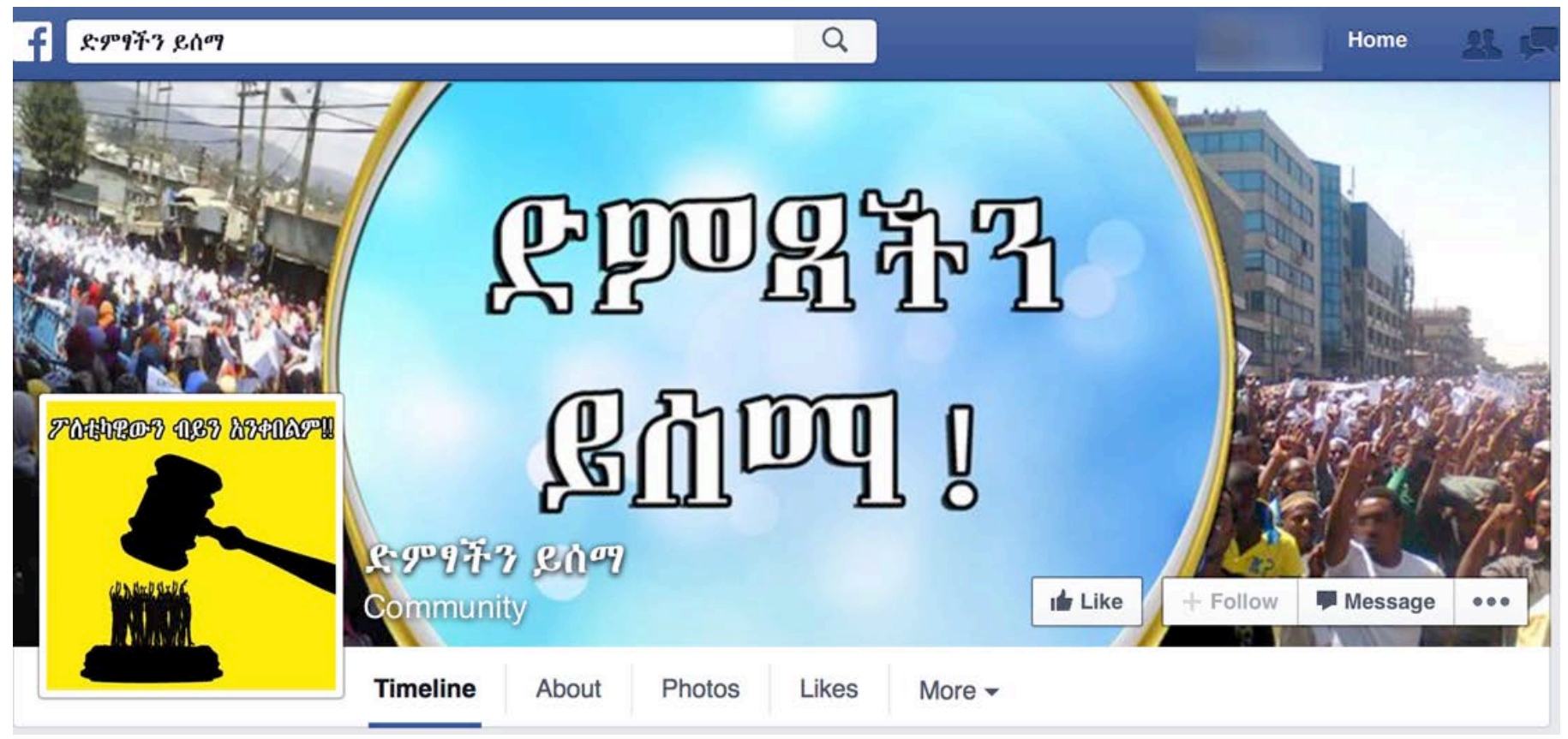

\section{DIMTSACHIN YISEMA}

Since 2011, there has been recurrent conflict between EPRDF and the Ethiopian Islamic Affairs Supreme Council (EIASC, popularly known as the "Majlis"). Dimtsachin Yisema has emerged as one of the most popular forums for Ethiopian Muslims. The group uses Facebook to create awareness and to centrally coordinate protests against government intervention in religious affairs. At the end of each protest, multimedia reports are shared on Facebook with the general audience. By organizing online campaigns using the hashtags \#Justice4EthioMuslims and \#EthioMuslimCommitteeTrial, the group has managed to mobilize a high turnout of attendees at the court hearings for the trial of imprisoned leaders of the Muslim community.

FIGURE 24: TYPES OF STATEMENTS (DIMTSACHIN YISEMA)

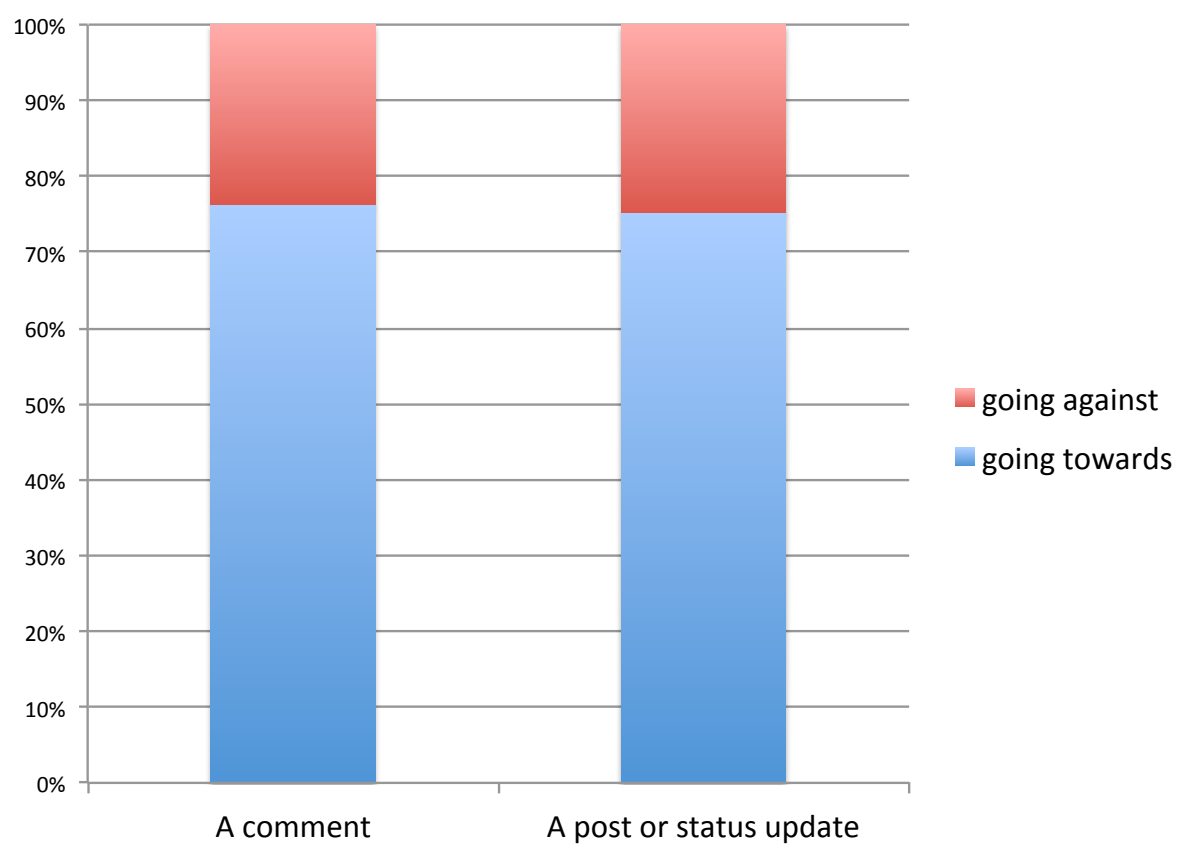




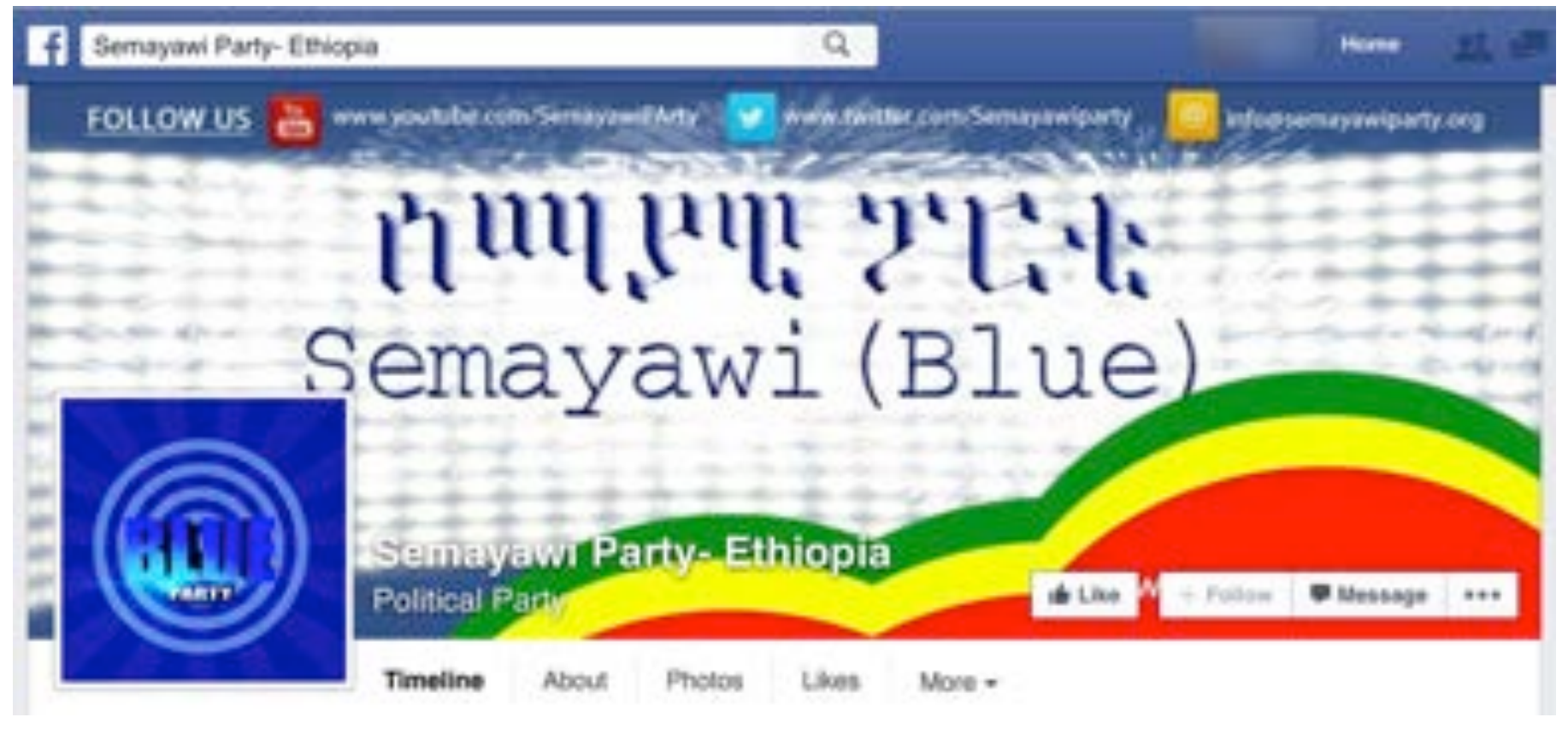

\section{SEMAYAWI PARTY}

The Semayawi Party (or Blue Party) was established in 2010 by young politicians who identified with moderate political liberalism. It was at the forefront of political debates in September 2013 when it organized the first public political demonstration in Ethiopia since the 2005 elections. Social media activists responded positively to the Semayawi Party's call and joined the rally - an event that was popular among the Ethiopian Facebook community. On Facebook, the Semayawi Party has the most popular page of all opposition parties, and this page is one of the most important sites gathering discussions on Ethiopian opposition politics, especially around the 2015 elections. The Facebook page was created in 2012 and it has been used to discuss the party's political program, hosts calls for mass rallies, and posts frequent reports of government harassment. It also shares the articles of the party's weekly online media Negere Ethiopia, which has a separate page on Facebook (37,837 fans). Most of the leadership of the party are also available online to answer questions from the online community and debate with online audiences.

\section{FIGURE 25: TYPES OF STATEMENTS (SEMAYAWI PARTY)}

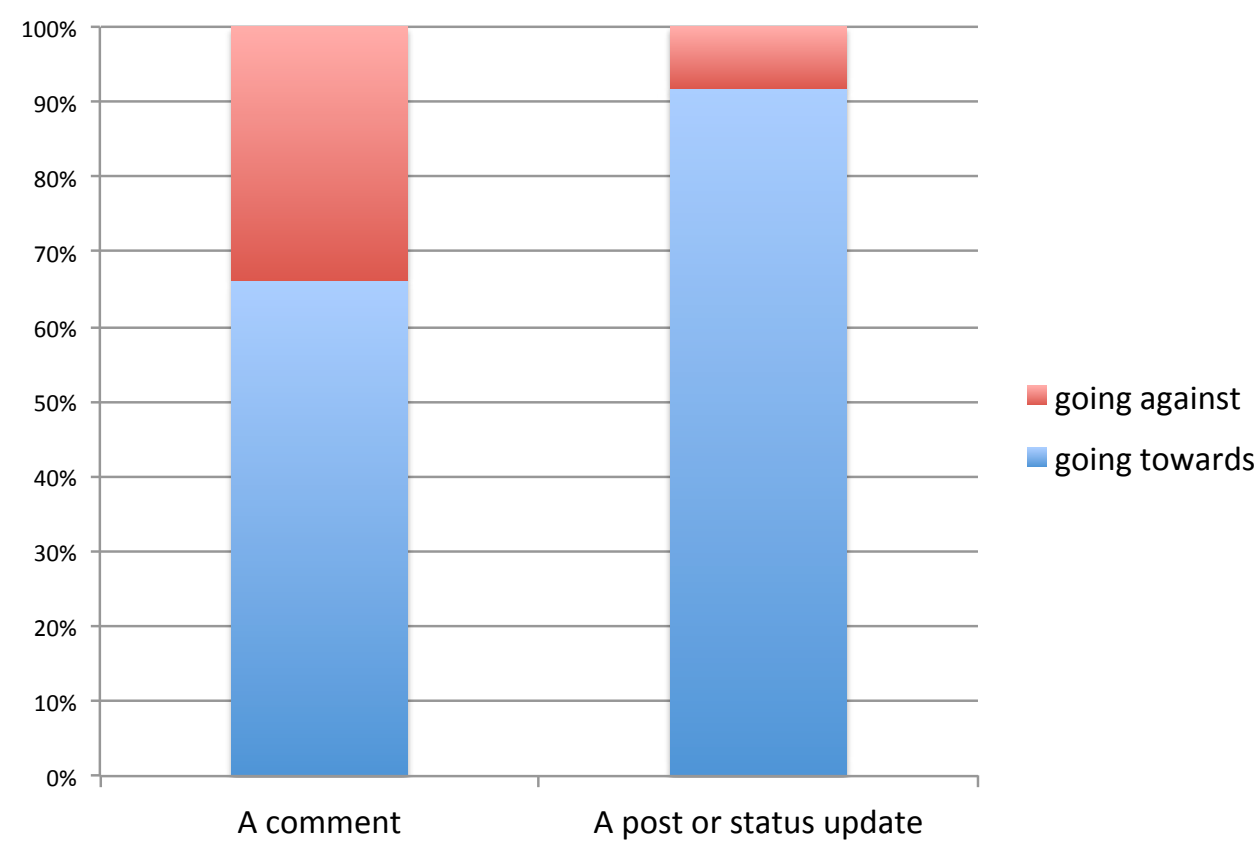




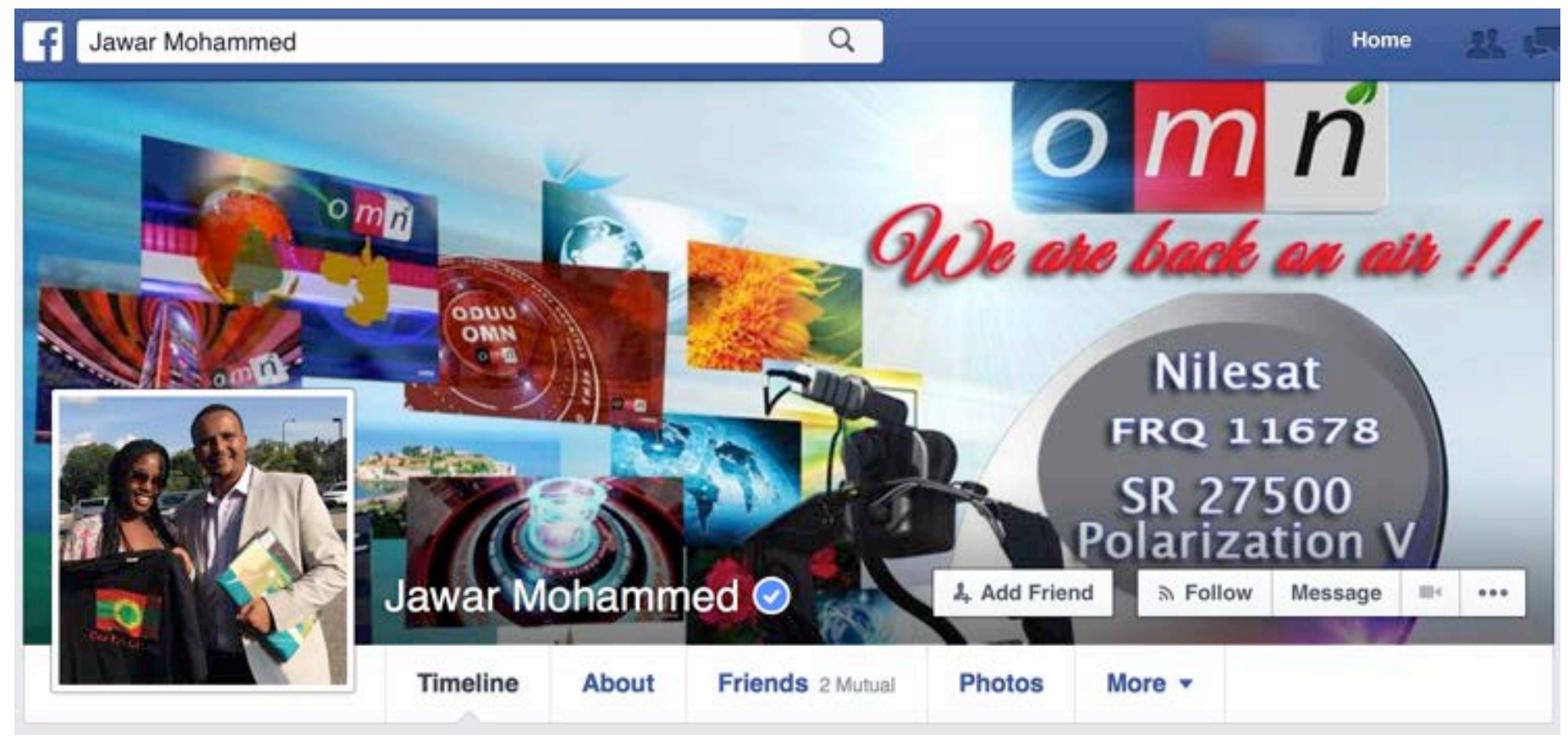

\section{JAWAR MOHAMMED}

Jawar Mohammed has a visible social media presence in Ethiopia and in the diaspora and he has been a central figure behind the influential \#BoycottBedele, \#Oromofirst and \#OromoProtests campaigns on Facebook and Twitter. The first of these campaigns succeeded in forcing Bedele Brewery to withdraw its sponsorship of the Ethiopian popular pop singer Teddy Afro, who became controversial for his eulogies of past Ethiopian rulers such as Emperor Menelik II (who is judged critically among Oromo nationalists). The second campaign was triggered by a question about whether Oromos should identify as ethnic Oromos or as Ethiopians first. The third campaign was created as a response to the government's master plan for the expansion of Addis Ababa. Many Oromo university students demonstrated against these plans, during which some students were arrested and others killed.

\section{FIGURE 26: TYPES OF STATEMENTS (JAWAR MOHAMMED)}

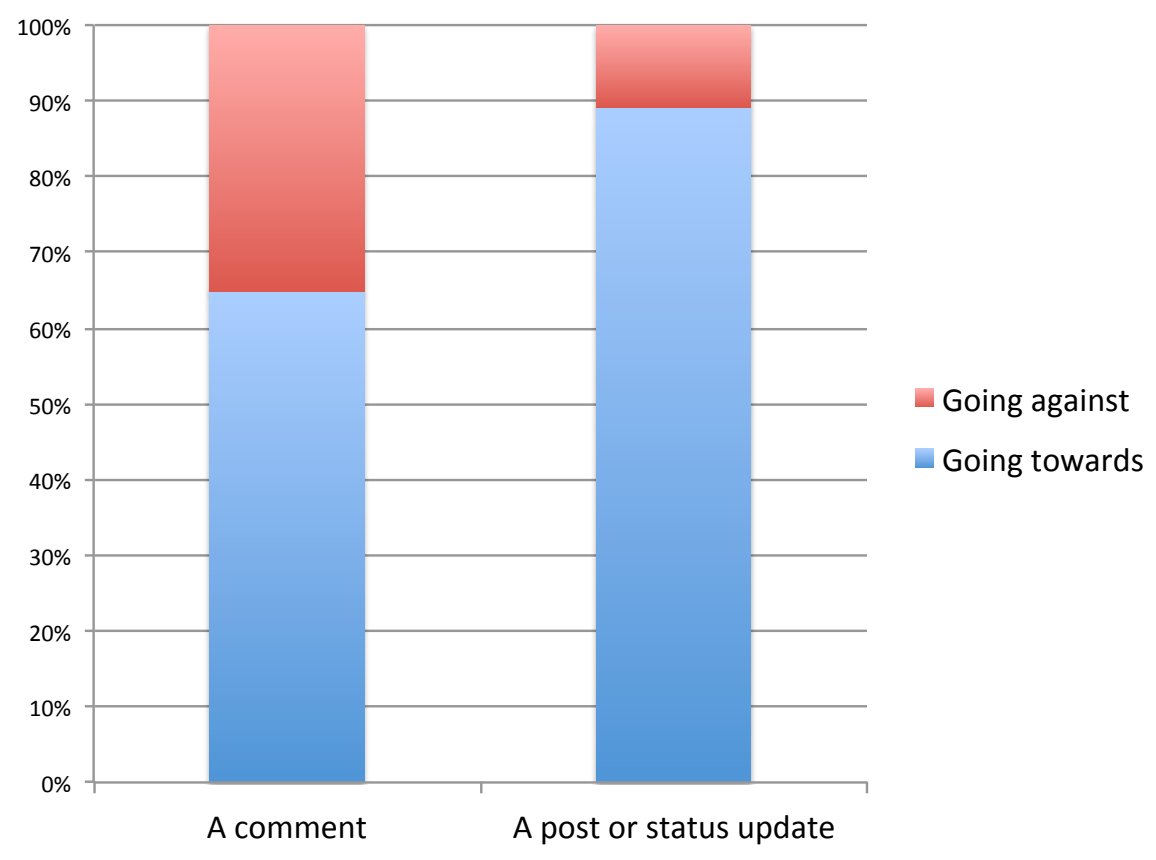




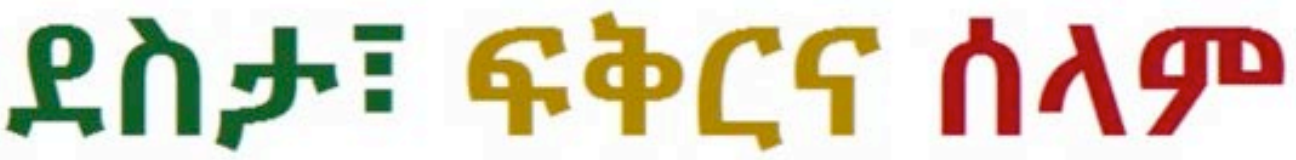

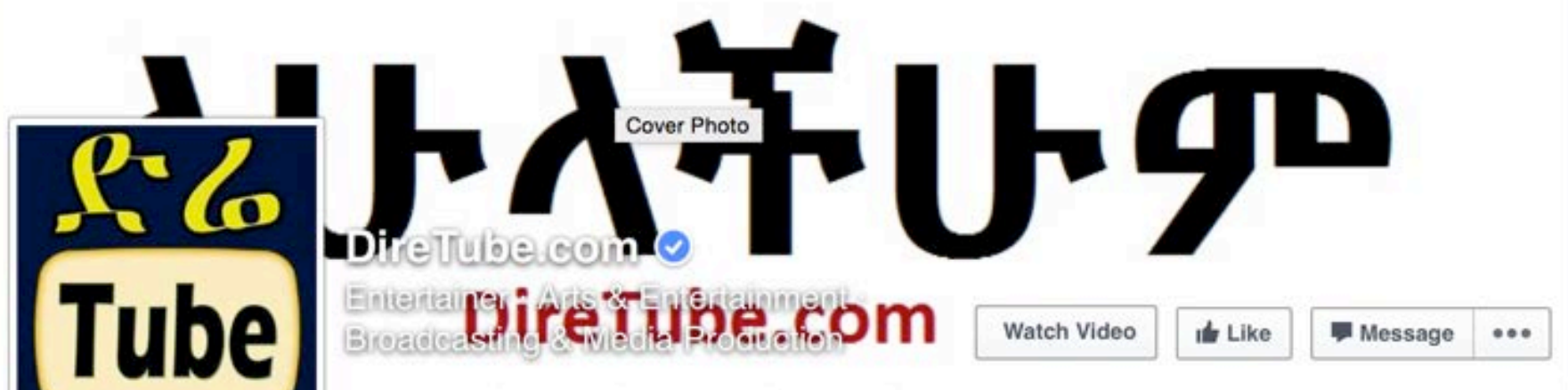

Timeline About Photos Likes More -

\section{DIRETUBE}

Diretube is one of the most popular Facebook pages in Ethiopia and it the diaspora, with almost 1 million fans. The page focuses primarily on popular culture. Its parent site, diretube.com, is a video aggregator that collects and organizes dramas, music, movies, comedies, and TV shows from different Ethiopian sources. The Diretube Facebook page usually shares snippets of entertainment links, including videos from EBC (Ethiopian Broadcasting Corporation) and other government-affiliated media (so called "developmental media"). Comments on its posts often provide lively commentary on Ethiopian political affairs.

FIGURE 27: TYPES OF STATEMENTS (DIRETUBE)

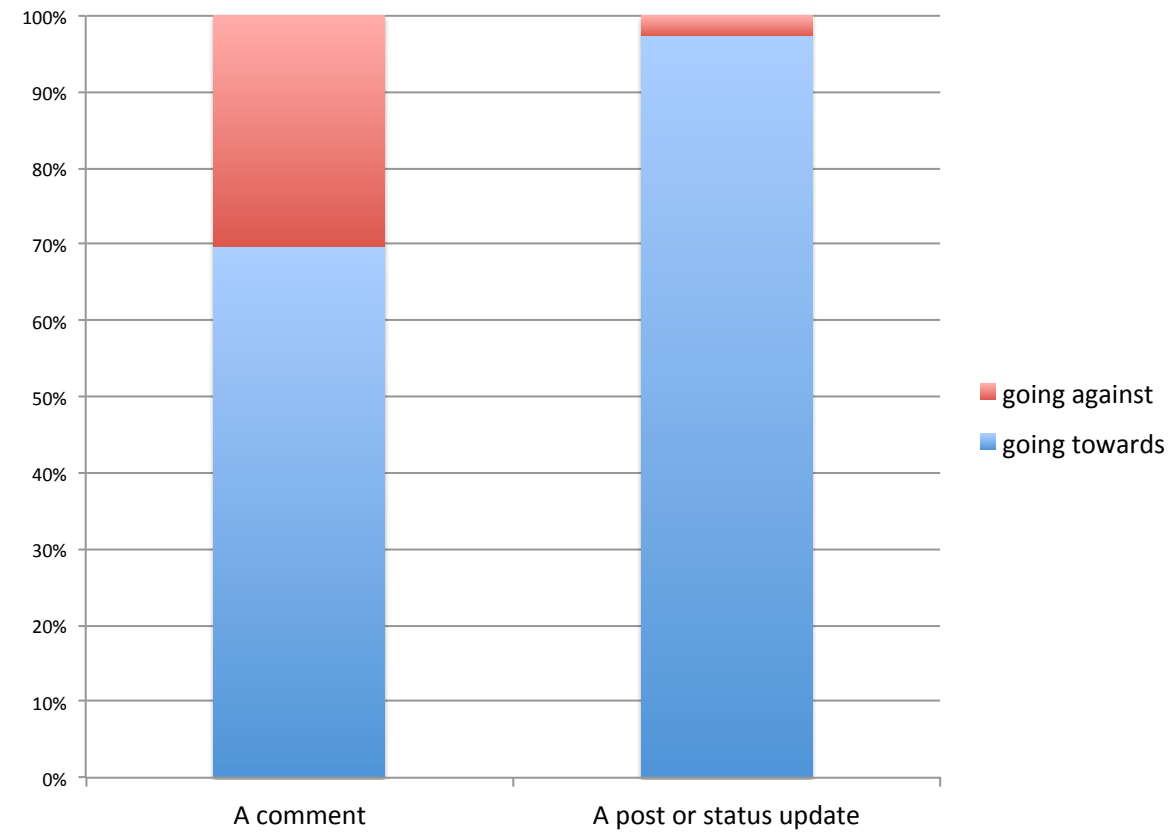




\section{ONLINE SPACES AND DIGITAL BOUNDARIES}

All six spaces analyzed in depth are characterized by distinctive 'identities': in terms of the topics regularly discussed, the users' demographics, and the different types of interactions they encouraged. Figure 28 provides an overview of the most debated issues on the different spaces. As we can see, apart from a few events that attracted attention across most spaces, conversations in these spaces tended to be stove-piped, with each space focusing on a particular set of issues.

Dimsatchin Yisema, the page launched by the Ethiopian Islamic Affairs Supreme Council, is the space that displayed the greatest focus on a specific agenda, campaigning for a transformation in the relationship between the Ethiopian government and the Muslim community. When users addressed other issues (e.g. the elections), they did it through the lenses of religion and politics.

Similarly, the page created by the Semayawi Party regularly carried statements focusing on the elections and opposition politics, mostly engaging with events considered significant for the electoral process.

At the opposite end, the Facebook pages of Daniel Berhane and Diretube exhibited the greatest variety of topics, covering issues from the Blue Nile agreement, to the UN Commission on Human Rights to more generic event.

FIGURE 28: THE MAIN TOPICS DISCUSSED BY DIMTSATCHIN YISEMA

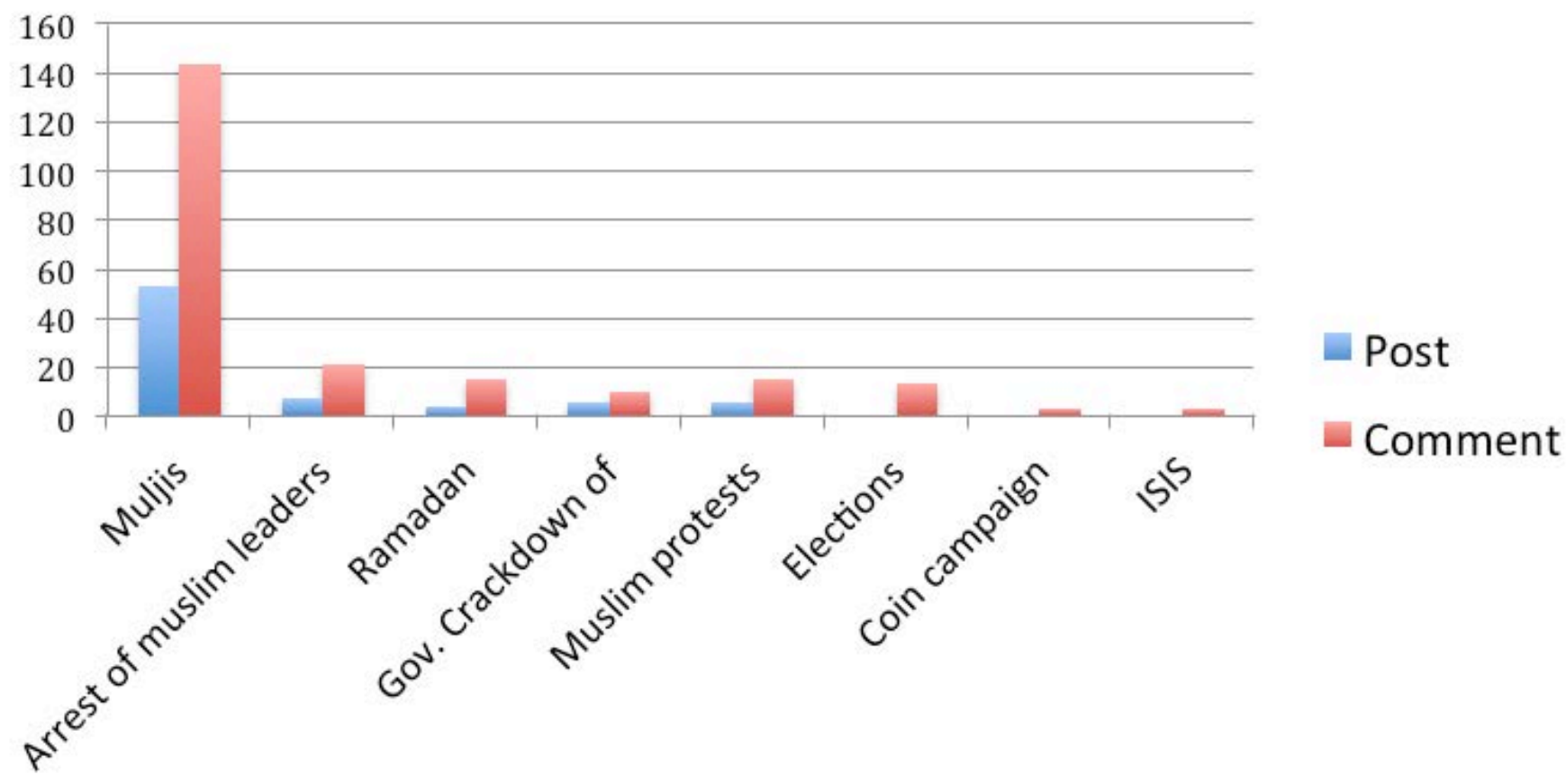


FIGURE 29: THE MAIN TOPICS DISCUSSED BY THE SEMAYAWI PARTY

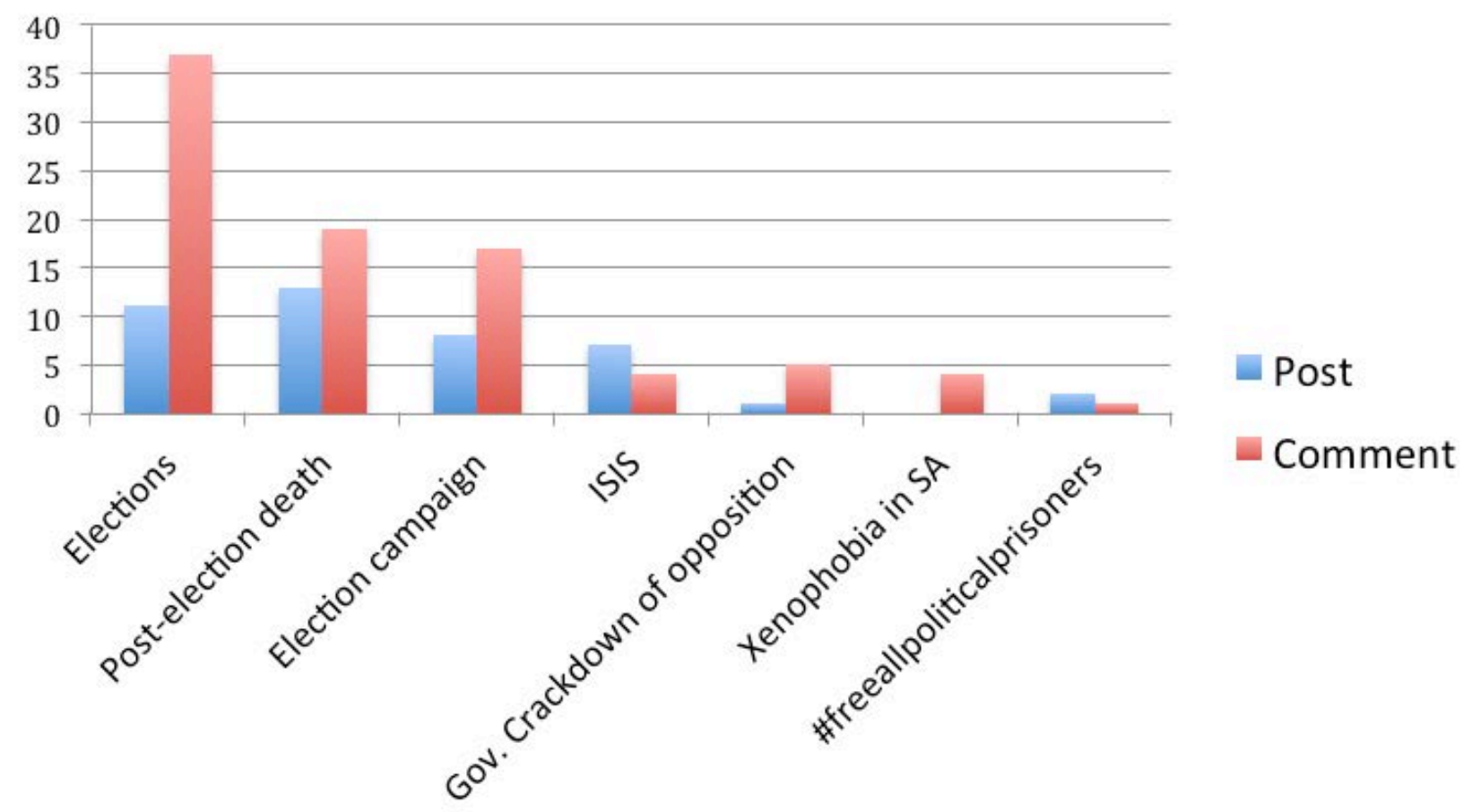

FIGURE 30: THE MAIN TOPICS DISCUSSED BY DANIEL BERHANE

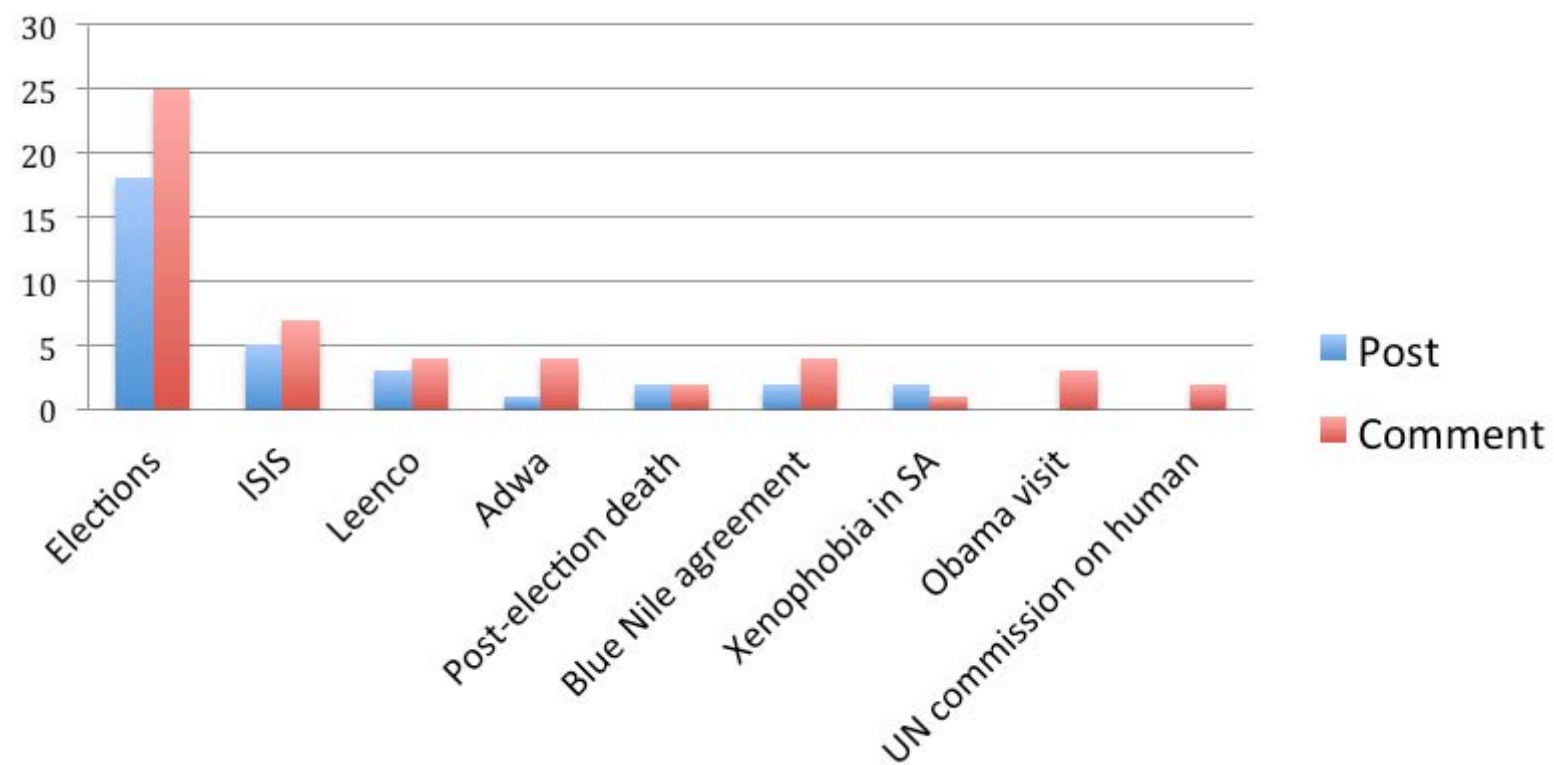


The analysis of the geographic composition of users commenting on these spaces offers a similarly fractured picture, characterized by varying proportions of users posting from within and from outside Ethiopia, and by significantly different diasporic communities. For instance, Jawar Mohammed is the only figure whose base is predominantly in the diaspora, while all other pages received the majority of their posts from within Ethiopia. The page of the Semayawi Party tops the ranking with the largest follower base in Ethiopia, trailed by Daniel Berhane, Diretube, Tedros Adhanom, and Dimtsachin Yisema.

The most significant differences, however, emerge when we analyse the diasporic communities that contributed to the debates on each site. The spaces that are more oriented towards discussing politics, such as Jawar Mohammed, Daniel Berhane and, to a more limited extent, $\mathrm{Dr}$ Tedros, tend to have more commentators based in the USA and the UK, whereas the more religious and popular culture-focused pages seem to have more representation in the Middle East. In particular, Saudi Arabia emerges as the largest source of commentators for Dimtsachin Yisema and Diretube. As illustrated in the previous chapters, this also reflects some of the historical patterns of migration of different Ethiopian diasporic communities.

\section{FIGURE 31: THE LOCATION OF DIFFERENT ONLINE COMMUNITIES}

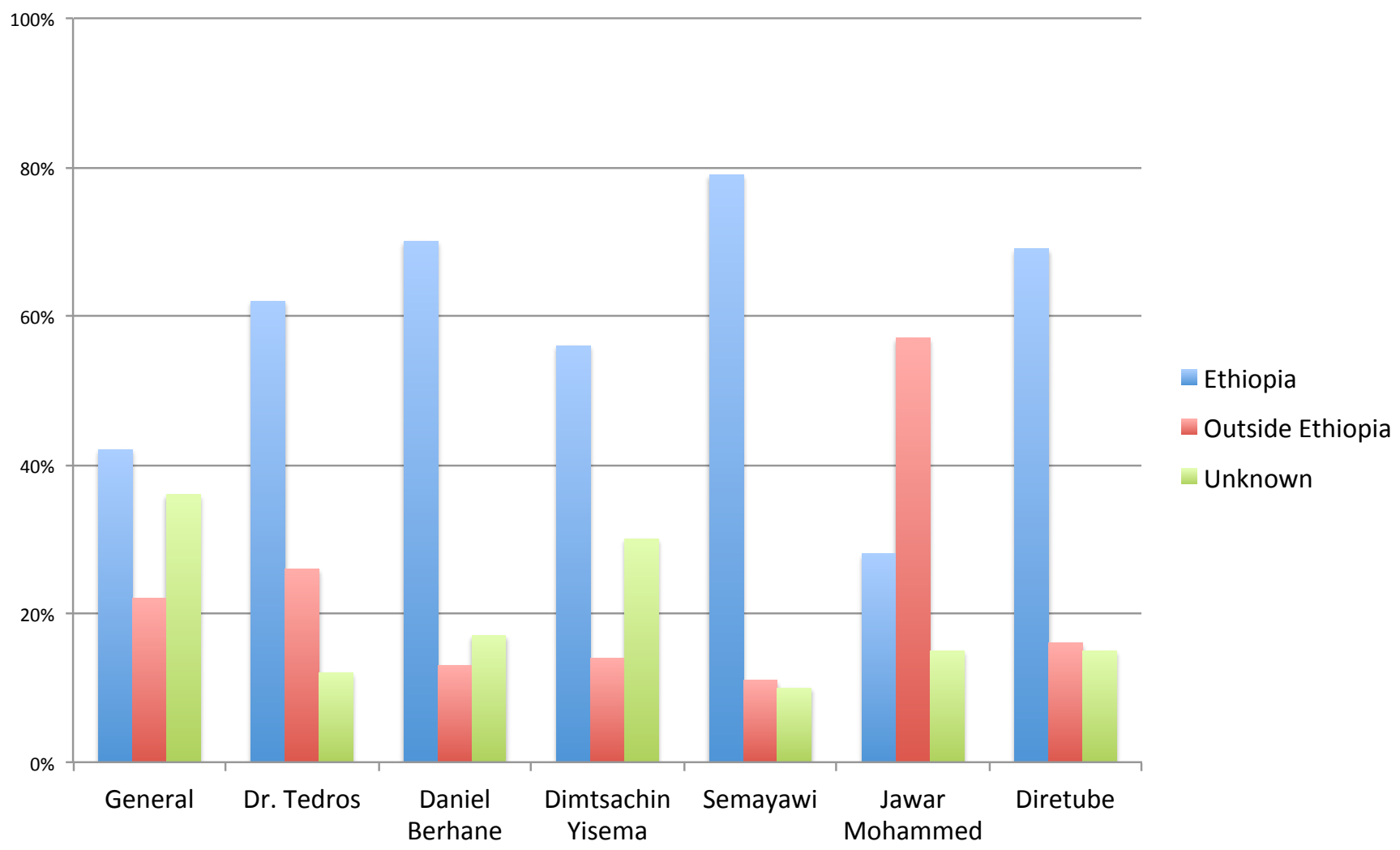




\section{FIGURE 32: COMPARATIVE SPEAKER LOCATION IN COMMENTS}

DR. TEDROS

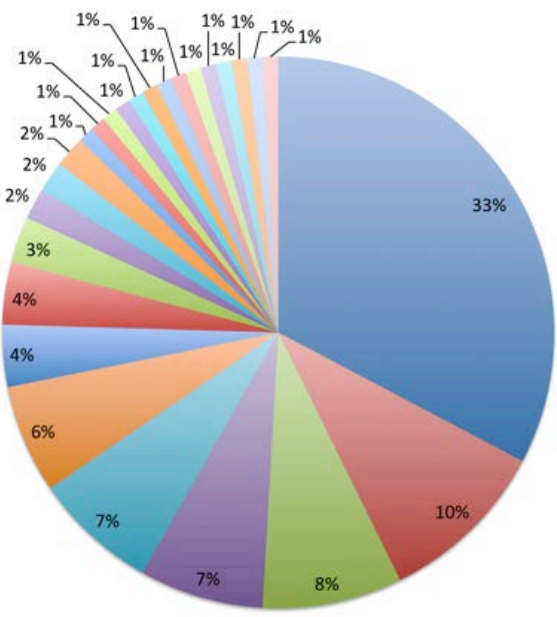

DIMITSATCHIN YISEMA

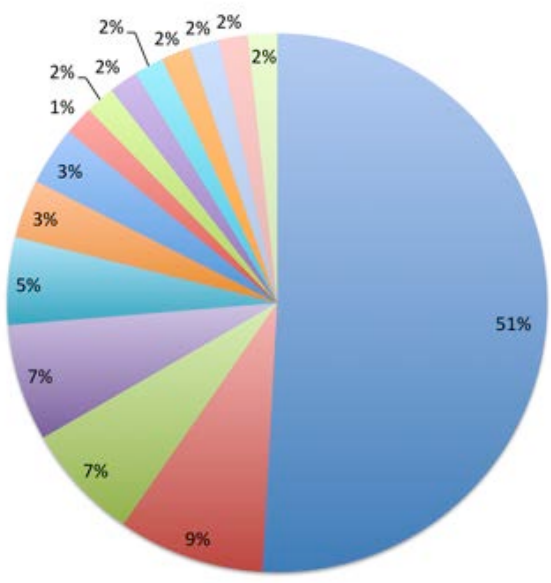

JAWAR MOHAMMED

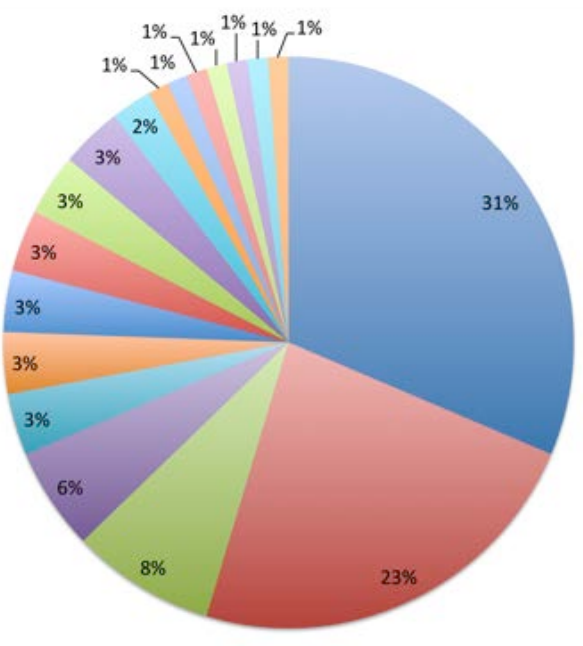

DANIEL BERHANE

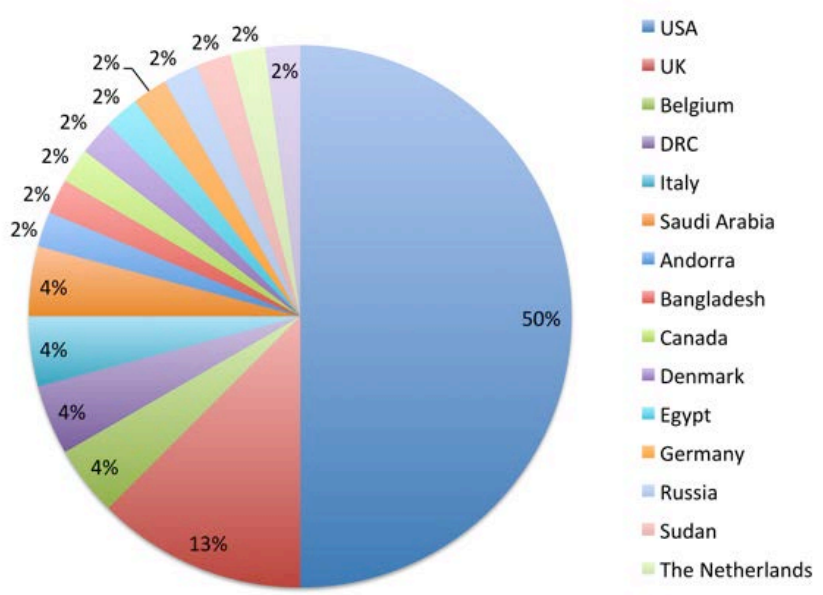

SEMAYAWI PARTY

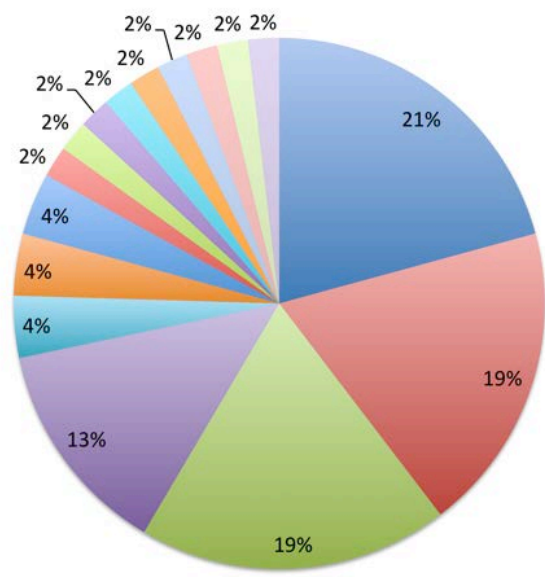

= Saudi Arabia

= Germany

USA

- Armenia

a Denmark

- UAE

= UK

- Cyprus

- India

Iran

= Italy

Kenya

- Kuwait

Nigeria

Sudan

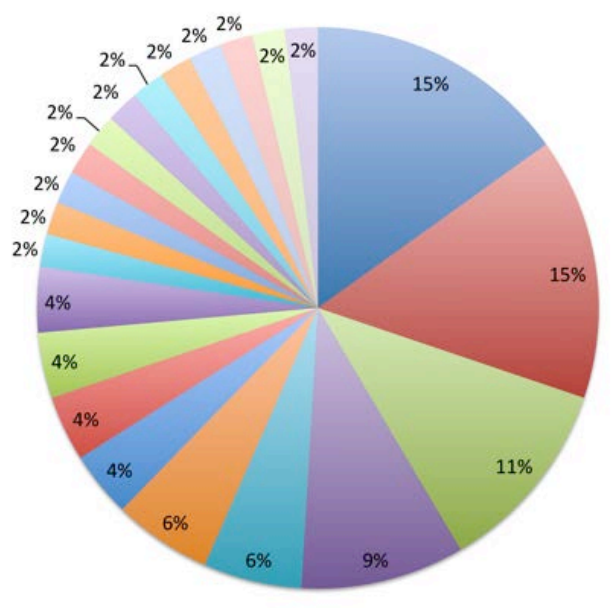

= Saudi Arabia

$=$ UAE

USA

= Kuwait

= Canada

- South Africa

= Bahrain

= Belgium

- Qatar

= Sudan

= Brazil

= Cote d'Ivoire

Eritrea

= India

- Italy

= Jordan

= Lebanon 
As explained earlier, these six spaces were selected for their popularity and their ability to reflect different types of conversations and interests among Facebook users. It is not surprising that we can find limited interaction among the users of the different pages. This is partially a reflection of Facebook's architecture, which - in contrast with other social media such as Twitter - structures conversations on a single page. This, in turn, limits the possibility of users contributing to a debate who do not regularly follow that particular page. Figure 34 offers a social network analysis of the six pages, indicating that only a handful of users have commented on more than one of the six online communities.

\section{FIGURE 33: USERS WHO COMMENT ACROSS (AND ON MORE THAN ONE OF) THE SIX PAGES}

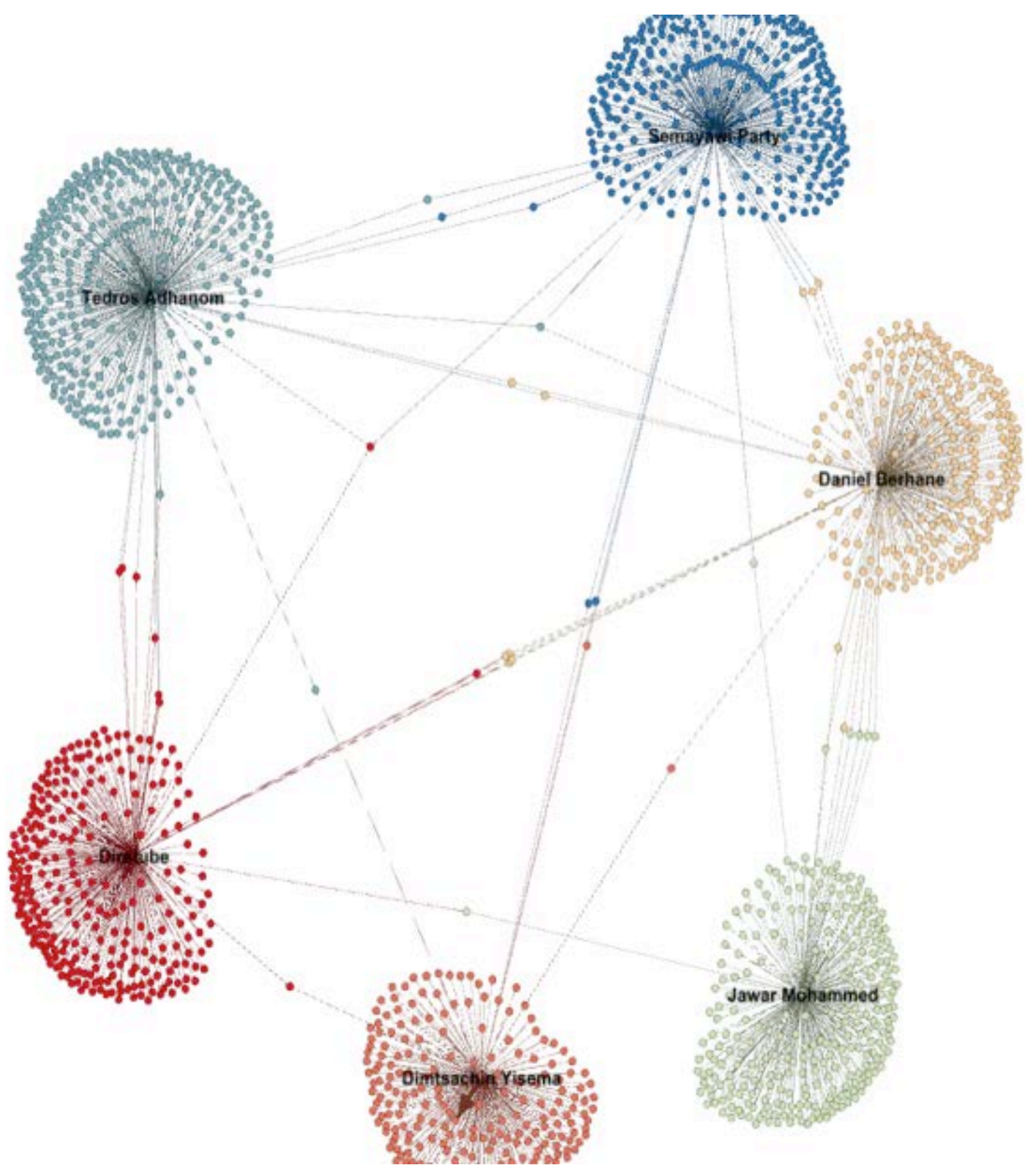




\section{FROM BROADCASTING TO ... ENGAGEMENT}

The spaces analyzed in the research tend to attract different types of users but this does not mean that users are simply seeking information they like or agree with. In contrast, there is a complex relationship between posts and comments. This is reflected both in the issues discussed - with commenters often returning back to other issues in the comments than discussed in the posts- as well as in the tones of the discussions. In particular, the commentators tend to be more antagonistic than the owners of the pages.

An illustration of this phenomenon is offered in the different ways the 2015 elections attracted the attention of page owners and commenters in each of the six spaces. Figure 36 shows the ratio between posts and comments related to the elections. In our sampling strategy we systematically selected two comments per post, thus a ratio of " 2 " indicates there is perfect equivalence between what the page owners suggest as a topic for discussion and what the followers want to comment on (i.e. for each post focusing on the elections there were two comments discussing the elections). A figure below or above "2" indicates a discrepancy between what owners and commenters want to talk about. Thus, when we look at different pages, we find a complex picture emerge as to how different posts were commented on. Dimtsachin Yisema offers a particularly interesting case. On this page, posts related to the elections were almost absent, reflecting how the movement did not perceive the elections as a strategically important event in pursuing its objectives. The Dimtsachin Yisema movement has always sought to underline the apolitical nature of its demands, which requires maintaining a distance from politicized events such as national elections.

The following statement illustrates this. Despite attempts by the page owners to avoid openly discussing politics, there were, however, nearly six times more election-themed comments than posts on Dimtsachin Yesema's page. This indicates that commenters were invested in talking about the elections more directly. A similar pattern was discernible in Tedros Adhanom Ghebreyesus's page, where comments outnumbered posts by three to one. In the case of the Semayawi Party, in contrast, there seemed to be a perfect identity of views between leaders and followers in terms of the topics being discussed: for every electionthemed post on the party page there are two election-themed, as reflected in our sampling strategy. At the opposite end, commenters on Jawar Mohammed's page seemed to snub his attempts to discuss the elections and steer the debate in different directions.

\section{FIGURE 34: RATIO OF ELECTION THEMED COMMENTS TO POSTS}

Jawar Mohammed

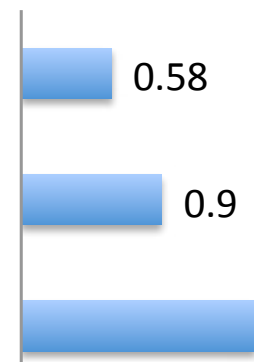

1.5 


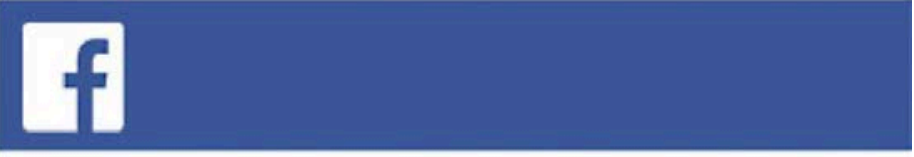

Timeline Photos

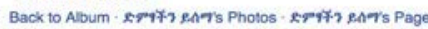

Previous - Next

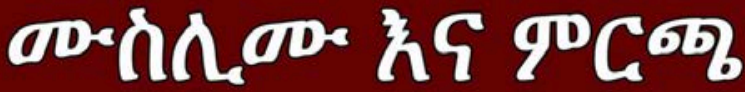

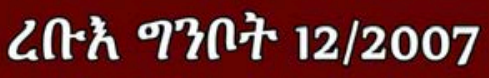

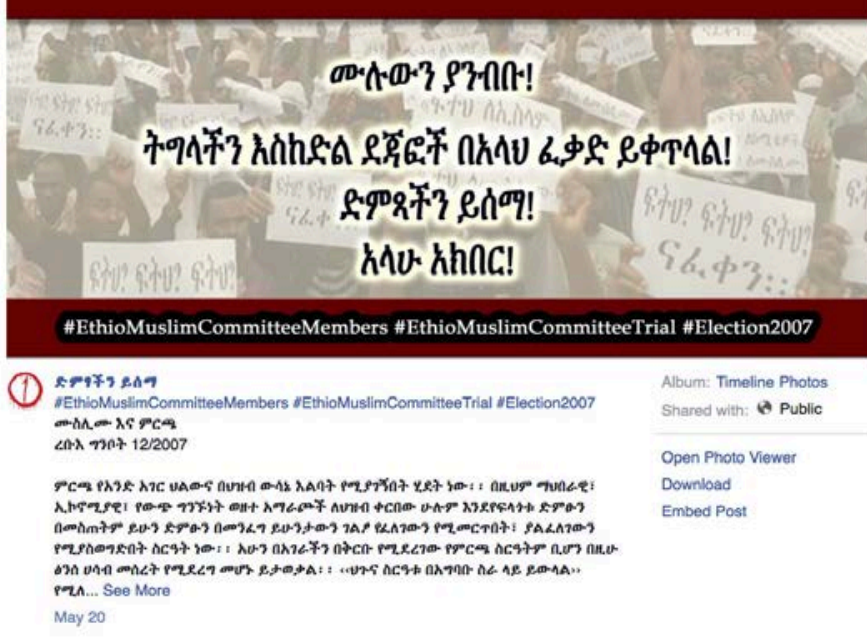

The discrepancy in the tone, rather than the subject, of the statements between posts and comments is even more significant. While posts generally tend to display a smaller proportion of antagonism when compared to the general sample, the opposite is true when

\section{$66_{\text {TRANSLATION }}$}

Regarding the election, we learnt that there is misconception among some people that "the Muslim community's question is changed into a political question". For now and for the future, it should be known that the Muslim communities' questions are only religious and religious only.

We will continue our struggle with no content change.

\section{FIGURE 35: TYPES OF STATEMENTS IN POSTS}

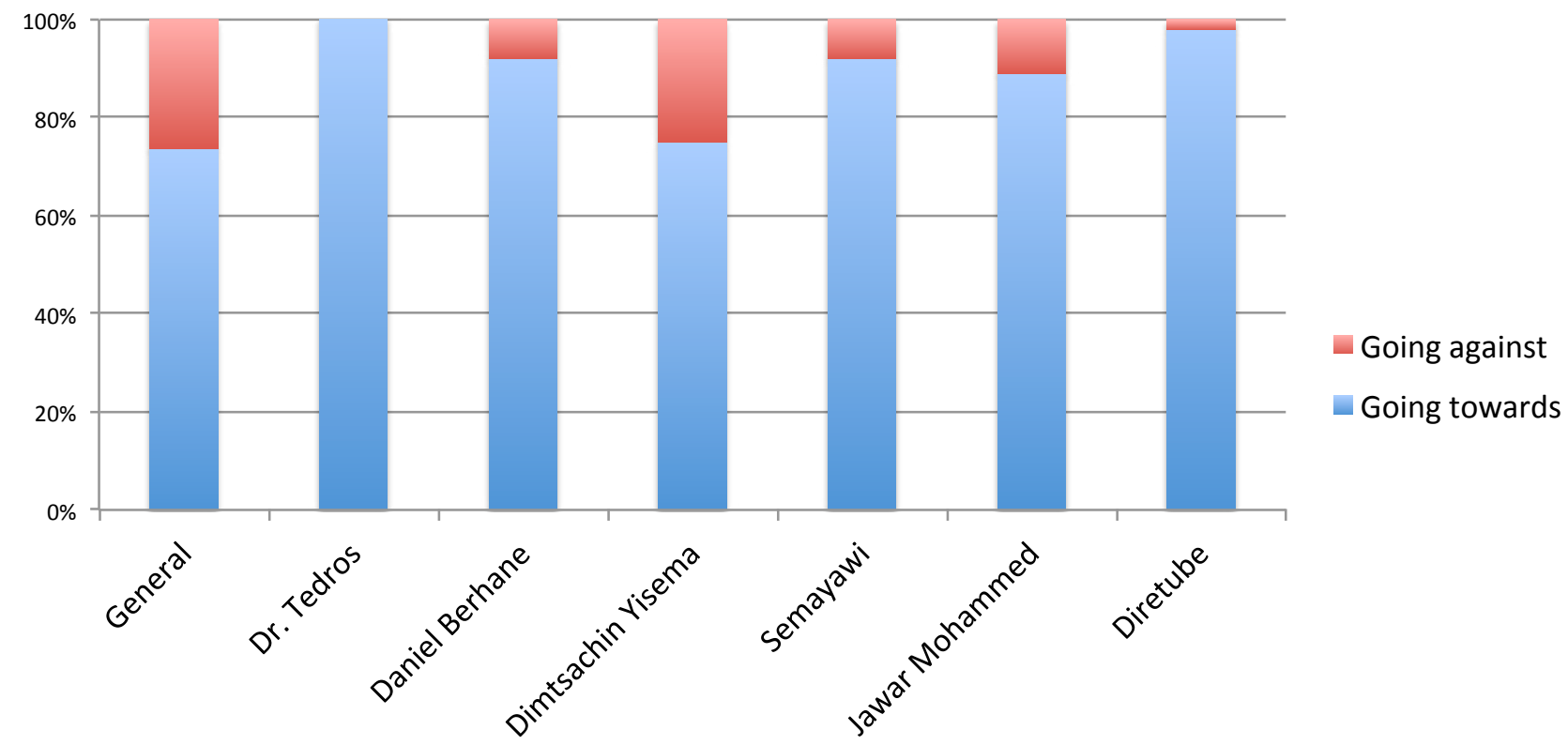




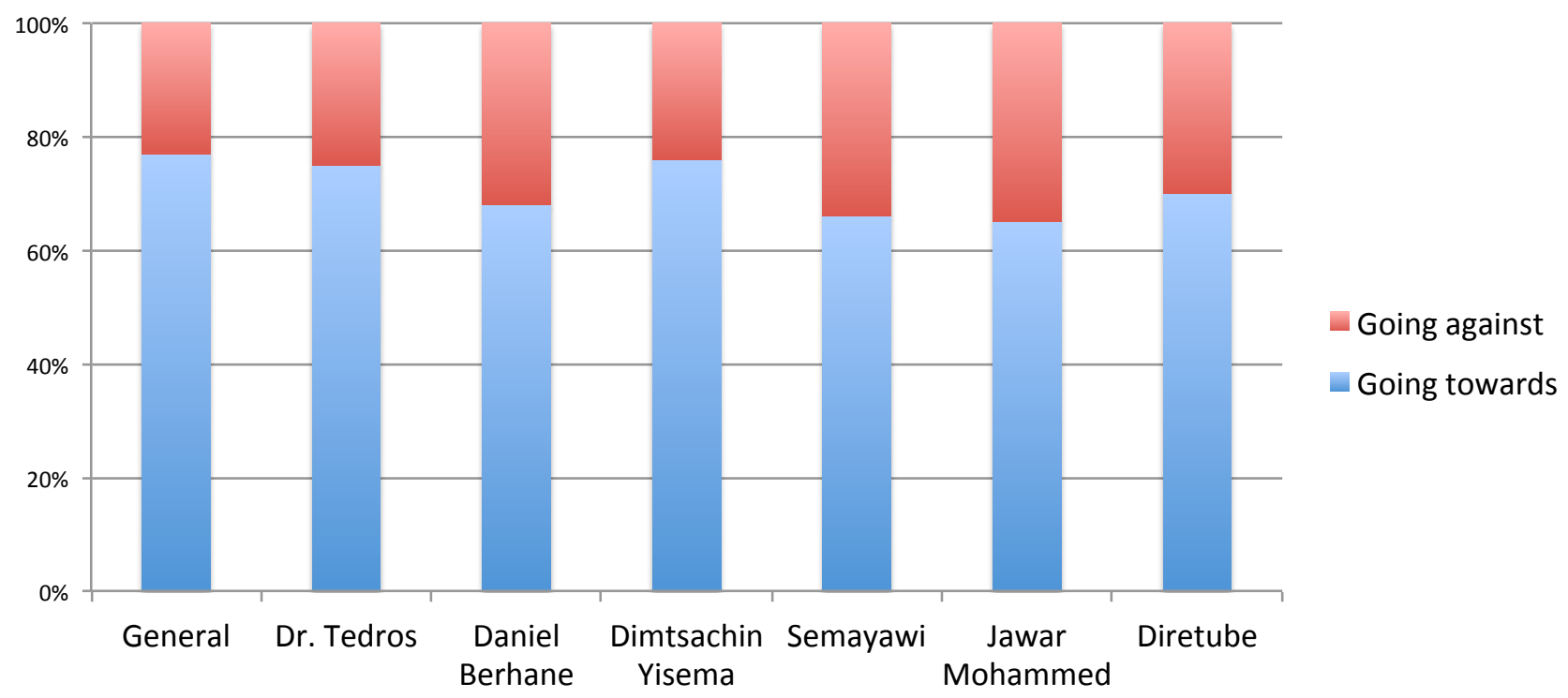

The sharp divide between people with high and little influence that characterizes these spaces can offer some clues to understanding why antagonistic statements tend to be more prevalent in those pages, despite the fact that page owners actually tend to adopt a more polished tone.

\section{FIGURE 37: ONLINE COMMUNITY BY INFLUENCE}

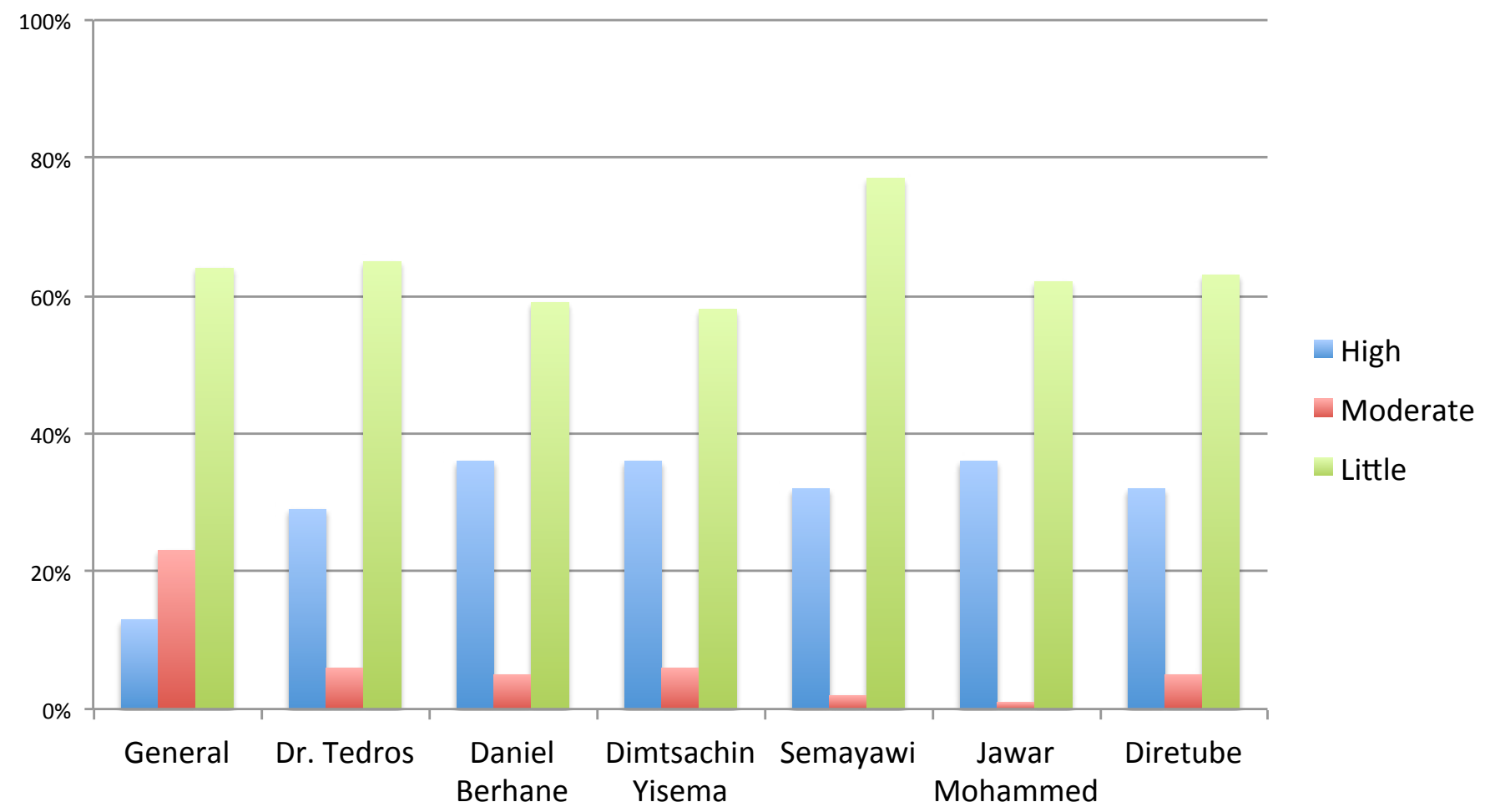


It appears as if comments are a bitter response to power, and to those who represent it or engage with it, rather than an expression of hatred towards a particular group. This finding must be substantiated by additional research, but it suggests that the links between power inequalities and the more aggressive tones used by individuals with little influence should be further examined before flagging and dismissing certain types of speech as inappropriate or raising undue concerns about their danger. Especially in contexts where individuals enjoy few opportunities to affect change in a concrete way, or have access to outlets in which they can voice discontent or criticism, social media offers an opportunity to voice frustration, not just towards the speakers, but at the processes through which power is exercised more broadly.

Taken together, the discrepancies encountered between posts and comments suggest a complex, often adversarial relationship between page owners and their followers. This seems to challenge the idea of social media as echo chambers, as spaces that reinforce user's belief system by providing them with viewpoints they already believe in. While users may be attracted by specific spaces because of the issues they expect to be discussed in these spaces, they also seem to steer these discussions into different directions if necessary.

\section{DEBATE AND DIALOGUE IN POPULAR SPACES}

Moreover, in most of the six spaces analysed, there was very little interaction between the page owners and users commenting on their posts. Pages such as Dr. Tedros (government politics) and Diretube (popular culture) despite being part of conversations in social media - still adopted a more traditional style of communication where the primary aim is disseminating messages to the audiences but not engaging with them. On the contrary, the page of Daniel Berhane has numerous examples where he actively interacts with comments left by his followers - both in the case of statements that go toward and those that go against. The examples from the pages of Dr. Tedros and Daniel Berhane illustrate some of the complex ways pages interact with followers and that cannot be automatically extrapolated from a more general analysis of the discussions.

\section{Dr. Tedros}

On May 8th, 2015, Dr. Tedros's page posted a short statement with a picture. This post attempted to show how his office was involved in helping bring back Ethiopian immigrants from Libya. The statement claimed that, with the help of the Ethiopian government, a number of Ethiopian migrants had been able to return safely to Ethiopia. This statement was typical of the kind of posts on Dr. Tedros's page, where the primary purpose of the page is to provide information about government policies. This post was immensely popular: it generated 963 shares, 11,501 likes and 1,699 comments. The majority of the comments were positive, applauding the actions and congratulating Dr. Tedros on the work he is doing and the overall policies of the EPRDF government. A few of the comments was critical either of the politics of Dr. Tedros or the government more broadly. Nonetheless, there was no attempt from Dr Tedros to engage with critical comments. Rather, the only debates that took place on the page consisted of interactions between the many followers who commented on the post, but not with Dr. Tedros himself. 


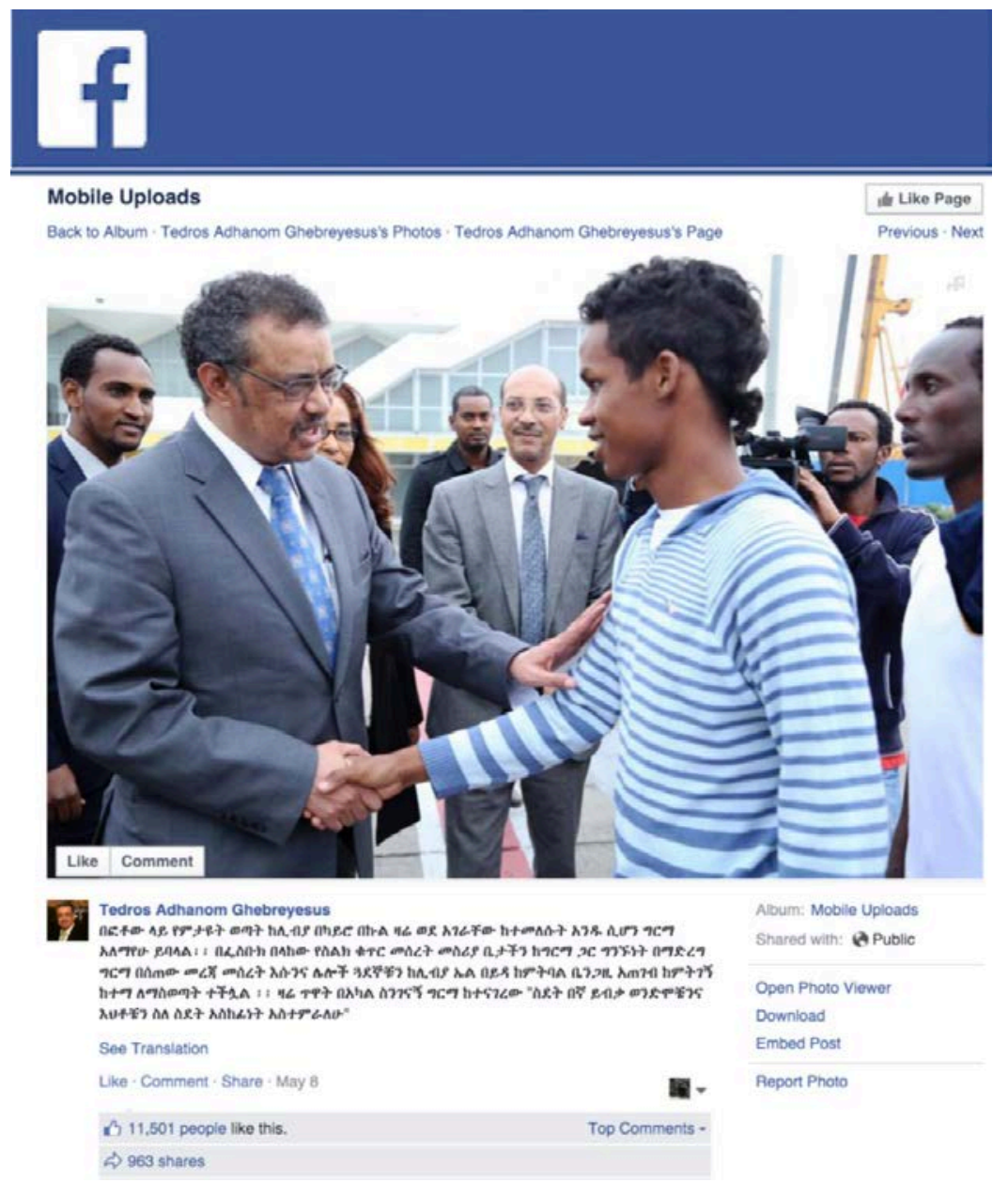

\section{Daniel Berhane}

In contrast, the page of Daniel Berhane, one of Ethiopia's most prominent young bloggers - who is also perceived to have views sympathetic to those of the government - has adopted a more dialogic format of interaction. For example, on 27 April 2015
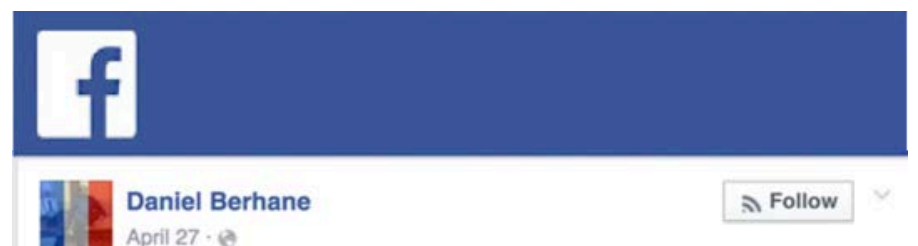

S Follow

April $27 \cdot$ e

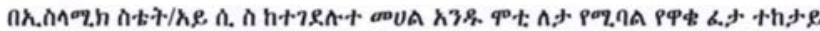
อา

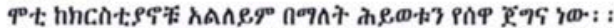

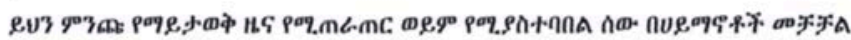

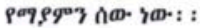

See Translation

If Like Comment $\Rightarrow$ Share

158 people like this.

1 share

View previous comments
Daniel Berhane posted a statement about the killing of Ethiopian Christians in Libya. The post looked critically at the claim that one of the people killed along with the Christians by ISIL in Libya was a Muslim.

\section{$66_{\text {TRANSLATION }}$}

One of those killed by Islamic State/ISIS is called Moti Lata who was a follower of Waka-Feta.

Moti is a patriot who gave his life saying he did not want to be separated from the Christians.

Anyone who doubts or denies this unconfirmed news does not believe in tolerance among religions. 
This post was liked by 158 people, shared once, and had 103 comments, making it a popular post by Ethiopian online standards. The response to this post was varied. Some of the commentators noted that it was not sensitive enough to the long tradition of tolerance that has existed in Ethiopia. Some accused the writer of using political motives to discuss religious issues. Other comments were insulting and accused Daniel of being insensitive to the pains of the family of the deceased and the religious sensitivities behind the ISIL killings in Libya. However, what makes this example different is that Daniel Berhane characteristic of his overall Facebook activity - actively interacted with many of the critical replies. At times this involved long debates about the issue at hand.

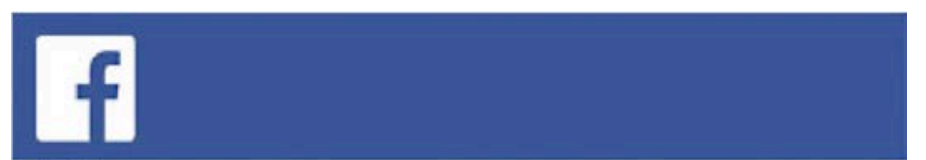

19 Solomon Ungashe Daniel Berhane, asking for evidence to substantiate a claim is not the same as denying the validity of the claim. I for one have been asking for evidence in Jamal Rahman's story but I did so because of its exemplary value and not because I doubted it could not have been true. Can you see the difference?

April 27 at $11: 17 p m \cdot$ Like - I 22

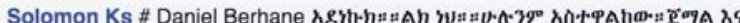
qD十: n就!

See Translation

April 27 at 11:19pm - Like

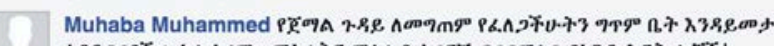

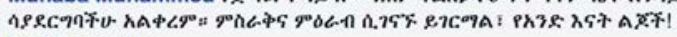
See Translation

April 27 at 11:20pm - Like - ß22

ๆ. $\mathrm{An}-\boldsymbol{n} \cdot$ - Hahaha this guy is crayzy

A. April 27 at 11:21 pm - Like

14. Daniel Berhane Solomon Ungashe

2 You turned the logic of media reporting on its head.

Not every conceivable possible scenario is presumed true unless proven wrong.

In this case: The source of the information is not credible, so I didn't spend a minute trying to disprove it.

Somaliland press citing Al-Shaabab sources? Give me a break.

Plus, as someone involved in the media business, you should know Somalilandpress and Geeskaafrika repeatedly make up stories as they know the gullibility of Ethiopian and Eritrean readers.

April 27 at $11: 53 \mathrm{pm}$ - Like - $\mathbb{R} 2$ 61. Solomon Ungashe LOL! Daniel Berhane, what's the matter with you. You just mentioned that got you confused.

April 27 at $11: 57 \mathrm{pm}$ - Like $\cdot$ I $^{3} 2$

287. Alema Dola $\bullet$ If it is true that he is killed because he refused to separate from his compatriots, he is true hero, he should be nominated national hero. April 28 at 12:08am - Like

\section{TRANSLATION}

Solomon \#Ks: Daniel Berhane I applaud you. You are right. You observed everything. Jamal and Moti Lata!!

Muhaba Muhammed. This Jamal issue must have prevented you from writing the poem as you wanted. It is surprising when east meets west. Children of the same mother. 


\section{CASE STUDY: ISIL COVERAGE IN POPULAR PAGES}

The events following the release on 19 April 2015 of a video showing the murder of Ethiopians by an ISIL affiliated group in Libya received ample coverage in all six popular spaces, attracting the majority of the statements posted by the six pages in the period from 18 April to 30 April (a total 261 were sampled as part of the research). The way in which these events were covered by different spaces also reflected their disctinctive identities and modes of interaction. For instance, Tedros Adhanom, in his role of Minister of Foreign Affairs, is among the speakers who tackled the events more directly, with the objective of promoting engagement, encouraging national union, defending the government's track record in fighting against terrorism, and showing the government's efforts in defending Ethiopian citizens abroad.

Despite this, the coverage differed from page to page, but for all of the pages the ISIL events remain the main focus of attention for the period under consideration. The only exceptions are Jawar Mohammed and his followers, who discussed the killings much less frequently than speakers on the other five pages. The pan-Ethiopian nationalism mobilized by the ISIL events might have contributed to limiting Jawar's interest in them, particularly when compared to the central role he played in popularizing \#OromoProtest that followed at the end of April.

Tedros Adhanom's page is the space that received the highest number of likes, shares and comments, particularly soon after the release of the video of the excecutions in Libya, thus showing how the audience turned to government pages, and most naturally that of the Minister of Foreign Affairs, in search of official news on the murders. The page maintained its usual lack of interaction between commentators and between speaker and commentators. The total number of likes to comments, for example, remained low, in contrast to the more engaging and community-oriented page of Daniel Berhane, where likes to comments were high.

\section{FIGURE 38: NUMBER OF COMMENTS}

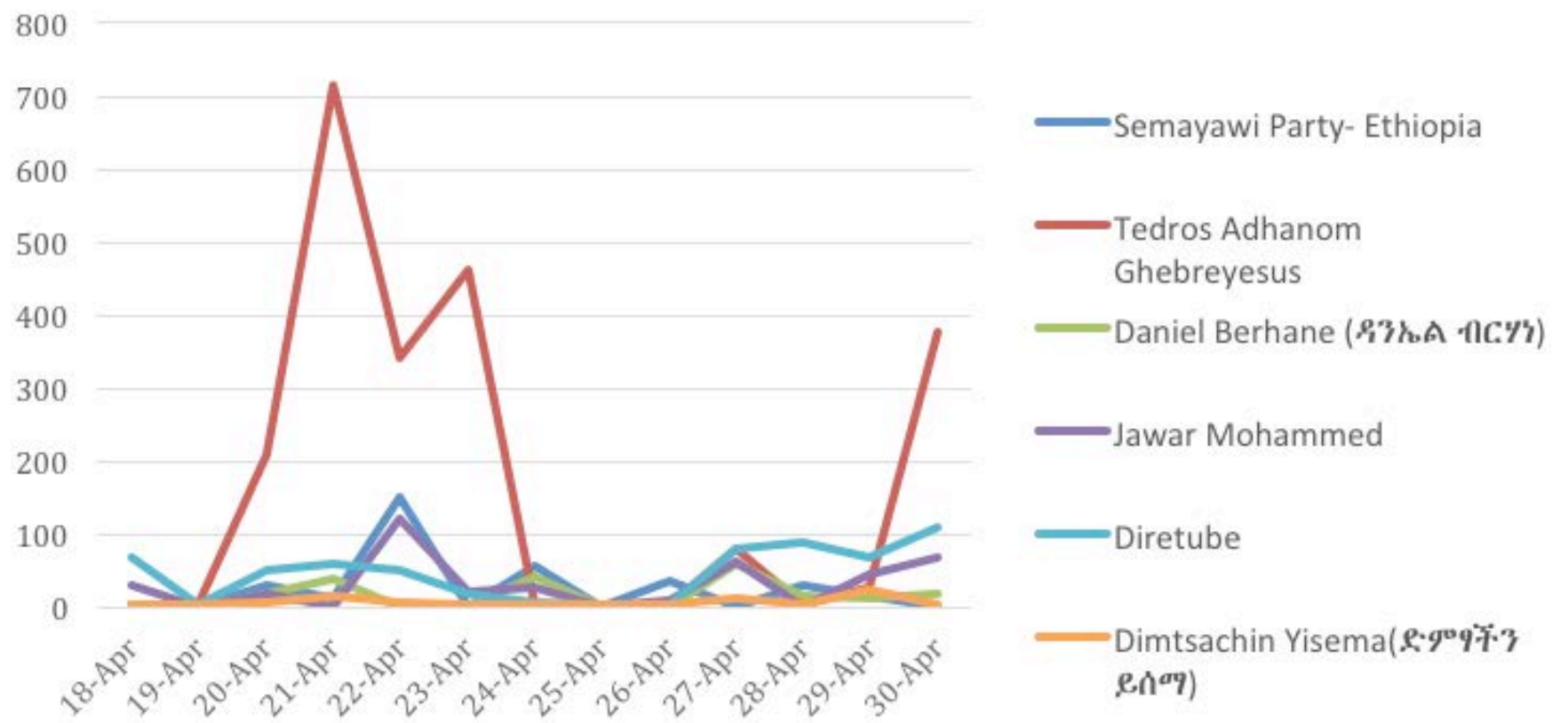




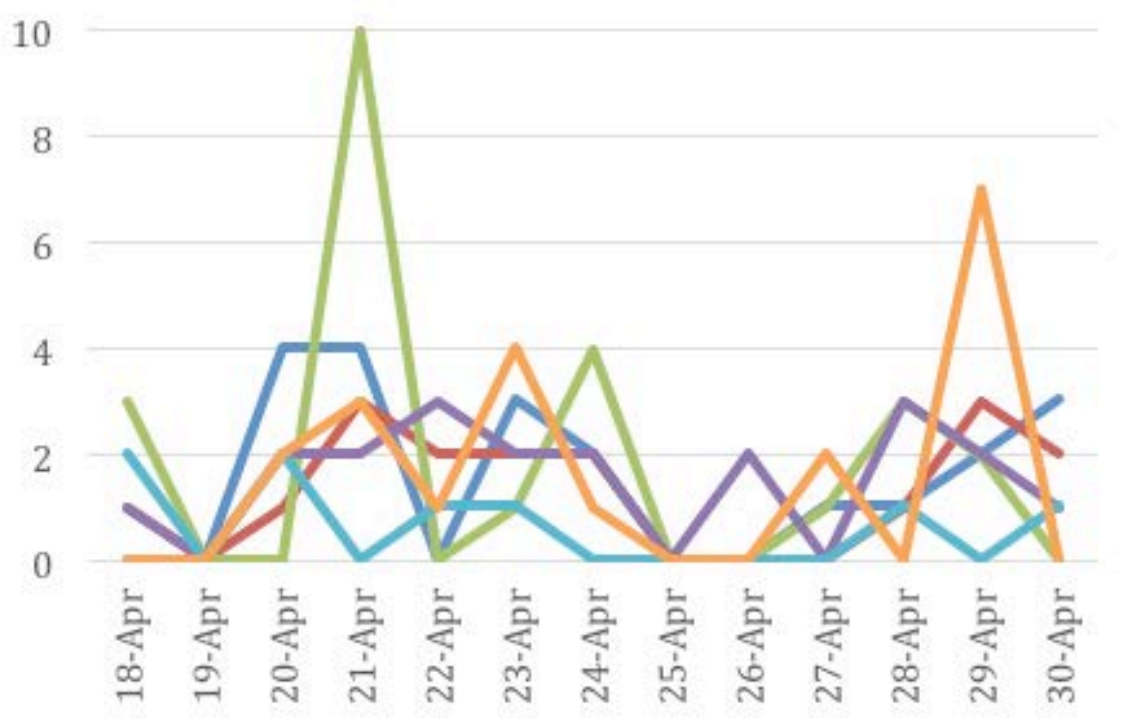

- Semayawi Party- Ethiopia

-Tedros Adhanom Ghebreyesus

Daniel Berhane ( $93 \%$ A -nc\%?)

-Jawar Mohammed

Diretube

The page that most actively followed the events soon after their occurrence was that of Daniel Berhane, where both Daniel himself and his fans followed closely the first reactions to the ISIL video and the following demonstrations in Addis Ababa. Other pages increased the number of posts about the ISIL events later on, about one week to ten days after the original video first appeared. For Tedros Adhanom, the increasing number of ISIL-themed posts had to do with his attempt to show the government's decisiveness in collaborating with the Egyptian government and other regional authorities to protect Ethiopian citizens abroad. On the page of Dimtsacchin Yisema, commentators were particularly interested in the story of a Muslim Ethiopian who allegedly preferred to die alongside his Christian Ethiopian companions rather than side with ISIL. This was mostly discussed in the comments, while the page itself maintained its usual exclusive focus on the EPRDF's interference in Muslim affairs and imprisonment of Muslim leaders. While commentators debated the implications of the ISIL killings for the Muslim community and interreligious tolerance in Ethiopia, the page mostly referred to the events in terms of a generic denunciation of violence and calls to unity. Even during the tense and traumatic days following the release of the video, the Dimtsachin Yisema page remained highly disciplined, never abandoned its dialogic and constructive type of criticism, and refused to take advantage of the events to score political points against the government. 
Posts and comments on all of the pages were overwhelmingly going towards (more than 80\%). Jawar Mohammed posted a slightly higher than average number of statements going against, although still a small percentage compared to his statements going towards.

A slightly different picture emerges, however, if we analyze the comments, among which the percentage of statements going against is significantly higher. The followers of the Semayawi Party produced, on average, the highest percentage of statements going against, although for them, as for the followers of the other five pages, statements going towards remain by and large the dominant type of statement. Posts on Muslim-Christian engagement were proportionally higher on Dimtsachin Yisema, in tune with the engaging nature of the page's posts. Political antagonism was primarily targeted against the government, particularly in spaces with an explicit anti-government orientation such as Jawar Mohammed's. Anti-EPRDF feelings dominated statements going against on Tedros Adhanom's page, showing how the government's track record and actions were challenged in the comments. Political antagonism was more diversified on Daniel Berhane's space, where statements going against targeted the opposition as well as the government, and on the page of the Semayawi Party, where many of the comments criticized the party itself and the opposition in general.

\section{FIGURE 40: TYPES OF POSTS}

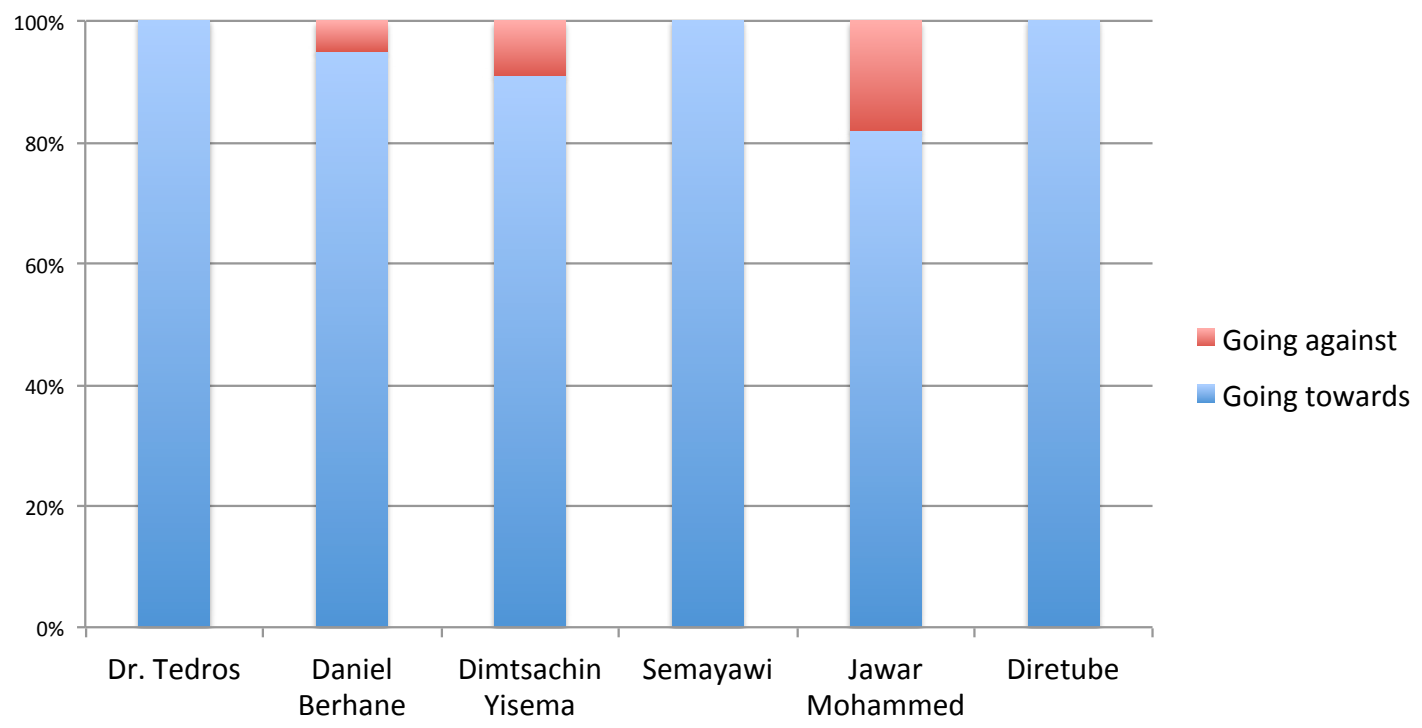

FIGURE 41: TYPES OF COMMENTS

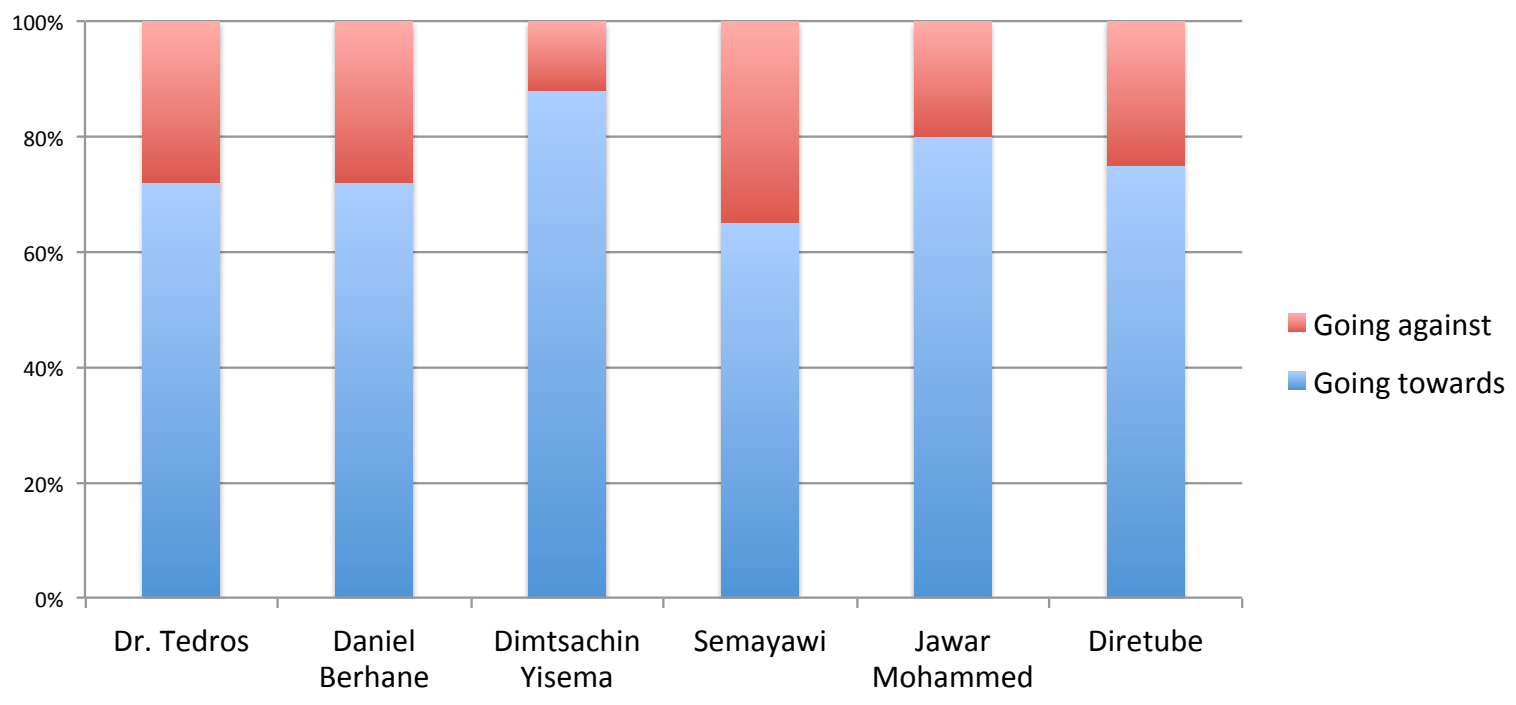


Religious antagonism, perhaps surprisingly considering how the ISIL events had a strong religious connotation, was extremely limited, with only three statements out of 261 antagonizing Muslims. Most going towards statements with a religious theme were found onDimtsachinYisema'spage. Thisengagement came from Christians, directed at Muslims and, even more frequently, from Muslims, directed at Christians. Daniel Berhane's page emerged as a second significant forum for interreligious engagement, mostly from Christians towards Muslims.

\section{FIGURE 42: MUSLIM-CHRISTIAN ENGAGEMENT}

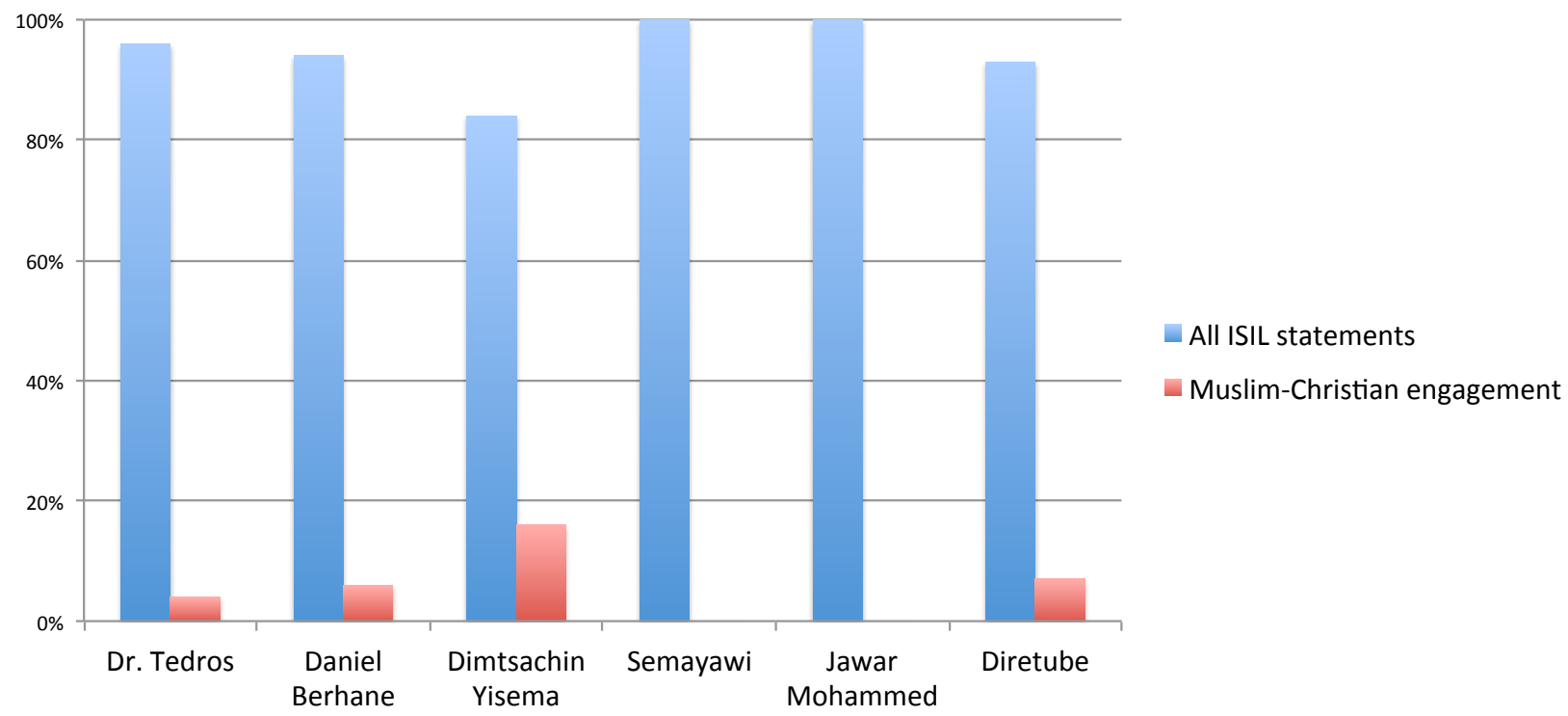

The majority of followers of Tedros Adhanom's page produced statements going towards the EPRDF, with only a very small percentage of statements going towards the opposition. The situation was more varied on the Semayawi
Party's page, where statements going towards the party prevailed, but the page followers also kept producing statements going towards the government.

\section{FIGURE 43: GOING TOWARDS WHOM}

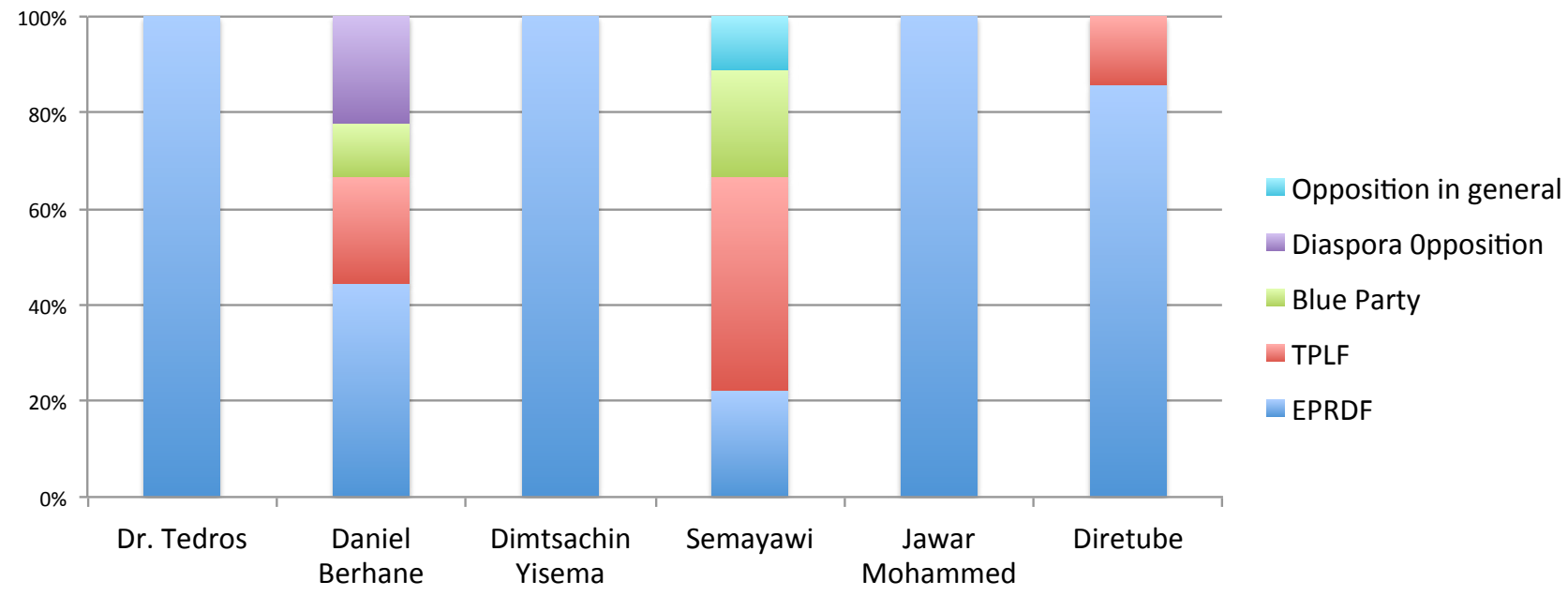




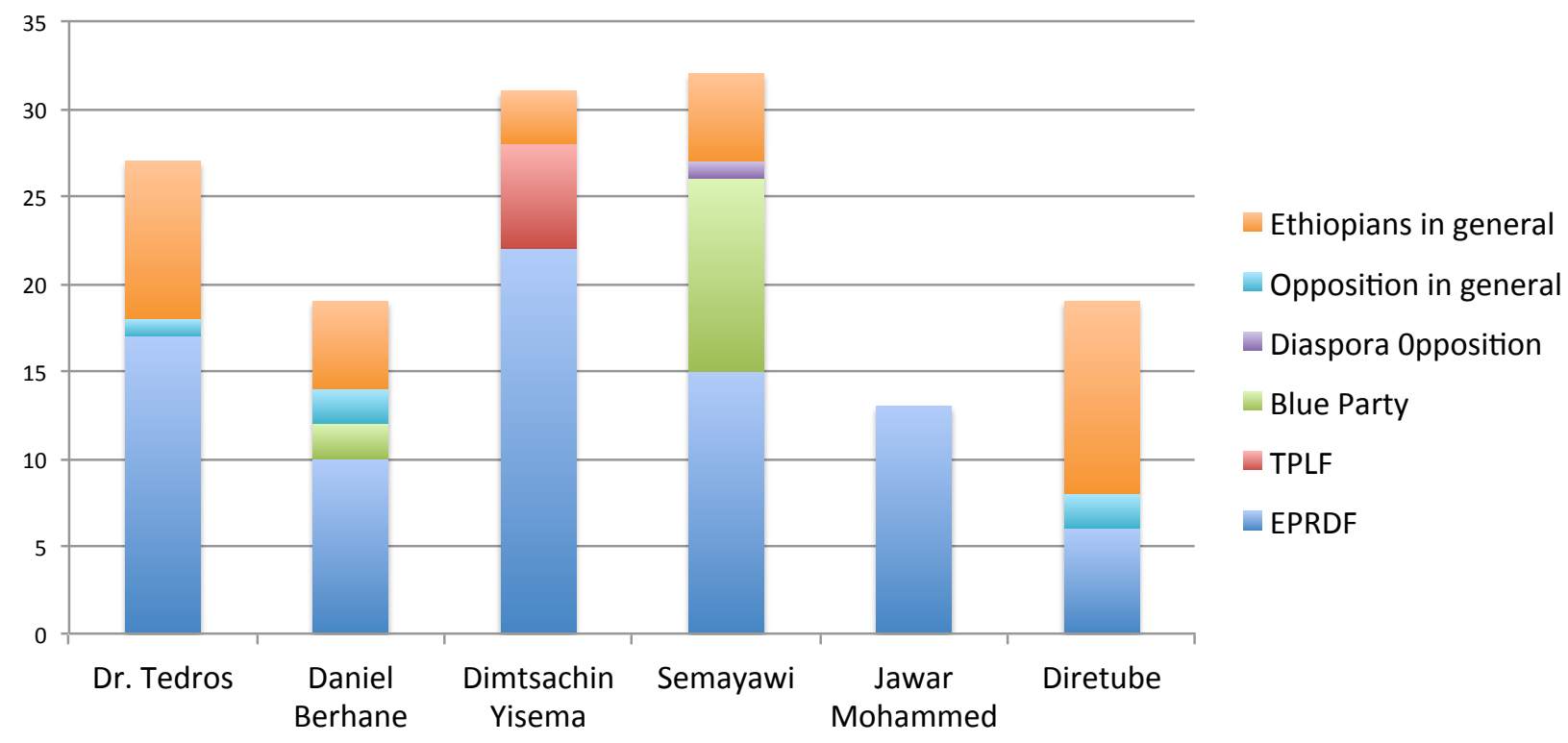

In general, as can be seen from the analysis, the events that unfolded after the killings of Ethiopians in Libya displayed a significant variation in the type of interactions normally encountered in the six spaces analyzed. On the one hand, the level of antagonism decreased during these events while the number of statements going towards increased. On the other hand, the type or the target of the latter form of engagement also changed. Most notably, many statements were directed to "All Ethiopians" and displayed high levels of inter-religious engagement across the Christian and Muslim communities. While statements going against followed a general anti-government trend across the six pages, statements going towards had more diversified trajectories. In the general climate of Pan-Ethiopian solidarity following the ISIL events, statements going towards "Ethiopians in general" or "All Ethiopians" also occupied a significant amount of the total engagement. Even more than on other pages, this was the case with Diretube, a non-explicitly politicized page with an extremely broad and varied fan base. One explanation for this is that such events seem to transcend some of the ethnic and political divisions in Ethiopia by bringing people together when faced with a common tragedy. They provide spaces where engagement across divides is the highest and can mend - however temporarily - some of the rifts that exist between online communities in Ethiopia and more broadly in its diaspora. 


\section{ETHIOPIA'S \\ 2015 ELECTIONS}




\section{ONLINE PARTICIPATION IN THE 2015 ELECTIONS}

The general elections of 2015, the fifth since the formation of the Federal Democratic Republic of Ethiopia in 1995, were held on 24 May to elect members for the House of Peoples' Representatives (the lower house of the Ethiopian parliament) and regional councils. Over 6000 candidates were registered by 58 parties. Only a few parties and coalitions, however, dominated political discourses both online and offline: the incumbent Ethiopian People's Revolutionary Democratic Front (EPRDF), the Ethiopia Federal Democratic Unity Forum ("Medrek" in Amharic, a coalition of regional parties such as the Oromo Federalist Congress and Arena-Tigray), the Blue Party ("Semayawi Party" in Amharic), Unity for Democracy and Justice (UDJ, "Andinet" in Amharic), and the Ethiopian Democratic Party (EPD).

Most national and international commentators referred to the elections as "suspenseless", and expectations were low that voting could bring any significant change in power. $^{17}$ Despite this seeming indifference to the voting process, in the period covered by the research (from 24 February, three months before the voting day, to 24 June, one month after), the elections were widely discussed across social media. An average of $11 \%$ of statements in our general sample focused on the electoral context. Election-themed speech gathered momentum in the weeks leading up to voting day, with the largest number of statements registered during this period. Interest in election-related issues also remained relatively strong in the month after the vote, due to the fact that official results were announced a month after voting, and as a response to the allegations of post-election violence.

The elections were the most widely discussed topic in the six dynamic spaces regularly followed by the research. This finding is even more significant if we consider that, as explained in the previous chapter, each space tended to focus on relatively distinct sets of topics and events, and issues discussed across spaces were very limited.

\section{TABLE 3: PREVALENCE OF ELECTION-THEMED STATEMENTS ON ETHIOPIAN FACEBOOK}
MONTH
DATES
GENERAL SAMPLE TREND SAMPLE

\begin{tabular}{l|l|l|l}
\hline $\mathbf{1}$ & 24 February- 24 March & $6 \%$ & $14 \%$ \\
\hline $\mathbf{2}$ & 25 March- 24 April & $3 \%$ & $13 \%$ \\
\hline $\mathbf{3}$ & 25 April-24 May & $17 \%$ & $36 \%$ \\
\hline $\mathbf{4}$ & 25 May-24 June & $8 \%$ & $26 \%$ \\
\hline & Average & $\mathbf{1 1 \%}$ & $\mathbf{2 2 \%}$
\end{tabular}


TABLE 4: KEY FACEBOOK PAGES DURING THE ELECTIONS

\begin{tabular}{l|l|l|l}
\hline FB PAGE & Election 2007 & $\begin{array}{l}\text { m i r c h a . o r g } \\
\text { \#Election2015 }\end{array}$ & Ethiopian Election Watch \\
\hline AIM & $\begin{array}{l}\text { Facilitating the } \\
\text { electoral process, } \\
\text { promoting the } \\
\text { elections as peaceful } \\
\text { and fair }\end{array}$ & $\begin{array}{l}\text { Documenting } \\
\text { the electoral } \\
\text { process and } \\
\text { denouncing } \\
\text { biases in } \\
\text { electoral } \\
\text { procedures }\end{array}$ & Initiating ideas for discussion \\
\hline MOTTO & $\begin{array}{l}\text { Vote for a better } \\
\text { Ethiopia }\end{array}$ & $\begin{array}{l}\text { Election Beyond } \\
\text { Results }\end{array}$ & $\begin{array}{l}\text { Defending freedom of } \\
\text { expression and information }\end{array}$ \\
\hline FOLLOWERS & $\begin{array}{l}7,549 \\
12,786\end{array}$ & 428 \\
\hline ADMIN & $\begin{array}{l}\text { Anonymous } \\
\text { Government-affiliated } \\
\text { bloggers }\end{array}$ & $\begin{array}{l}\text { Exiled Zone9 } \\
\text { members and } \\
\text { supporters }\end{array}$ & Anonymous \\
\hline BLOG LINK & - & Mircha.org & eajournalistdefencenetwork.org \\
\hline
\end{tabular}

EXAMPLE OF STATEMENT ABOUT ELECTIONS

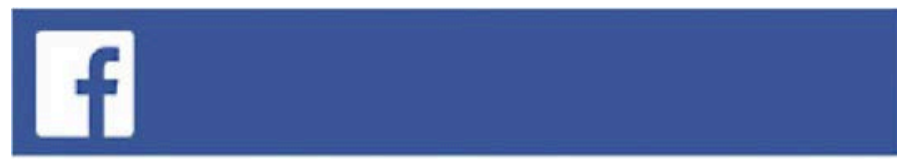

Timeline Photos

Back to Abum - Eloction 2007 ifcas 2007/s Photos - Eloction 2007 irces 2007/s Page

07・7・\% poqmnt hChcer !!

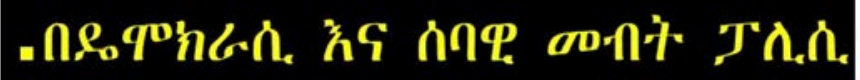

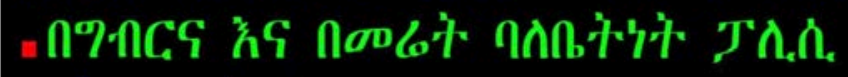

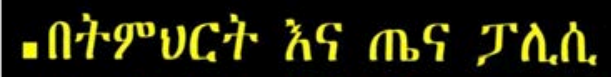

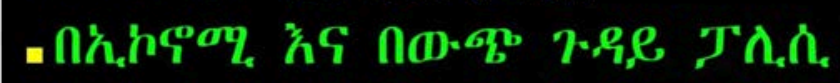

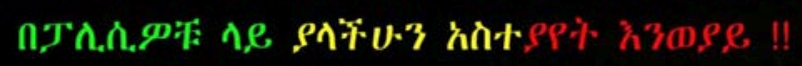

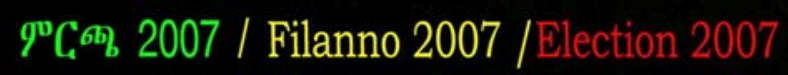

TRANSLATION

We call on you to share your opinions with us.

We expect better public participation in the 2015 election than was the case in the 2010 election. Let us all urge all eligible citizens to take part in the elections. Free, fair and peaceful election in May 2015." 
These pages, with their focus on the voting process, appeared to give significant political weight to the elections. A considerable part of the electorate, however, disagreed with this perspective. Many pointed out, often adopting a cynical or sarcastic tone, that the outcome of the elections had already been decided in advance, and as such, the elections did not deserve further attention or discussion.

\section{EXAMPLE OF CYNICAL OR SARCASTIC TONE ABOUT ELECTIONS}

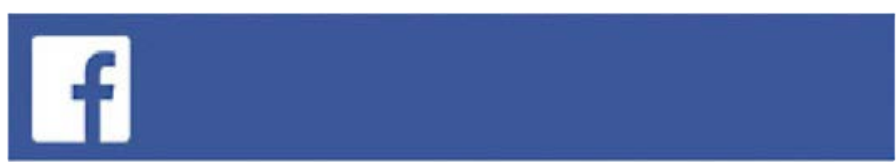

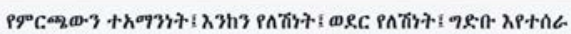

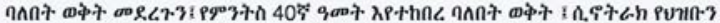

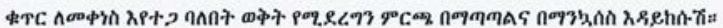
See Translation

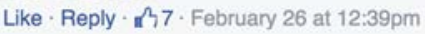

\section{$66_{\text {TRAnsLation }}$}

Beware lest they accuse you of belittling and defaming an election when a lot is being done to make the election credible, faultless and unrivalled; when the dam is being constructed; when something's [i.e. TPLF's] 40th anniversary is being celebrated; and when sinotruk is working hard to reduce the population size." 


\section{THE SOCIAL MEDIA STRATEGY OF ETHIOPIA'S MAIN PARTIES}

All the main parties recognized social media as an important new space for electoral politics, but we identified significant variations in the ways in which each of them made use of social media in combination with other, more traditional and widely tested strategies.

Interviews conducted with members of the EPRDF showed, for example, an advanced social media strategy, and an awareness of the growing importance of social media in informing electoral debates. Social media management for the EPRDF is part of a complex and well-staffed structure organized at a directorate level.

There is a commitment at a party level to use the social media. There are reasons to making this decision. First, the social media, on its own, is a new opportunity. Second, if we do not use it, because others use it, it would be a threat. In order to reduce the threat, there is a commitment to use the social media."

An interview with a representative of the Semayawi Party similarly highlighted the centrality of Facebook in the party's electoral communication strategy, but in a rather more proactive way. For the Semayawi Party, social media did not simply represent a space to occupy in order to prevent others from gaining a prominent position on it, but an unprecedented opportunity to communicate with their electorate in a space where other media were unable to offer a strong enough platform for political engagement.

\section{6}

Because there are no independent media, it is our website and Facebook page that clearly carries our ideas. Mostly our ideas are expressed on that. Though it is not being published, there is a [newspaper] called Negere Ethiopia. Negere Ethiopia is our press. Journalists still do it online. There is also a Facebook page titled Negere Ethiopia. They work on that actively. Therefore, given the media situation, Facebook is more preferable, currently. Printing and distributing brochures and pamphlets is difficult. Not the printing, but you cannot give it out to people easily.

In that regard, the main objective would be to provide information for people, who have no knowledge of parties owing to lack of media. There is a complaint regarding not moving with the times, not updating oneself and being stuck in the old generation. By the way, we opened the Facebook page during the establishment of the party. So things developed together [with our presence on social media]. The objective is to communicate the society that lives in fear and that lacks information.

The party [also] gets information from Facebook; verify that on its own way; it may bring it back as an agenda; and there are times when it uses Facebook to mobilize people. It serves as a source of information and helps to set agenda. Above all, it makes the party always engaged with its supporters and members, and overall with those concerned about politics" 
However, when we compare the stated commitment of the ruling party and of the opposition towards using social media with the actual use politicians made of Facebook during the campaign, a more nuanced picture emerges. The EPRDF's use of Facebook for mobilization of supporters did not reflect the intensity of the party's ambitious grassroots mobilization strategy. As Figure 45 indicates, although opposition politicians represented a far smaller proportion of candidates in the electoral contest, they were significantly more active online than government politicians. ${ }^{19}$ The number of posts by EPRDF on the election issue for the entire period was considerably lower than those by opposition parties such as the Semayawi party. On top of this, government politicans and government-affiliated pages rarely interacted with their fans. The only exception was Alula Solomon, an influential government-affiliated commentator, who always maintained a dialogic and interactive attitude towards his followers.

\section{FIGURE 45: WHO WERE THE SPEAKERS IN THE ELECTIONS SAMPLE}
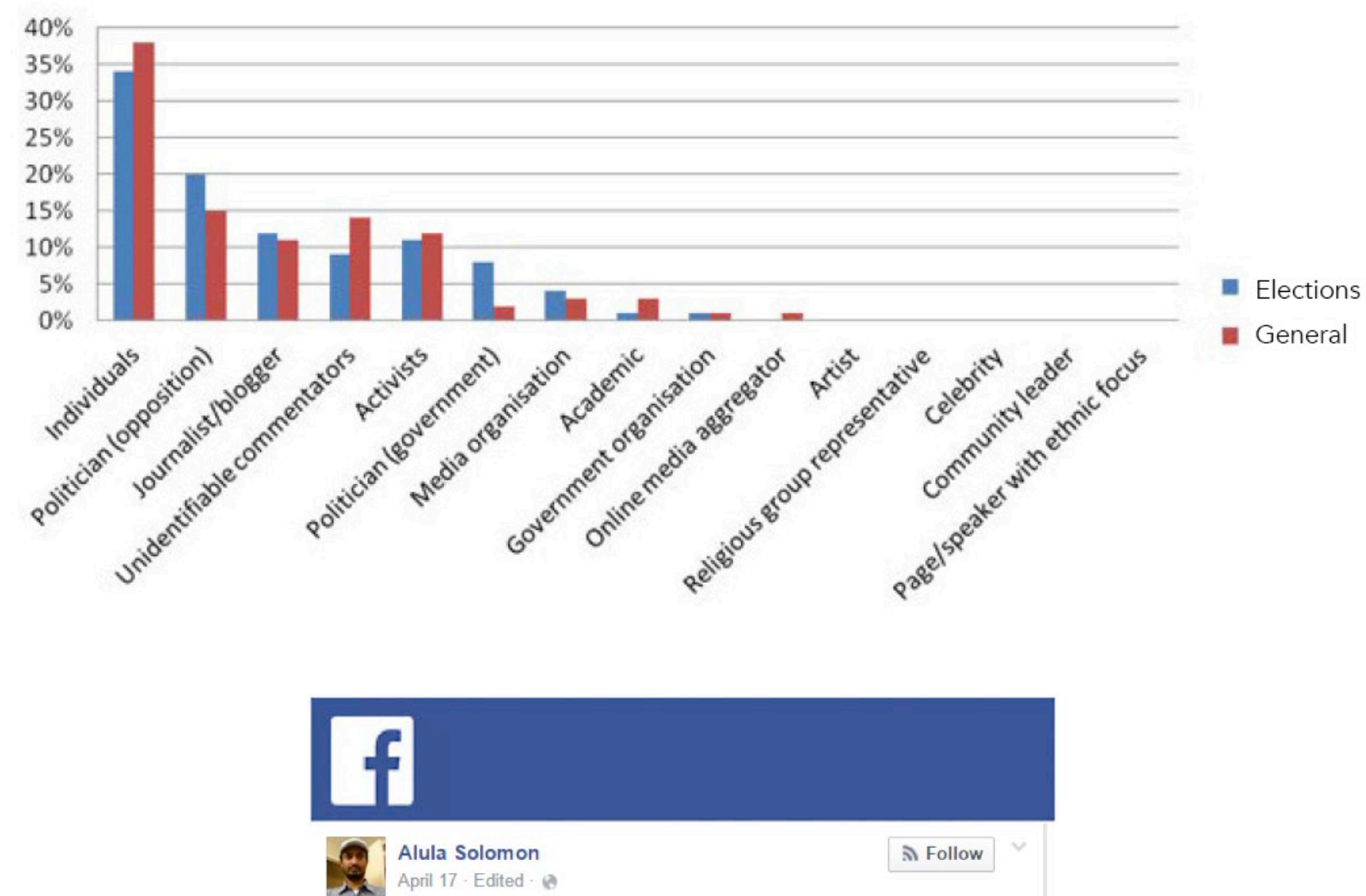

S Follow

A short convo between two Americans following U.S under secretary Ms. Sherman's declaration of Gim-boat 7 as a terrorist group

Matt Payne-Funk (the King-maker): What do you make of this endorsement by the United States that \#Ethiopia's elections are "free, fair, and credible"? Is the United States selling its soul to the devil for the sake of good relations?

Terry Lapierre: are our elections free, fair and credible?

Matt: compared to Ethiopia's elections much more so.

*Me: How old is American democracy, Matt?

$$
\text { itu Like Comment } \Rightarrow \text { Share }
$$


As a workshop participant suggested after reviewing this data, the discrepancy between commitments and reality within the EPRDF may be ascribed to the bureaucratic culture that dominates the party. The effort to make greater use of social media has encountered resistance on the part of party members who tend to maintain a low profile and are generally risk-averse and group-oriented.

While the EPRDF and its affiliates could rely on a strong and long-established network reaching down to the grassroots, opposition parties, particularly newly-established ones, had to rely more heavily on other means to gain support, hence for them social media acquired a particular importance. According to information posted on the website of the NEBE, almost $50 \%$ of the government's financial subsidy for election purposes went to the EPRDF, a figure 7 and 18 times larger than the subsidies given to the Medrek and Semayawi parties respectively. ${ }^{20}$ Similarly, the formula applied to allocate national radio airtime and column space in the government press to parties for election campaigning was largely based on the number of seats in the existing federal and regional parliaments, as well as the number of candidates a party fielded. Both of these factors gave the EPRDF substantially more space for election-related speech. ${ }^{21}$ Given that the EPRDF received the most significant percentage of the NEBE's campaign funding, most opposition parties could not afford campaign aids and social media experts to run their Facebook pages. The only exception was the Semayawi Party, which managed to attract 42 million birr, ${ }^{22}$ mostly from the diaspora, and had the resources to set up a proactive public relations team.

This suggests that social media, and Facebook in particular, went some way to redressing this imbalance of resources by offering both the public and the opposition an alternative medium in which to campaign and express their views. It therefore acted as a 'leveller' of existing inequalities in access to media outlets and campaign resources.

As the next sections will highlight, posts by the opposition received higher levels of positive responses compared to posts by the government, indicating that opposition sympathizers also gravitated towards Facebook as a way of expressing their opinion on the elections.

\section{$f$}

Daniel Berhane
March $19 \cdot 8$

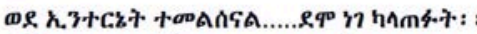

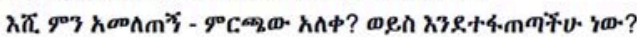

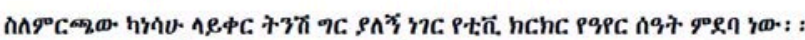

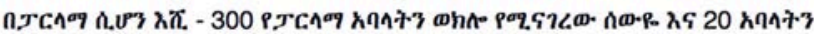
whก- pozราL

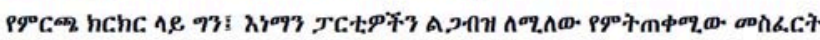

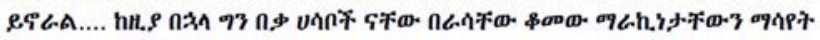

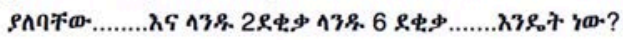

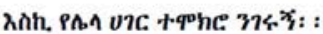

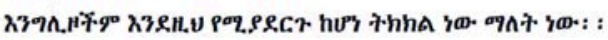

71 Likes 34 Comments

\section{TRANSLATION}

Back to the Internet... unless they switch it off tomorrow. So, what did I miss - is the election over? Or are you still locked?

Talking of the elections, I am a bit confused about the sharing of airtime for the TV debate. In parliament it is ok; after all someone representing 300 members of parliament and another talking on behalf of 20 members cannot be given equal time.

But, in election debates you may have criteria who to invite or not. After that it should be the ideas themselves which show their attractiveness... so how come one is given 2 minutes while the other is given 6? Please tell me of other countries' experiences." 


\section{THE ELECTORAL PLATFORMS OF FACEBOOK}

In previous electoral contests, electoral debates revolved around the structure of ethnic federalism and the role of the constitution. However, these themes remained largely absent from the 2015 campaign. Policy issues in general were seldom discussed, and foreign politics also received little attention. The range of topics discussed by Ethiopian parties and politicians remained, overall, very limited. Both the government and the opposition chose targeted and narrow electoral platforms, concentrating their campaigns on a few general themes, often discussed in vague and nondescript ways.

\section{EPRDF}

The EPRDF centred its campaign almost exclusively on developmental messages. Communication focused on publicizing Ethiopia's development gains, economic

\section{$f$}

A) EPRDF official

April $7 \cdot(8)$

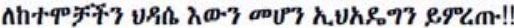

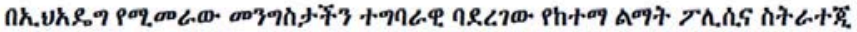

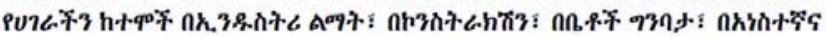

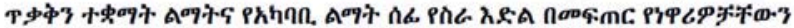
tag.

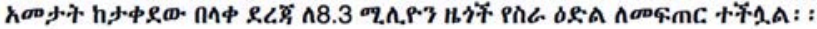

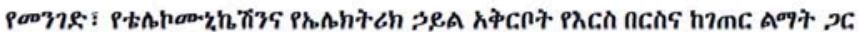

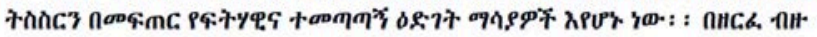

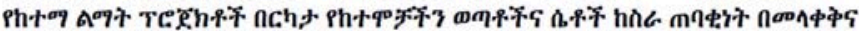

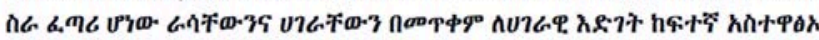

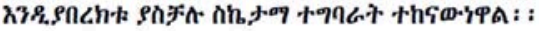

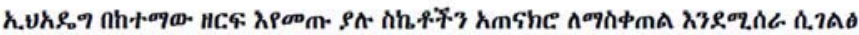

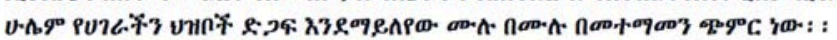

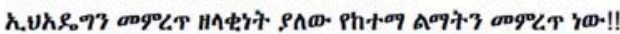

89 Likes 14 Comments 67 Shares

Like Comment growth and accomplishments in infrastructural development. In general, EPRDF pages listed the substantial positive changes Ethiopia achieved under EPRDF rule, drawing the audience's attention to the improved economic situation many citizens had been able to enjoy. The emphasis was on the role of the state in providing such gains, even if at times this strategy challenged the orthodoxy of Western donor countries or international organizations. The campaign was therefore rather past-oriented, without a new vxision for the future or a new set of policies for the years to come. Domestic issues that attracted the attention of Ethiopian Facebook users in other online spaces were not taken up by the EPRDF official page or by the pages of EPRDF politicians. Similarly, the owners of EPRDF-affiliated pages showed low levels of interaction with their online followers. This approach was first articulated by Meles Zenawi, who advocated for Ethiopia a 'unity of vision' whereby once the party decides on a policy path it has to get the rest of the country on board without continued deliberation. The post below illustrates this approach.

TRANSLATION

Vote EPRDF for the renaissance of our cities!! Due to the urban policy and strategy of our EPRDF-led government, our cities have been creating job opportunities in industrial development, housing construction, and micro enterprises that benefit residents. In the last four growth and transformation years jobs were created for 8.3 million citizens which exceeded the planned target. Road, telecommunication and electric supply are being integrated with rural development, and are becoming symbols of just and balanced development. Plenty of our cities' youth and women transformed from job seekers to creators helping support themselves and highly contributing greatly to national growth thanks to multipurpose urban development projects. When EPRDF pledges to continue the success stories in the urban sector with extra reinforcement, it is with full confidence in our country's people's support. Voting EPRDF is choosing sustainable urban development." 
Only $9 \%$ of statements by government politicians or government-affiliated pages were antagonistic, and no antagonistic statements were produced by the official Facebook page of the EPRDF. While the tone and attitude of the statements going towards is quite varied, some being informative, others supportive or critical, a good $41 \%$ encouraged the audience to vote for a specific party - in this case the EPRDF or other government-affiliated parties. More than half of government statements received a positive response from the audience (53\%), while only

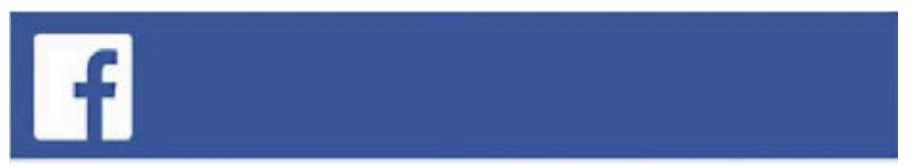

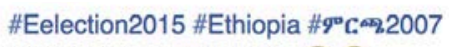

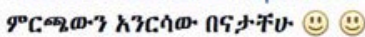

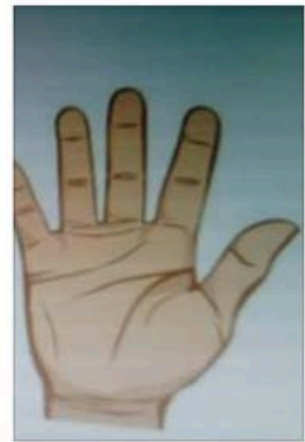

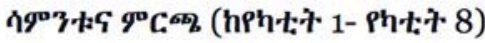

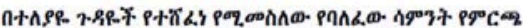

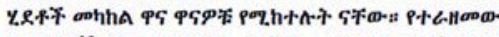

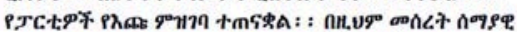

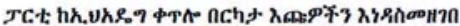

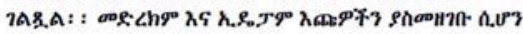

14 Likes 8 Comments

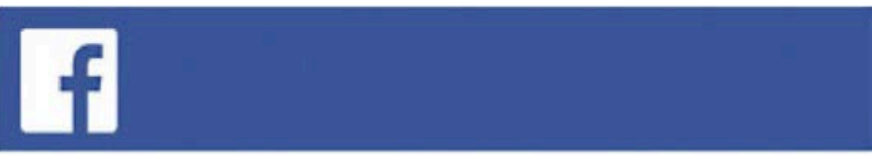

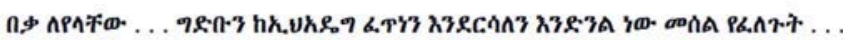
(1)

https://www.facebook.com/semayawiethio/posts/888671191175480 \#election2015 \#Ethiopia \#change \#freedom \#semayawi

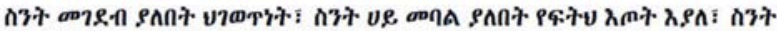

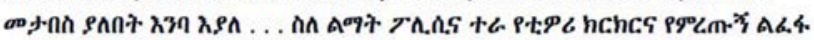

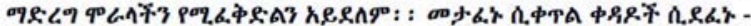

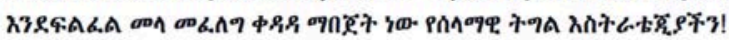

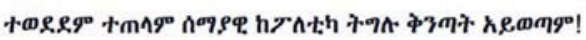
XรF?4.n3!

32 Likes 6 Comments 1 Share a few received a negative response (8\%). In terms of antagonistic calls to action, there is only one statement out of six which calls for the audience to discriminate.

The EPRDF campaign was criticized by Facebook users for its low interactivity with online users, and for the tendency to broadcast news in a top-down fashion, without engaging voters in conversation. The party's exclusive focus on developmental issues also received criticism.

\section{TRANSLATION}

"For your mother's sake let us not forget there is an election. Apparently it is only us (mirch.org bloggers) and EPRDF who won't let free the election hahaha (sarcasm)."
66

\section{TRANSLATION}

"... I guess they want us to promise ending the dam ahead of EPRDF in our campaign. \#election2015 \#Ethiopia \#change \#freedom

While there is enough injustice that needs be called a stop to, while there are enough tears to be wiped away...our moral conscience does not allow us to debate on development policy and other silly theories or empty promises. As the political space continues to narrow and oppressions resume, our peaceful struggle strategy is to find scheme, search holes like Mole. Like it or not Blue Party will not go out of the political struggle even for a moment.

We will win 


\section{THE OPPOSITION}

The opposition was less organized on the ground and without access to a country-wide network as developed as EPRDF's, attempted to compensate with a strong online presence. The opposition's electoral campaign focused almost exclusively on denouncing government harassment against opposition politicians, and the increasing restrictions on political and civil liberties. The instances where policy issues were discussed remained very few, and only

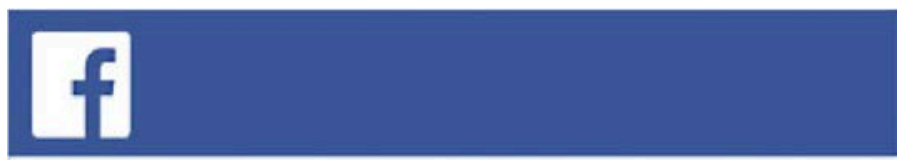

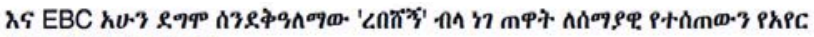

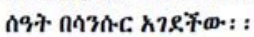

\#election2015 \#Ethiopia \#change \#semayawi

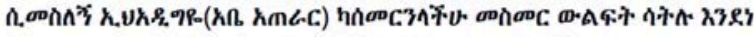
'Tட.9 $T^{\prime}$ ' ते.,.P.

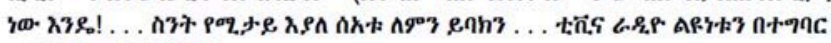

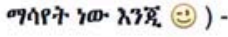

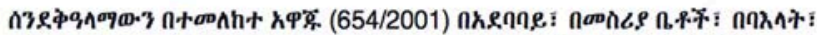

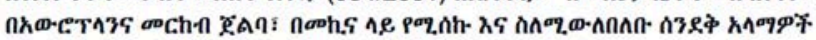

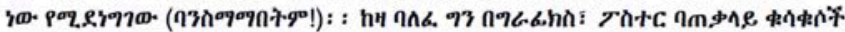

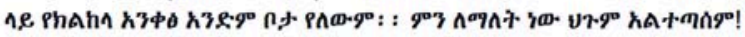

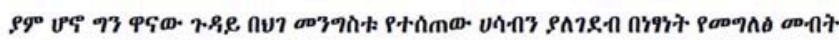

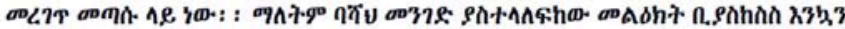

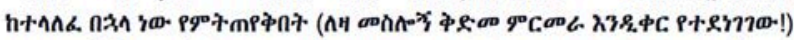

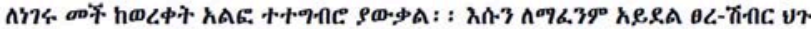

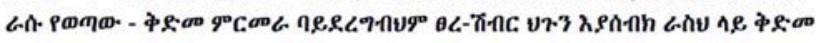

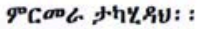

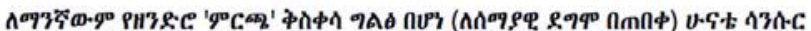

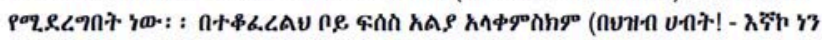

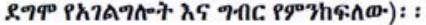

29 Likes 8 Comments 3 Shares. on rare occasions did opposition parties and politicians present programs and proposals. Opposition-affiliated pages repeatedly accused the EPRDF, and sometimes the NEBE, of foul play in the electoral process, from curbing the opposition's freedom to campaign, to vote-rigging in the aftermath of the elections. Pleas for sympathy for the victims of government persecution were common.

\section{6}

\section{TRANSLATION}

"...EBC refused for the 6th time to broadcast Blue Party's campaign message under the pretext of not using the official flag. The proclamation does not say anything about banning of non-official flags on graphics and posters. In addition, if we break the law, let us take responsibility. However, pre-censorship is what is being practised in this election period (in a much tougher way for Blue Party). As a matter of fact the anti-terrorism law is drafted so that we can impose self-censorship, thinking about the consequence in our mind." 


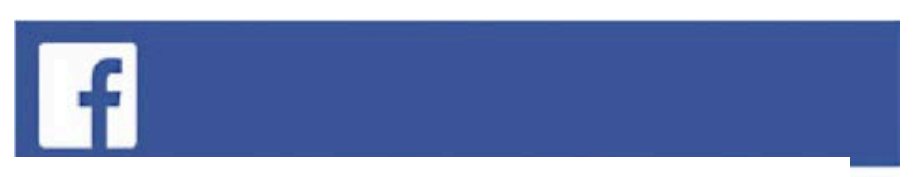

9LG-ane:Ch 9ాLn::

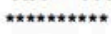

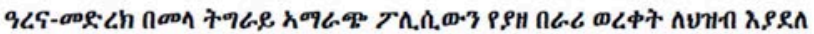

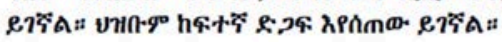

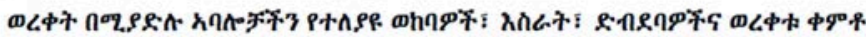

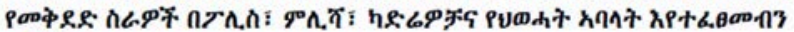
อารัด:

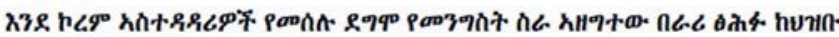

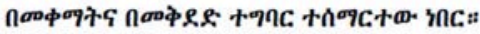

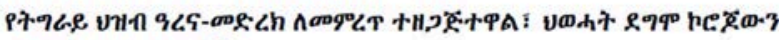

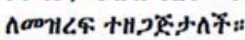

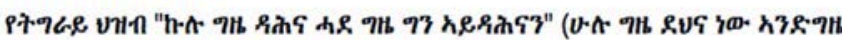

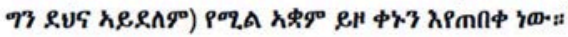

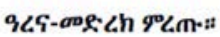

IT IS SO..!

\section{TRANSLATION}

"Vote for Arena-Medrek.

Arena-Medrek is distributing leaflets about its alternative policy throughout Tigrai. The people are showing much support. Our members who distribute the leaflets are being harassed, imprisoned, and beaten and the papers destroyed by police, militia, cadres and TPLF members. Those administrators of Korem stopped government work to engage in snatching and destroying leaflets. While the people of Tigrai are prepared to vote Arena-Tigray, the TPLF is getting ready to steal the ballot box. The Tigrai people are waiting for the day while holding their view that all days are good but some may not be."

of statements by opposition-affiliated pages received a positive response, a percentage significantly higher than for statements by government-affiliated pages. This suggests that Facebook tended to gravitate towards the opposition, with opposition supporters much more active on social media than government supporters.

Criticism against the opposition's campaign, coming both from rivals and sympathizers, centred on the lack of an articulated and coherent political line. More than proposing an alternative political vision to that offered by the government, the opposition's campaign asked Ethiopians, more reductively, to cast a protest vote against the government. 


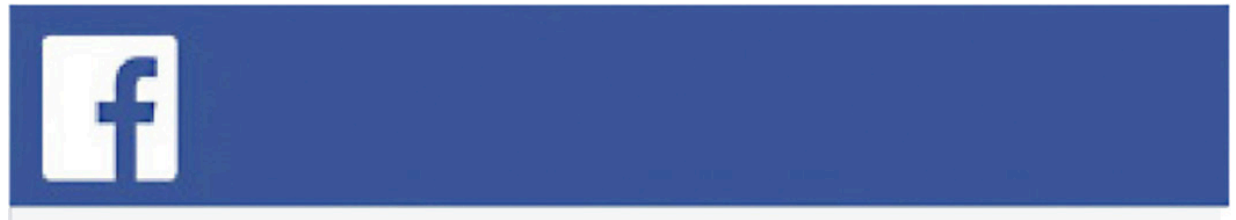

$\geqslant$ I think most opposition groups also forgot to show us what they would do differently if they get elected.All I saw was their hate towards EPRDF and that doesn't look like a solid platform to run a country for five years.

Like $\cdot$ Reply $\cdot 凸 2 \cdot$ May 23 at 8:01pm

\title{
EXAMPLE OF STATEMENT OF CRITICISM FROM A GOVERNMENT SYMPHATHIZER
}

\begin{abstract}
If (when) the oppositions lose this election again for EPRDF, I am going to blame their social media activists. Instead of spitting filth of hate $24 / 7$ instead of convincing people why they are better than the ruling party, show their strategies of for a better Ethiopia, all the ruling party supporters would have lines along side them. - hrn hahe
\end{abstract}

50 Likes 9 Comments 1 Share

\section{SOCIAL MEDIA USERS}

A few reflections on the behavior of social media users more generally, including both identifiable and unidentifiable commentators, help to put the use of social media by political parties in context. Once again, statements going towards are more prevalent than statements going against $168 \%$ and $31 \%$ respectively), but members of the public tend to discuss the elections in a more antagonistic way than politicians. Both statements going against and statements going towards are primarily directed at the EPRDF and/or TPLF, demonstrating that, in line with expectations, the government remains at the core of the electorate's concerns. Members of the general public are least likely to make calls to action compared to politicians, as $60 \%$ of statements lack such a call. Members of the general public encourage others to vote for a specific party in $18 \%$ of cases, similar to politicians in the opposition (18\%), and significantly less than government politicians (41\%), probably reflecting an awareness, on the part of individual users, of their lack of influence on the online community. However, in terms of antagonistic calls to action, members of the general public are more vocal than politicians. $29 \%$ of the statements going against uttered by individuals or unidentifiable commentators make a call to action, compared to only $17 \%$ by government politicians and $18 \%$ by opposition politicians. 


\section{ELECTION-THEMED SPEECH AND ONLINE COMMUNITIES}

Social network analysis ${ }^{23}$ shows the existence of separate and self-contained online communities. Online political communities are not necessarily divided by political affiliation, therefore it would be misleading to talk about 'echo-chambers' for the Ethiopian online sphere. Individuals do not tend to interact with all pages belonging to a certain political line, but to concentrate their time online on a single page of their choice. Users, in other words, tend to coalesce around individual pages, rather than dividing their time between all the pages representing their own political line.

\section{FIGURE 46: ELECTIONS: ELECTION-THEMED COMMUNITIES}

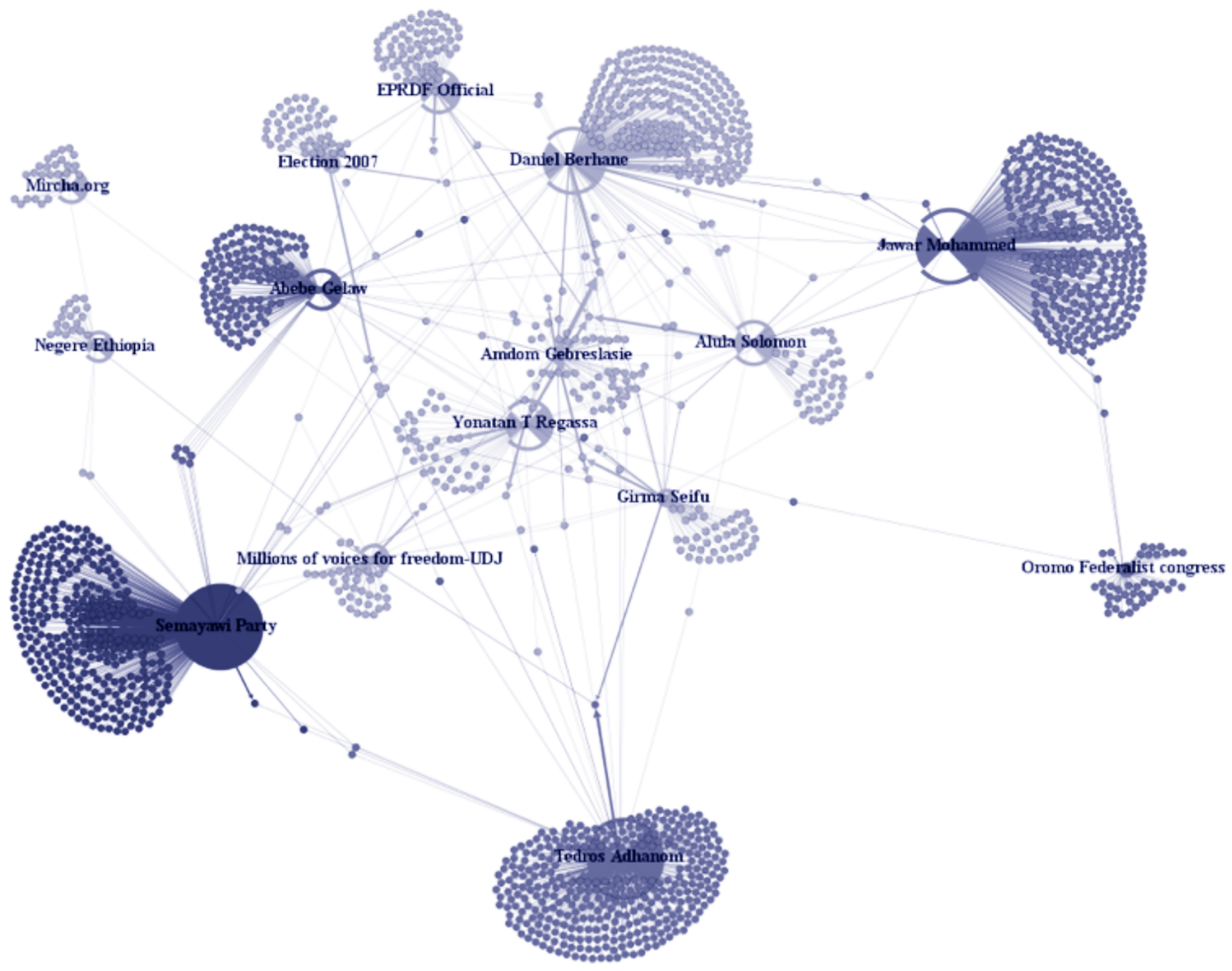


The analysis reveals seven loosely identifiable clusters of pages, i.e. groups of pages that users are likely to follow and interact with at the same time.

\section{- The Semayawi Party}

- Dr. Tedros Adhanom

- Mircha.org + Negere Ethiopia + Millions of Voices for freedom + Girma Seifu (cluster representing anti-government and unionist views, close to those of UDJ/ Andinet)

- EPRDF Official + Daniel Birhane+ Alula Solomon + Amdom Gebresilasie(Arena) + Yonatan T Regassa (cluster of pages, most of them run by influential individuals, where the debate is articulate, analytical and informed)

\section{- Election 2007}

- Jawar Mohammed + OFC (cluster dedicated to Oromo politics)

\section{- Abebe Gellaw}

Although some clusters can be linked to a specific ethnic or political position (e.g. Oromo nationalism), there is no direct correlation between political parties and clusters. A follower of the EPRDF page, for example, is statistically more likely to comment on the page of Yonatan $T$ Regassa than on the page of Tedros Adhanom. However, in general, there is little interaction between followers of parties belonging to different ends of the political spectrum. Among the pages analyzed, inter-camp statements going towards or going against are is rare. There are nevertheless a few speakers, usually journalists or activists such as Daniel Berhane, that act as bridges between these communities, and whose followers are more likely to comment on pages belonging to different ethnic and political affiliations. 


\section{GOING AGAINST AND GOING TOWARDS}

Over the four months of research, the number of statements going towards and going against about the elections remained roughly the same. This points to the general stability of Ethiopian Facebook discourse, largely dominated by comments going towards. It also suggests that the election, despite being one of the most high-profile national events in the time frame researched, did not have a significant impact in generating more of one kind of speech than usual. From the perspective of Facebook pages, the elections were a 'weak' event, unable to shift the general contours of Ethiopian online debates. They did generate interest, but the discussions surrounding the elections were not qualitatively different, in terms of tone and communicative attitude, from the usual Facebook discussions among Ethiopians.

\section{FIGURE 47: TYPE OF STATEMENTS IN THE ELECTION SAMPLE}

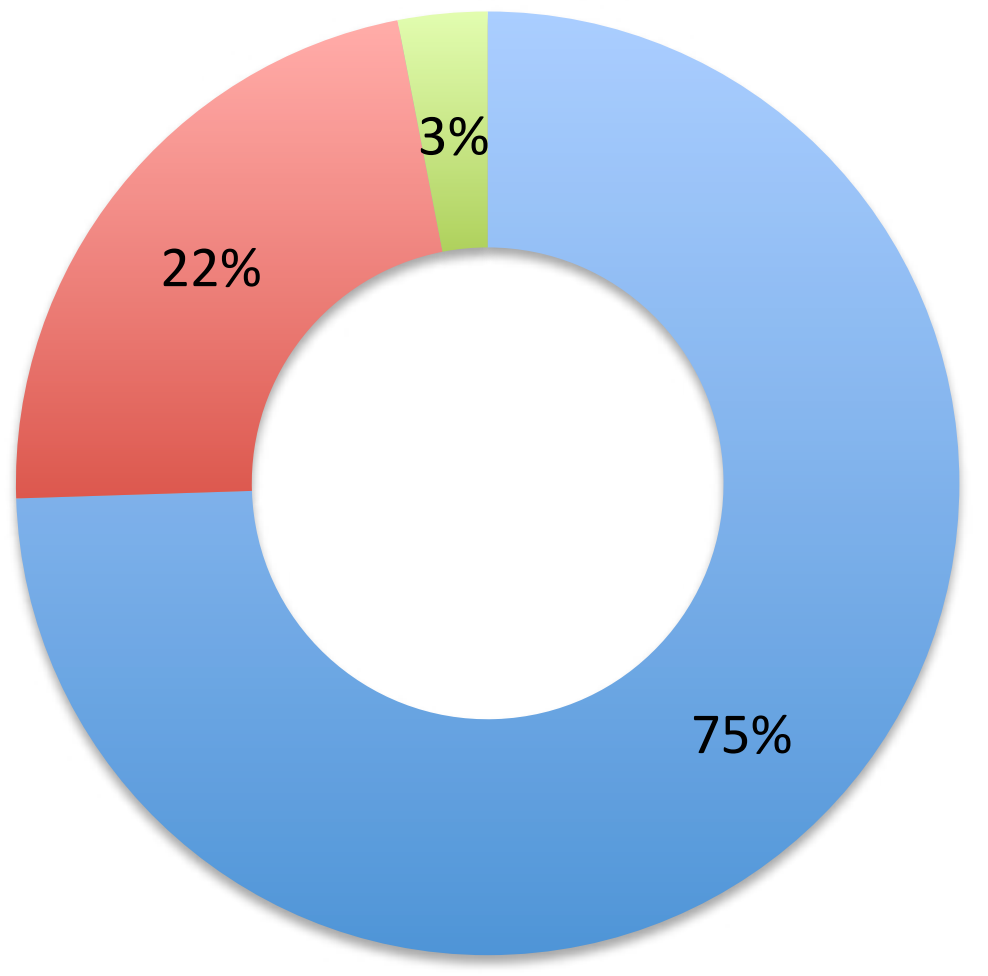

Going towards

Going against

Other 


\section{GOING AGAINST}

Although in the election sample the proportion of statements going against and going towards remained fairly stable, a breakdown of the two categories reveals minor, but nevertheless significant trends. In particular, as the elections were approaching, online debates became both more articulate and more militant, with an increase in the proportion of calls to action. As Figure 48 below shows, antagonism progressively became more articulated. In May, the month of the elections, calls to violence increased compared with April, while calls for nonviolent actions increased after the elections in June. In June there was also a significant increase in the number of rumours and deliberately misleading and one-sided information unsupported by evidence.

\section{FIGURE 48: ANTAGONISTIC CALLS TO ACTION IN ELECTION SPEECH}

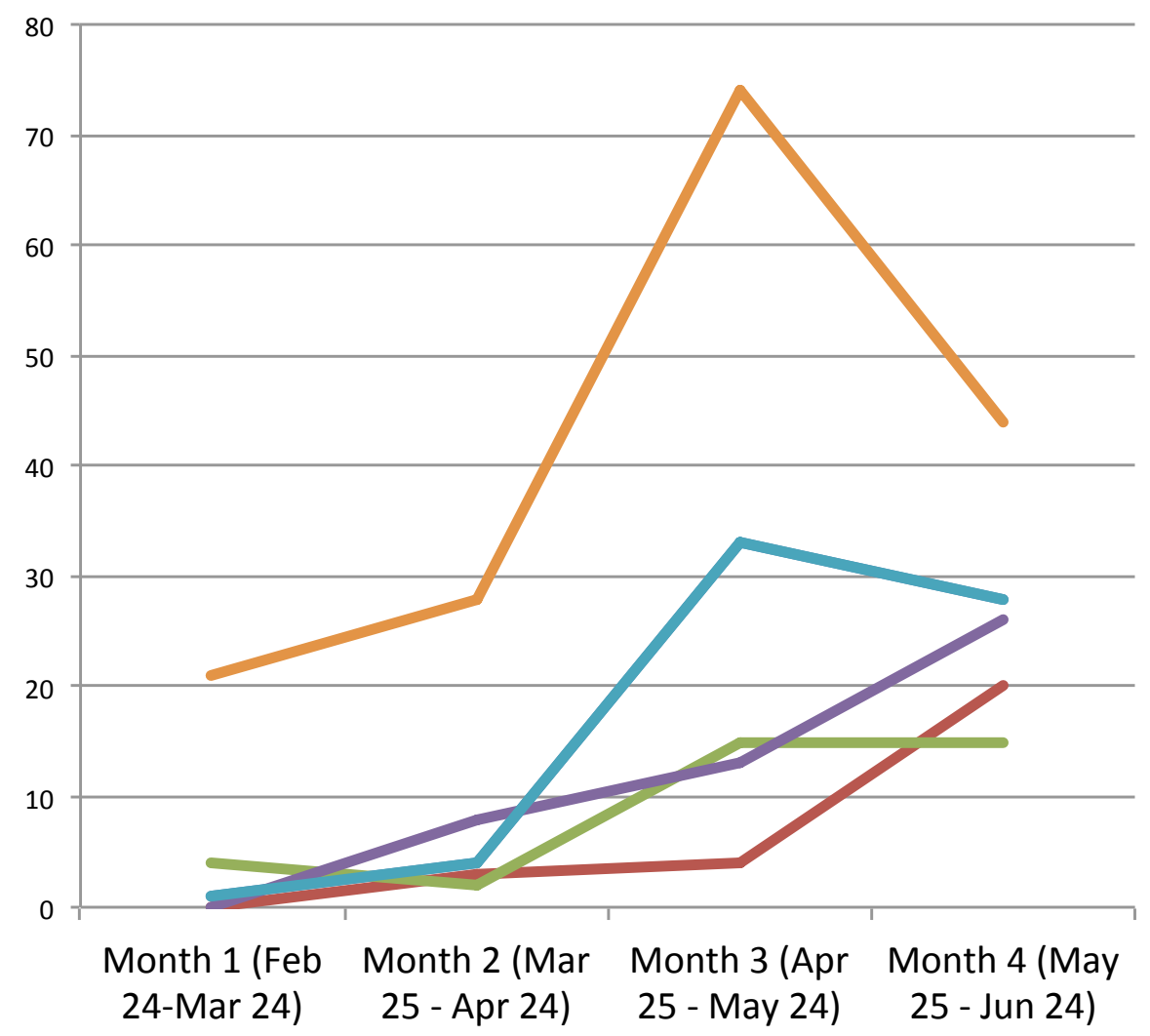

Other

Contains a call to action (separate from a call to violence)

Explicit call to physical or nonphysical violence

Spreading a rumour

Suggest that the audiences faces a serious threat

Insulting and derogatory terms 


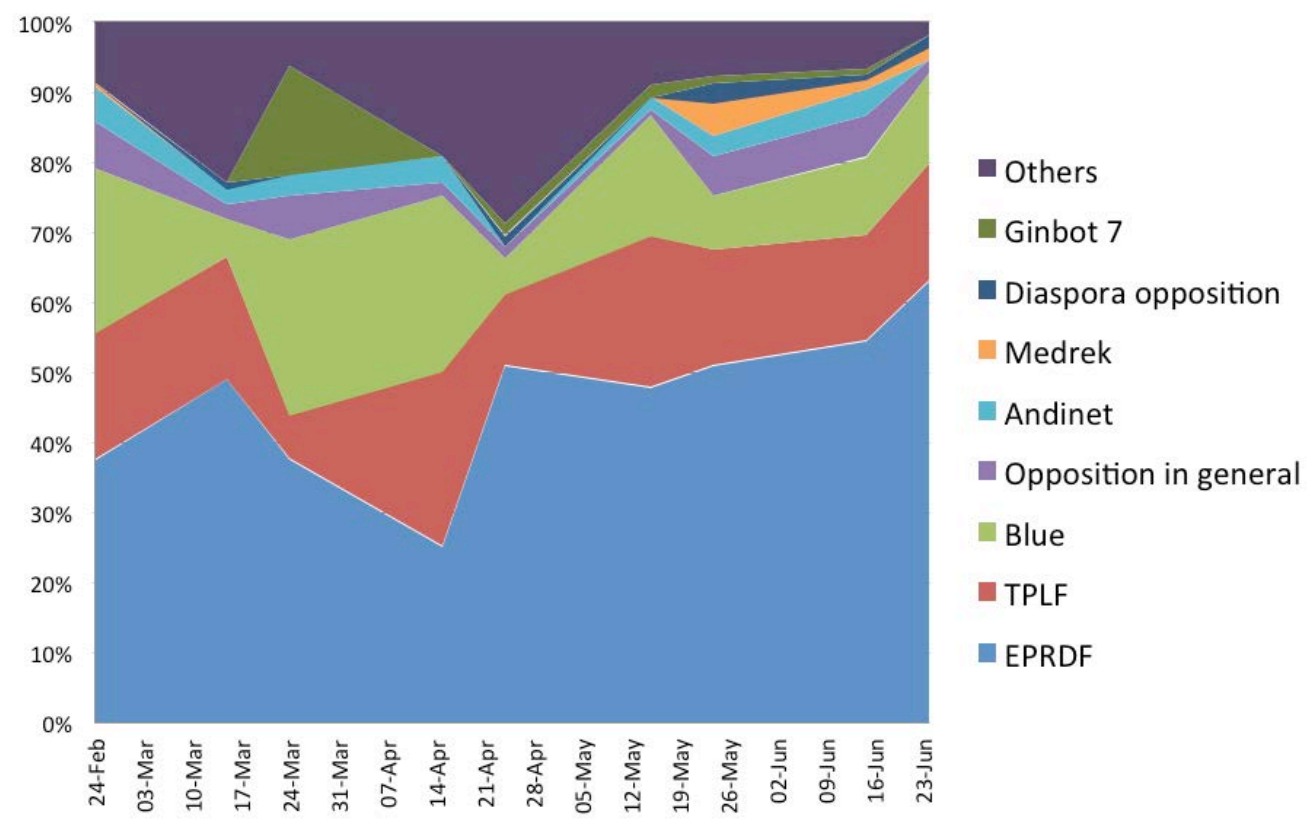

As can be seen in the figures above, in the period from 24 March to 24 April antagonism against the opposition increases its share of total antagonism. It is mostly driven by the government or government sympathizers. The ISIL killings on 19 Arpril result in an increase in antagonism against the 'Other' category, the target being mostly ISIL itself, foreign governments or Arab countries. Antagonism against the government, mostly driven by the opposition or opposition sympathizers, increases its share of total antagonism from after the ISIL killings in April right up to the elections.

Analyzing who antagonizes whom reveals few surprises. The EPRDF and its supporters mostly antagonize the opposition, and Semayawi Party in particular, while the opposition and its supporters antagonize EPRDF and TPLF. The only exceptions are speakers affiliated with Ginbot 7, who tend to antagonize the opposition to a much greater degree than the supporters of other opposition parties.

\section{FIGURE 50: WHO ANTAGONISES WHOM?}

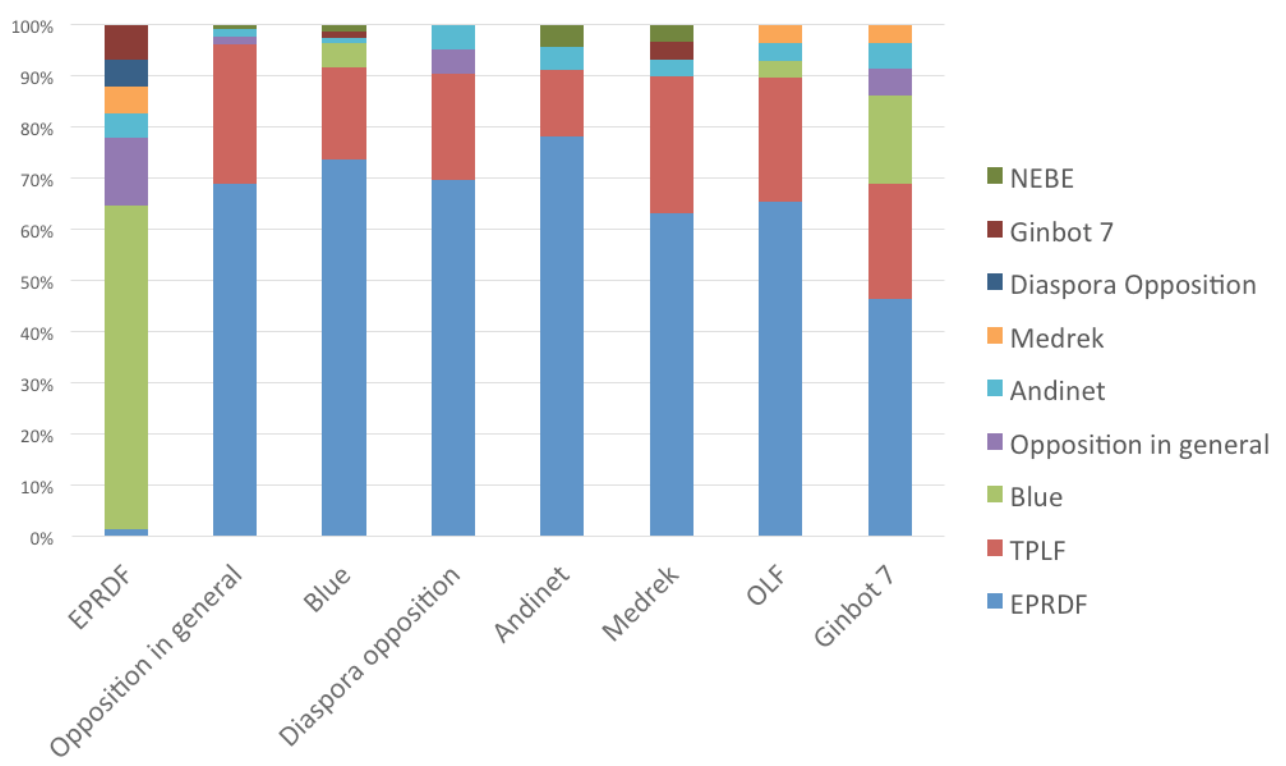


An analysis of who is antagonized by whom reveals a more nuanced picture, indicating several points of tension within the opposition. The main split seems to be between old and new parties. An old party like UDJ/Andinet attracts the hostility of government supporters as well as the hostility of supporters of the opposition in general, and the Semayawi Party in particular.

\section{FIGURE 51: WHO IS ANTAGONISED BY WHOM DURING ELECTIONS?}

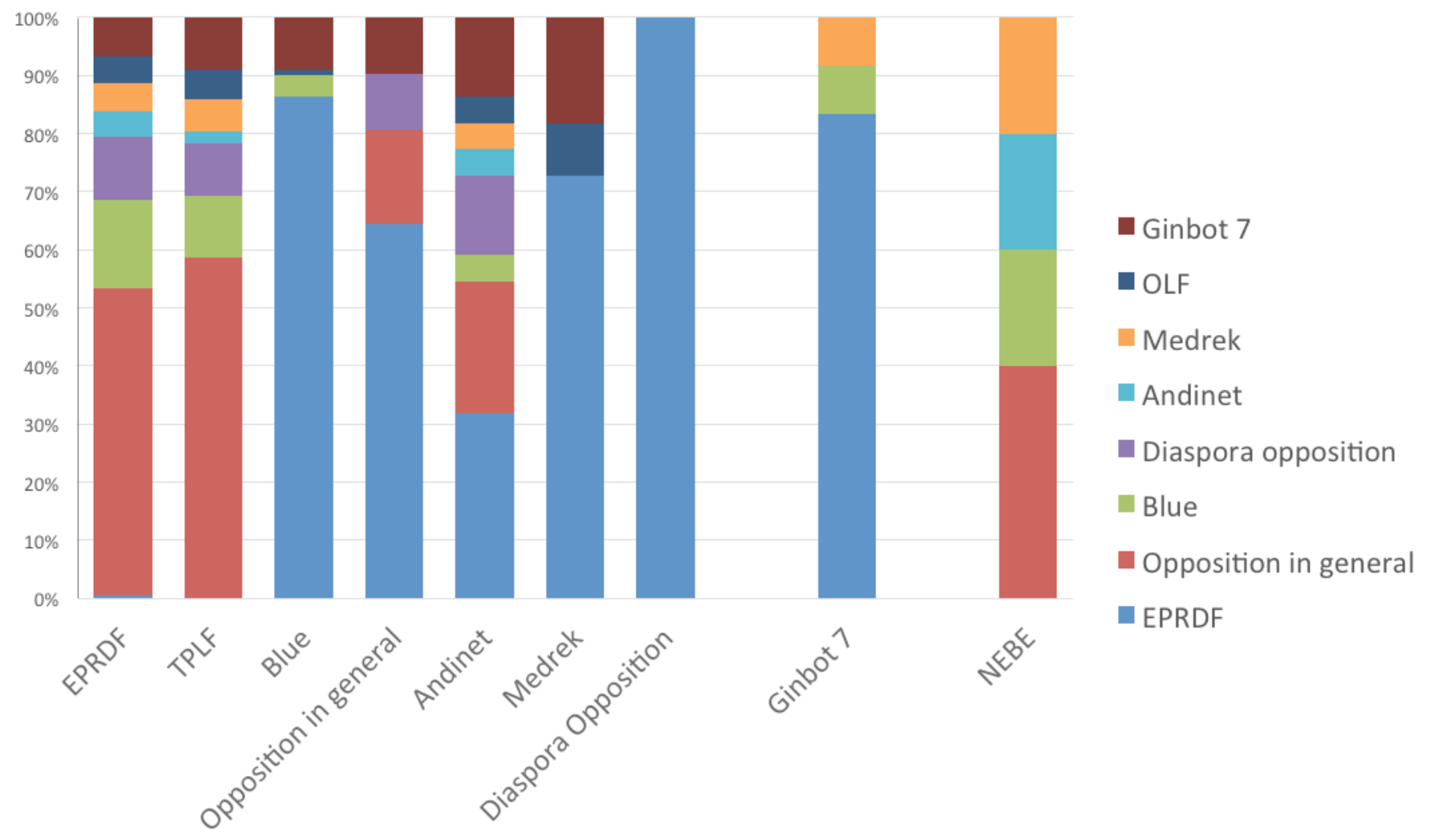


GOING TOWARDS

Similar to statements going against, statements going towards became more articulate as the election approached. Alongside the usual modalities of statements going towards (constructive criticism, informative news reporting, appeals to greater mutual understanding) was the increasingly important category of humorous and sarcastic statements. Humorous, mocking or sarcastic statements saw a sharp increase in the week before the elections, and slowly declined in the post-election period. Of all modalities of speech going towards, this type of statement is the one most directly responsive to the electoral contest.

\section{FIGURE 52: NATURE OF STATEMENTS GOING TOWARDS DURING THE ELECTION}

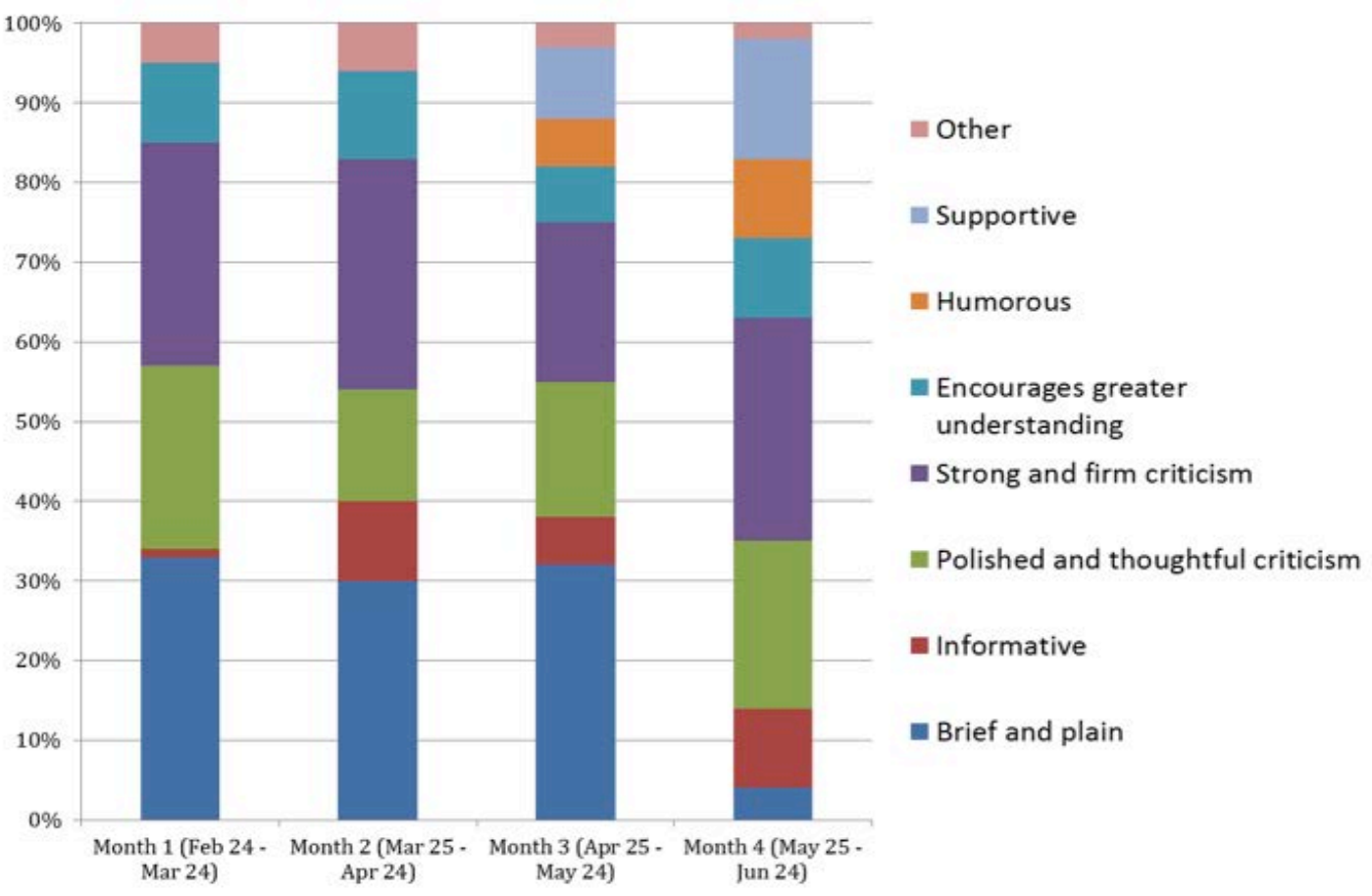

FIGURE 53: HUMOROUS SARCASTIC ELECTIONS STATEMENTS WITHOUT BEING EXPLICITLY OFFENSIVE

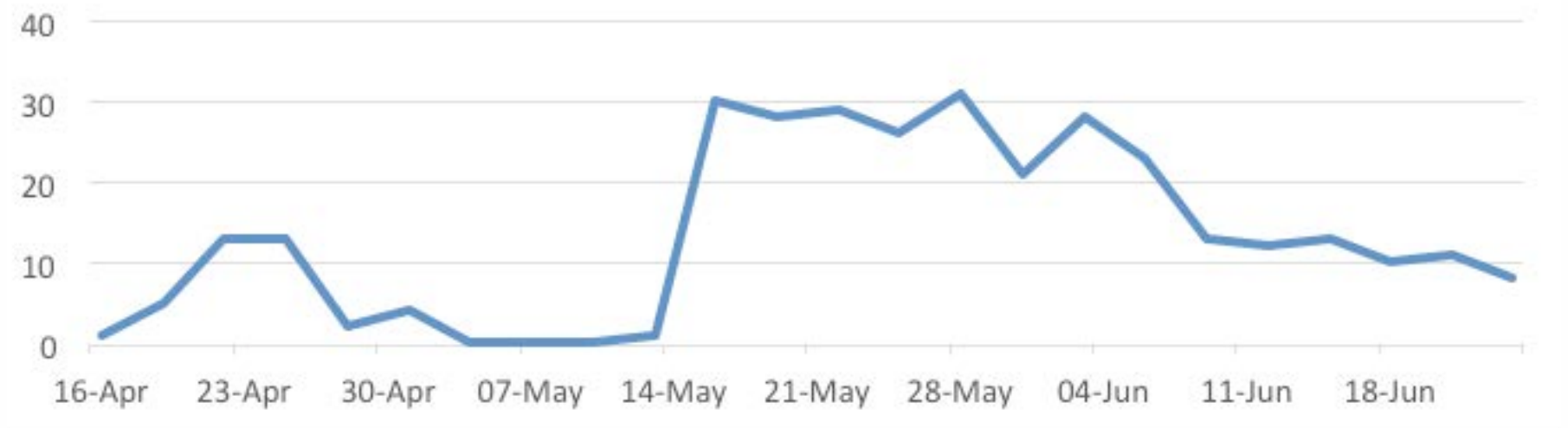


Posts of this kind represent a politically significant subdivision of statements going towards. Like all statements going towards, they recognize their interlocutor as legitimate, and initiate, maintain, and build a communicative relationship. Yet, at the same time, many of these statements are the product of a generalized frustration and disillusionment, not only with politics, but with political speech itself. These comments are inspired by the perception that one's voice does not matter, is not being heard, and will not have any impact. They therefore represent a specific kind of statements going towards, a form of venting motivated by cynicism and, in some cases, even hopelessness. Humorous, mocking and sarcastic statements do establish a communicative relationship, but at the same time express distrust in the possibility of building a politically-meaningful dialogue.

\section{EXAMPLES OF HUMOROUS CRITICAL ELECTIONS STATEMENTS}

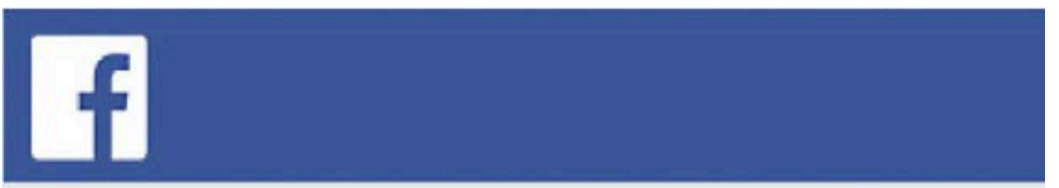

History do repeat itself, the cycle is unbreakable ... of course like the great Solomon said there is nothing new under the sun - just different ways to do it ... well that's why the end is unimportant but the way!

Though the end always predictable, quite a mystery it keeps you going! Hmmm

79 Likes 5 Comments
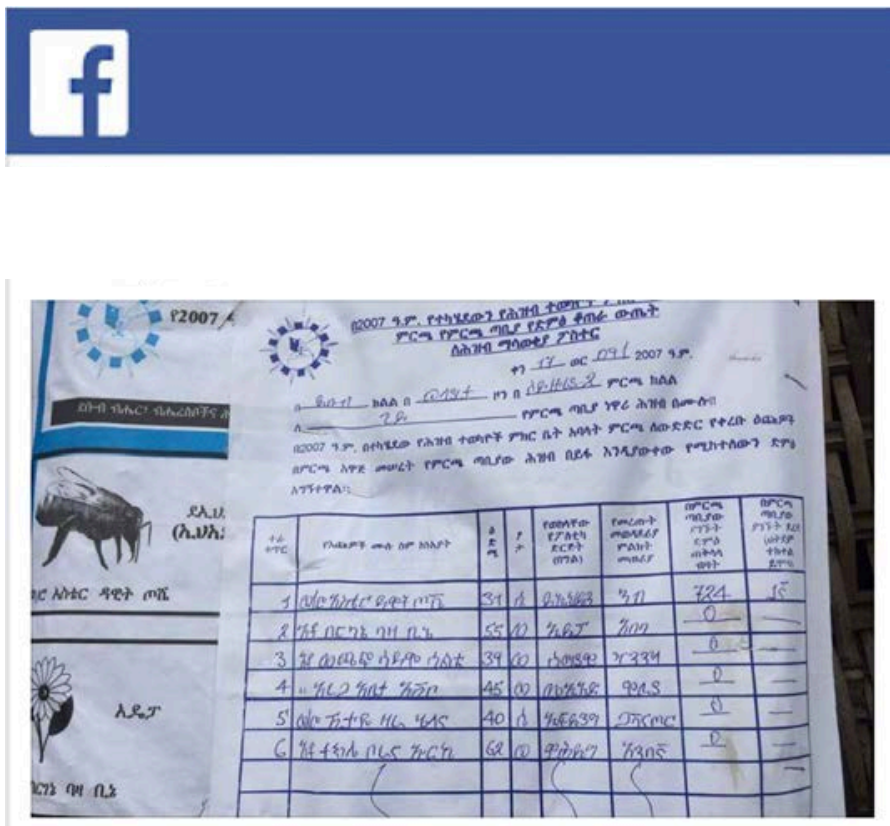

Golgul/rAマด: P\&ட78 วHศ

May $27 \cdot(8$

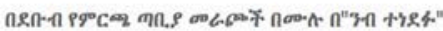

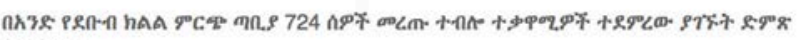
uce $y \rightarrow \cdot n$

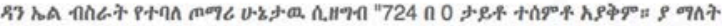
† sกक:"

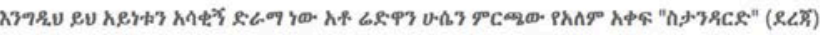

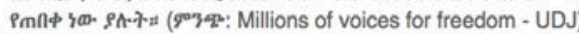

\section{6}

\section{TRANSLATION}

All electorates in southern polling stations are stung by the bee.

In one southern region polling station out of 724 voters the total sum of people who vote for opposition is zero. A blogger called Daniel Bisrat reported 724 to 0 has never been has never heard. This actually means even the opposition candidates were afraid of being stung hence voted bee.

This funny drama is hailed by Redwan husien as "an elelction of internation standard." 


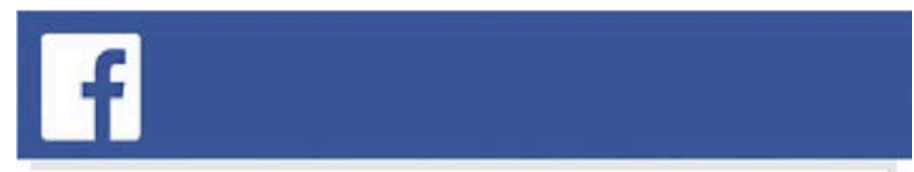

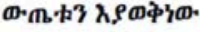

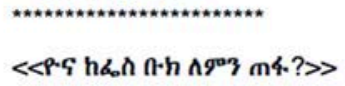

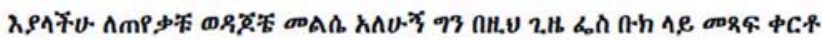

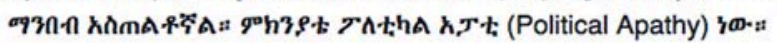

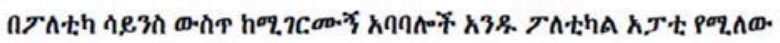
40.:

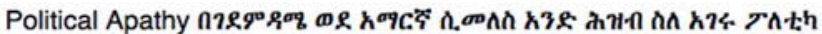
g०3 久า1

ก,

耳ั3 ลา17?

gั3 ९RCๆลรัด?

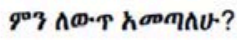

-... XS RRACYA;

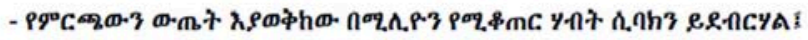

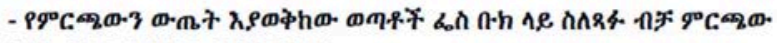

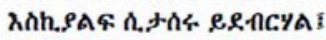

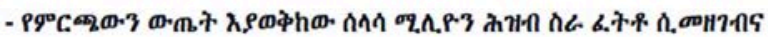

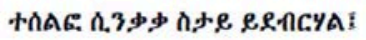

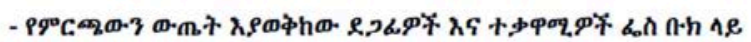

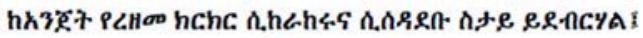

Many influential speakers, although deeply pessimistic about the outcome of the elections, nevertheless committed to campaigning and mobilizing support for opposition parties. The rapid rise of OFC-Medrek in the weeks preceding the elections, in particular, generated enthusiasm on the part of Oromo speakers and intellectuals, who contributed

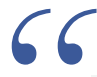

\section{TRANSLATION}

For those of you who ask where did I disappear? The answer is called "political apathy", an indifferent attitude of citizens towards their nation's politics. [...] It is disgusting that, while the result is already known, millions of resources are invested. Youths are sent to jail for writing on Facebook. The result is known yet the meaningless debate between opposition and supporters of the incumbent makes me disappear. I am not naïe. I will be back when the noise is over."

with their posts and comments to the party's momentum. Some speakers, although acknowledging the general climate of frustration and disillusionment, nevertheless expressed hope that the government would relax its control over civil society after the elections.

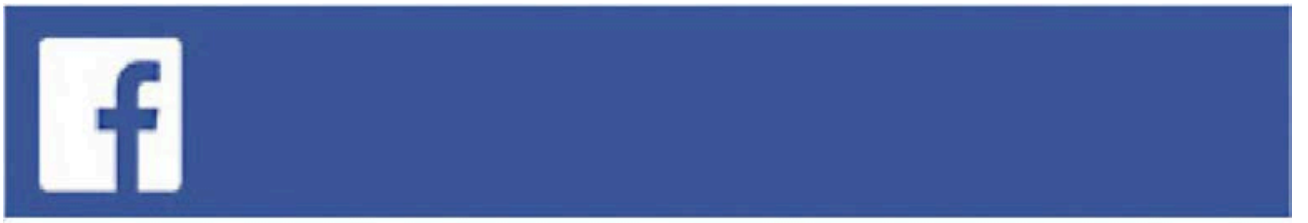

The only positive outcome I am expecting from this election aftermath is the release of \#Zone9Bloggers and journalists who got incarcerated in assumption that they would have been a threat/hazardous for failed state government officials . 
A significant proportion of statements going towards continued to call for various forms of collective action and mobilization, balancing out the more sarcastic posts. The percentage of statements containing a call to action is particularly high in the month preceding the elections, and, in line with expectations, declined in the month after voting. Most of the increase in the percentage of statements calling for action is to be traced to statements encouraging readers to vote for a specific party. Statements asking people to vote for a specific party are clearly an 'electoral' category, and, just like humorous and sarcastic statements, their volume increased as voting approached.

FIGURE 54: CHANGE IN CALLS TO ACTION DURING THE ELECTIONS (GOING TOWARD)

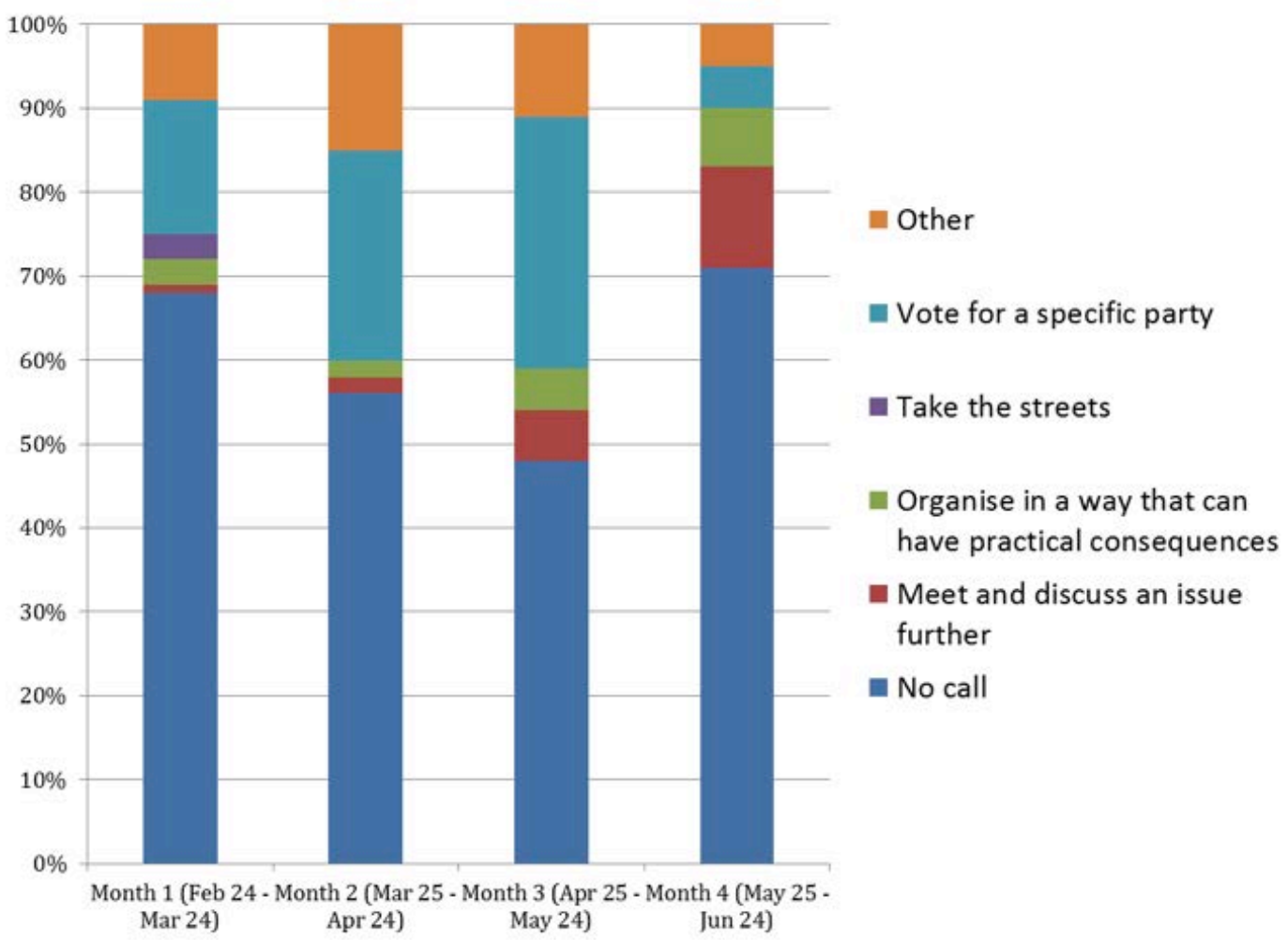

FIGURE 55: CALLS TO VOTE FOR A SPECIFIC PARTY DURING THE ELECTIONS

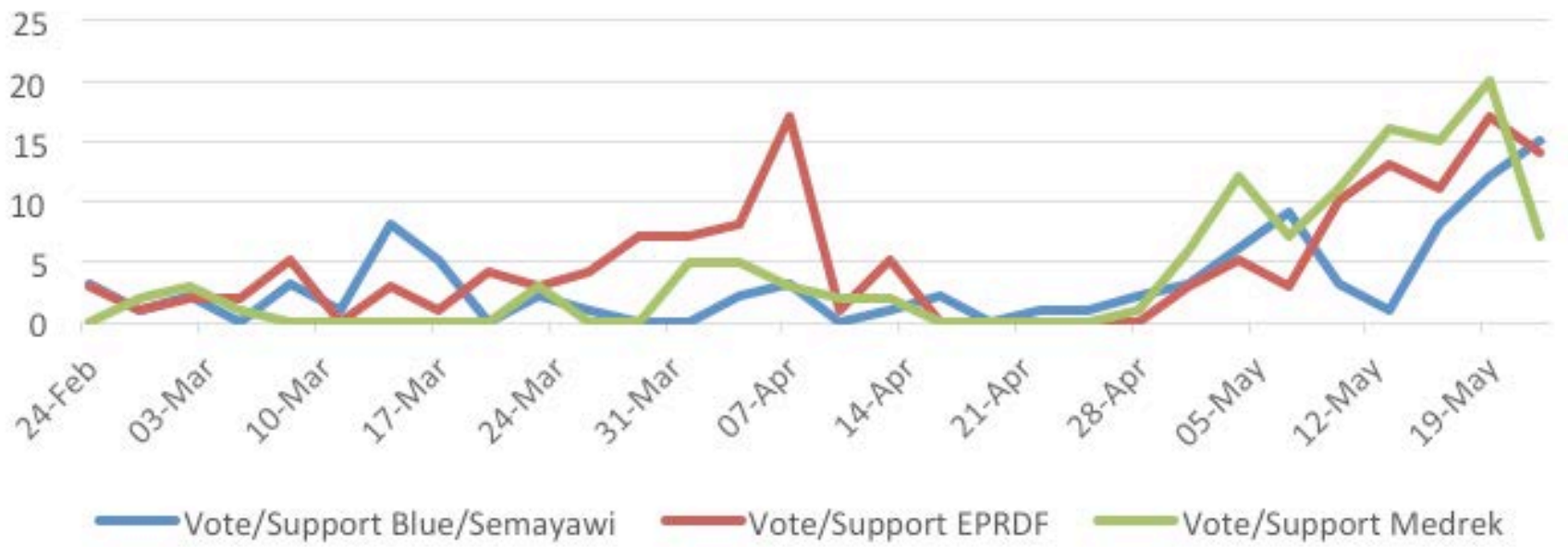


The three main parties in the electoral campaign, the EPRDF, the Semayawi Party and Medrek, received comparable amounts of support overall (respectively $3.50 \%, 3.86 \%$ and $2.95 \%$ of all statements in the electoral sample), with the EPRDF broadcasting more appeals to the electorate and receiving the highest share of endorsements.
When isolating the calls to vote for a specific party, a similar pattern appears, with the three main parties receiving comparable amounts of support, but with the EPRDF leading the way as the main beneficiary of electoral appeals.

\section{FIGURE 56: CALLS FOR VOTES FOR A SPECIFIC PARTY DURING THE ELECTIONS}

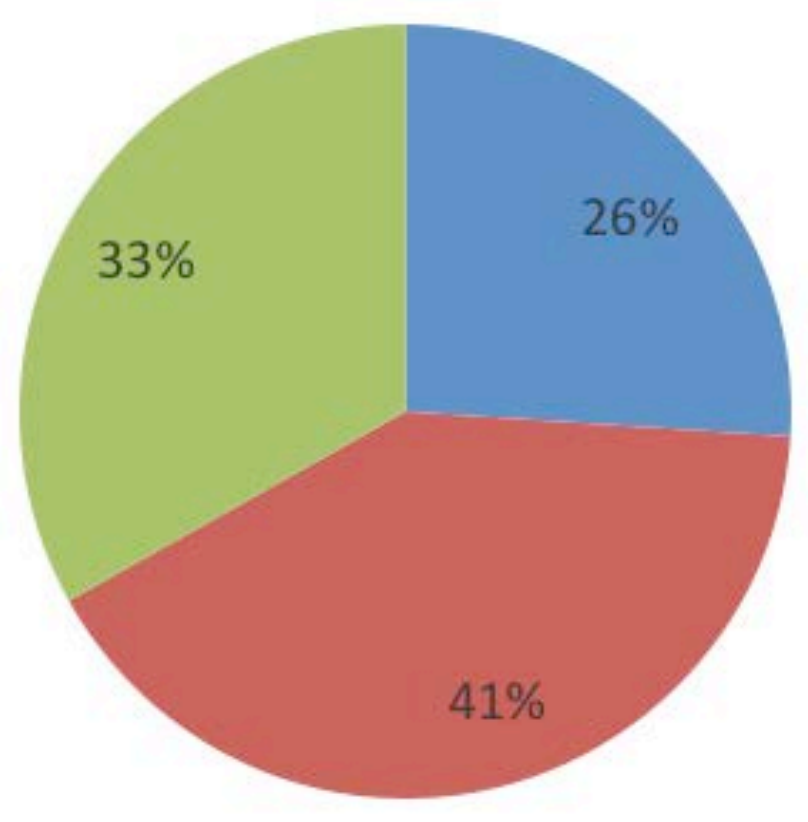

Vote/Support Blue/ Semayawi

Vote/Support EPRDF

\author{
Vote/Support
} Medrek
Overall, there was little outreach to different political communities by different political parties. Statements supporting Semayawi tended to be confined to the Semeyawi Party page, and the same applies to EPRDF and Medrek. Except for a few isolated instances (a Semayawi supporter posting on the EPRDF page, an EPRDF supporter posting in the Semayawi Party page, a few Medrek supporters posting in Alula Solomon's page), users tended to campaign within the spaces of their own online community rather than attempting to win over other sectors of the electorate by extending the campaigning to the online spaces of their opponents. It seems, therefore, that campaigning on Facebook had the primary objective of reinforcing the sense of identity of the various online communities - more an act of community-building than a competitive political effort. 
5. CONCLUSION 


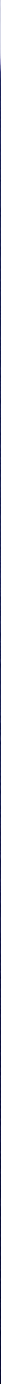

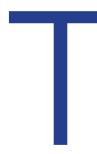
his report has sought to offer as detailed representation as possible of the nature and quality of online debates occurring among Ethiopians in Ethiopia and abroad. It is our belief that this challenging endeavor was exceptionally important given the lack of research and evidence around hate and dangerous speech online. Assumptions about its role have the very real potential to lead to over- or under-emphasise the promises and dangers of social media in public debates.

Along with the other two reports that have been published as part of the Mechachal project, these findings offer solid grounding for researchers, journalists, activists and policy makers to better understand how Ethiopia's past and future are discussed in social media; where opportunities for engagement lie; and what dynamics characterize antagonism, as well as calls to act against specific targets.

Mechachal offers a starting point, both conceptually and methodologically, for researchers interested in understanding the features that characterize online speech including hate speech - in other countries as well. We hope that the methods we used and are described at length in this report can offer useful questions and tools for other contexts.

This report comes at a time when hate speech online is of great public policy concern. Efforts are currently underway by a variety of actors - from tech companies to governments - to better understand how social media are contributing to public debates, but also how they can be used as tools for discrimination and radicalization. Despite the significant efforts we made to ensure our methods and analysis are both rigorous and contextually grounded, more research is needed to better understand the dynamics characterizing online conversations, especially in contexts characterized by fragility and conflict. We see two critical areas for further research.

First, there is a pressing need to understand not just the nature, but also the prevalence of hate speech in the context of broader online 
debates. The growing concern about uses of social media that can promote radicalization and incite violent acts has led to increasing demands for research that can detect and monitor these types of online behaviors. As attention towards the "darker" side of the Internet grows, however, in the absence of data that can contextualize how relevant and prevalent extreme speech is in the context of how online media are used more broadly, it may lead to creating an image of online conversations as a whole as potentially harmful.

Second, the importance of simultaneously detecting and understanding the functioning of spaces of engagement, where users seek to create communicative relationships across divides, rather than exacerbating existing tensions. These can be spaces where counter-speech emerges as a direct response to hateful messages but also, more broadly, spaces where users engage in other types of exchanges that have the potential to foster more debates. Detecting these types of behaviors can also be important for understanding what resources are already available online that can help counter the most aggressive forms of speech, before resorting to more severe measures such as censorship.

Together with the other material we will be publishing, with a specific focus on how the methodology we developed can apply to other context, in Africa and beyond, we hope this report, and the spirit that has informed it, will contribute to further research that is both able to detect critical risks associated with the diffusion of social media, but taking also in consideration the tremendous opportunities new communication technologies are offering to promote dialogue, also in divided societies. 


\section{ENDNOTES}

1 The most prominent recent case in Ethiopia is the arrest of the Zone 9 bloggers, with the accusation of using social media to destabilize the country (See, for example, http://www.bbc.com/news/worldafrica-28366841); Germany has historically taken a particularly hard line towards hate speech, including online. In December 2015, the German government signed an agreement with Facebook, Twitter, and Google, to ensure hate speech will be removed within 24 hours of it being reported (See for example http://www.reuters.com/article/us-germany-internet-idUSKBNOTY27R20151215); China is notorious for its limitations of speech online, but in recent years measures to contain certain forms of speech, including hate speech, have become increasingly stringent and sophisticated (See for example http:// www.theguardian.com/world/2014/aug/07/china-intensifies-social-media-crackdown-curbs-instantmessaging). In the case of the USA, the need to combat terrorism has often been invoked as a reason to increase control over communication on social media (See, for example, http://edition.cnn. com/2015/02/25/opinion/poe-terrorism-social-media).

${ }^{2}$ In Ethiopia, similarly to other countries where access to the Internet is very limited, Facebook has almost become a synonym for the whole Internet. For more details see Chapter 1.

${ }^{3}$ See, for example, Alex de Waal, "The Theory and Practice of Meles Zenawi," African Affairs 112, no. 446 (2013): 148-55; Alex de Waal, "The Theory and Practice of Meles Zenawi: A Reply to to René Lefort," African Affairs 112, no. 448 (2013): 471-75; René Lefort, "The Theory and Practice of Meles Zenawi: A Response to Alex de Waal," African Affairs 112, no. 448 (2013): 460-70; Iginio Gagliardone, "New Media and the Developmental State in Ethiopia," African Affairs 113, no. 451 (2014): 279-99.

4 See Jonathan Fisher, "Writing about Rwanda since the Genocide: Knowledge, Power and 'Truth," Journal of Intervention and Statebuilding 9, no. 1 (2015): 134-45; H. Hintjens, "As If There Were Two Rwandas: Polarized Research Agendas on Post-Genocide Rwanda," Conflict, Peace, Security and Development: Theories and Methodologies, 2014, 133-49.

5 See Leo Mirani, "Millions of Facebook Users Have No Idea They're Using the Internet," Quartz, accessed March 11, 2016, http://qz.com/333313/milliions-of-facebook-users-have-no-idea-theyre-usingthe-internet

"See Susan Benesch, "Dangerous Speech: A Proposal to Prevent Group Violence," World Policy Institute, New York 2 (2012).

7 Antoine Buyse, "Words of Violence:' Fear Speech,' or How Violent Conflict Escalation Relates to the Freedom of Expression," Human Rights Quarterly 36, no. 4 (2014): 779-97.

8 The debate on the legal foundations of hate speech is massive. For an overview of the literature see, for example, Robert Post, Ivan Hare, and James Weinstein, "Hate Speech," Extreme Speech and Democracy, 2009, 123-38; Jeremy Waldron, The Harm in Hate Speech (Harvard University Press, 2012); James Banks, "Regulating Hate Speech Online," International Review of Law, Computers \& Technology 24, no. 3 (2010): 233-39; Danielle Keats Citron and Helen Norton, "Intermediaries and Hate Speech: Fostering Digital Citizenship for Our Information Age," BUL Rev. 91 (2011): 1435; Elizabeth F. Defeis, "Freedom of Speech and International Norms: A Response to Hate Speech," Stan. J. Int'l L. 29 (1992): 57; Stephanie Farrior, "Molding the Matrix: The Historical and Theoretical Foundations of International Law Concerning Hate Speech," Berkeley J. Int'l L. 14 (1996): 1; Alexander Tsesis, "Hate in Cyberspace: Regulating Hate Speech on the Internet," San Diego L. Rev. 38 (2001): 817.

9 Every week we performed Intercoder Reliability Tests on four selected statements that were analysed by all coders. After having computed the scores, we had lengthy discussions about why each members of the team coded the way s/he did. This practice, over time, significantly increased the ability to apply our analytical framework to analyse conversations on Facebook. 
${ }^{10}$ An example of the convening power of evidence is offered by the fact that even people with longstanding grievances were interested to sit around the same table and debate the findings. For example Shimelis Kemal, former State Minister in the Communication Affairs Office and official prosecutor during the trials that followed the contested 2005 parliamentary elections, could sit in front of Yacob Hailemariam, former leader of the CUD, the most important political coalition contesting the 2005 elections, who was jailed for 2 years as a result of the post-election trials

11 These are the figures made available by Facebook for advertisers. It has to be noted, however, that, some Ethiopian Facebook users may refer to the Ethiopian calendar for their birthdate (which is 7 or 8 years behind the Gregorian calendar - new year begins on 11 September), meaning that the figure for the youth reported by Facebook may be slightly higher than the actual population.

12 For research on the relationship between diasporic communities and politics see, for example, Terrence Lyons, "Conflict-Generated Diasporas and Transnational Politics in Ethiopia," Conflict, Security \& Development 7, no. 4 (2007): 529-49; Terrence Lyons and Peter Mandaville, "Politics from Afar: Transnational Diasporas and Networks," 2013, http://scar.gmu.edu/book/politics-afar-transnationaldiasporas-and-networks.

13 For an overview of international standards, legal scholarship, and empirically grounded research on hate speech online see Iginio Gagliardone, Danit Gal, Thiago Alves, Gabriela Martinez, Countering Online Hate Speech (UNESCO, 2015).

${ }^{14}$ See "Ethiopia Zone 9 Bloggers Charged with Terrorism," BBC News, accessed March 11, 2016, http:// www.bbc.com/news/world-africa-28366841; "Ethiopian Zone 9 Bloggers Cleared of Terrorism Charges," BBC News, accessed March 11, 2016, http://www.bbc.com/news/world-africa-34550045.

15 Ginbot7's website, where official declarations by its leaders can be accessed, is http://www.ginbot7. org

${ }^{16}$ See "Ginbot 7 Leader Berhanu Nega Admits Receiving Military Training From Eritrea I Strategic Thinking On East Africa," accessed March 11, 2016, http://www.strathink.net/ethiopia/ginbot-7-leader-berhanunega-admits-receiving-military-training-from-eritrea/

17 See "Violent Clashes in Ethiopia over 'Master Plan' to Expand Addis," The Guardian, December 11, 2015, sec. World news, http://www.theguardian.com/world/2015/dec/11/ethiopia-protests-master-planaddis-ababa-students.

${ }^{18} \mathrm{See}$ http://www.worldpoliticsreview.com/articles/15834/ethiopia-s-suspenseless-elections-obscureruling-party-rivalries; http://www.theguardian.com/global-development/2015/may/23/ethiopiaelection-wake-up-call-human-rights-governance; http://www.aljazeera.com/news/2015/05/ethiopiareadies-general-elections-150524011231376.html; http://www.bbc.com/news/world-africa-32863508

19 This pattern of election speech on Facebook being more prevalent among the opposition holds true irrespective of the sampling strategy employed, purposeful or random. Interestingly, had it not been for the purposeful sampling of election statements, election speech from government would have become even more negligible

20 See http://allafrica.com/stories/201501130147.html

21 See Wondwosen Teshome-Bahiru, 2009. Political Finance in Africa: Ethiopia as a Case Study." International Journal of Humanities and Social Sciences. 3:2, pp. 119-132,

${ }^{22}$ See http://addisfortune.net/interviews/its-campaign-time-semayawi-moderate-liberalism/ 
${ }^{23}$ Our data has a directed networked graph model in which the nodes or source and target are Facebook users, while the edge of the graph is a relationship where a speaker posts or comments on a specific individual profile page, group or Facebook page. The above graph is retrieved from 2640 nodes and 2911 directed edges using Gephi, a network visualization tool. The size of a node is proportional to its degree size (the number of outgoing and ingoing edges), while the thickness of the edge is proportional to the weight of the connection. We have run Yifan Hu and Force atlas layout algorithms after setting 5.0 resolution modularity statistics, which results in seven communities depicted in different colours. 


\section{THE MECHACHAL TEAM}

Iginio Gagliardone is Lecturer in Media and Communication at the University of the Witwatersrand and Associate Research Fellow in New Media and Human Rights at the University of Oxford. His research has focused on the relationship between new media, political change, and human development and on the emergence of distinctive models of the information society in the Global South. He holds a PhD from the London School of Economics and Political Science.

Matti Pohjonen is a Research Fellow for VOX-POL, a European Union Framework Programme 7 (FP7)-funded academic research network focused on researching the prevalence, contours, functions, and impacts of Violent Online Political Extremism and responses to it. His work focuses on developing comparative and practice-based research approaches to understand digital cultures in the developing world. Previously he worked as an AHRC post-doctorate and a Teaching Fellow in Digital Culture at the School of Oriental and African Studies (SOAS).

Abdissa Zerai is Assistant Professor at the School of Journalism \& Communication, Addis Ababa University, where he focuses on the political economy of the Ethiopian media and ICT in the context of a democratic developmental state. He has been working on issues related to conflict reporting, political economy of communication, and the nexus between media, democracy \& civil society.

Zenebe Beyene is Assistant Professor of Journalism and Communication, Director of Office of External Relations, Partnerships and Communications at Addis Ababa University, Ethiopia and NAFSA Global Dialogue Fellow. Dr. Zenebe has taught in Ethiopia, Rwanda and the U.S.A. His publications include Media use and abuse in Ethiopia, the role of ICT in peace building, state building and governance in Africa (with Abdissa Zerai), and Satellites, Plasmas and Law (with Abdissa Zerai and Iginio Gagliardone).

Gerawork Aynekulu is reading for a MSc in computer science at University of Belgrade, where he focuses on data mining. He has been working on text analytics of online Amharic textual resources.

Jonathan Bright is Research Fellow at the Oxford Internet Institute, which is a department of the University of Oxford. He is also an editor of the journal Policy and Internet. He is a political scientist specializing in political communication, digital government and computational social science.

Mesfin Awoke Bekalu is a Research Fellow at Harvard T.H. Chan School of Public Health, USA. Prior to his current post, he has been a postdoctoral fellow at the University of Leuven, Belgium and a lecturer in Journalism and Communications at Bahir Dar University, Ethiopia. His research interests include communication inequalities in the areas of health and development as well as media discourse analysis.

Michael Seifu is an independent researcher based in Ireland and has completed a PhD in politics from Dublin City University. He has been working on issues related to the politics of economic development.

Mulatu Alemayehu Moges is $\mathrm{PhD}$ candidate in the University of Oslo, at the Department of Media and Communication, where he focuses on conflict reporting in the Ethiopian media. He has been working as a Journalist in Ethiopian media, and as Lecturer and Researcher in Addis Ababa University, School of Journalism and Communication. 
Nicole Stremlau is Head of the Programme in Comparative Media Law and Policy, Centre for Socio-Legal Studies, University of Oxford. Her research focuses on media and conflict in the Horn of Africa. She has worked extensively in Ethiopia, Somaliland/Somalia, Uganda and Kenya. As Head of PCMLP, she also directs the Price Media Law Moot Court Programme and co-directs the Annenberg-Oxford Media Policy Summer Institute.

Patricia Taflan is Research Assistant at the Programme in Comparative Media Law and Policy, University of Oxford. She completed an MSc in Criminology and Criminal Justice, also at the University of Oxford, where she focused on online hate crime.

Tewodros Makonnen Gebrewolde is $\mathrm{PhD}$ candidate at the University of Leicester, where he focuses on productivity growth and industrial policy. He has been working on issues related to economic growth and development of the Ethiopian Economy.

Zelalem Mogessie Teferra is PhD candidate in International Law at the Geneva Graduate Institute of International and Development Studies. His study focuses on the intersection between national security and the humanitarian norms of international law. He was previously an Instructor of Law at Jimma University (Ethiopia), Michigan Grotius Scholar in University of Michigan (U.S.A). 